\title{
LA INNOVACIÓN SOCIAL EN LOS ESCENARIOS DE FORMACIÓN PROFESIONAL: CASO DEL PROGRAMA DE PRÓTESIS Y ÓRTESIS EN EL SERVICIO NACIONAL DE APRENDIZAJE "SENA"
}

NEIDA YOLIMA CARO RUBIO

UNIVERSIDAD SANTO TOMÁS

FACULTAD DE SOCIOLOGÍA

MAESTRÍA PLANEACIÓN PARA EL DESARROLLO

BOGOTÁ, D.C.

2015 


\title{
LA INNOVACIÓN SOCIAL EN LOS ESCENARIOS DE FORMACIÓN PROFESIONAL: CASO DEL PROGRAMA DE PRÓTESIS Y ÓRTESIS EN EL SERVICIO NACIONAL DE APRENDIZAJE "SENA"
}

NEIDA YOLIMA CARO RUBIO

Código: 2141477

\author{
Directora: \\ DORIS YANETH HERRERA MONSALVE
}

\author{
UNIVERSIDAD SANTO TOMÁS \\ FACULTAD DE SOCIOLOGÍA \\ MAESTRÍA PLANEACIÓN PARA EL DESARROLLO \\ BOGOTÁ, D.C. \\ 2015
}




\section{AGRADECIMIENTOS}

Elevo mis gratitudes a Dios, por permitirme la superación como persona y como profesional.

A mi familia por el apoyo brindado durante mi proceso de formación.

Al Subdirector del Centro de Diseño y Metrología, por su disposición y colaboración en el desarrollo de la investigación.

A los integrantes del Grupo de investigación, desarrollo tecnológico e innovación del SENA, particularmente al Dr. Carlos Lugo, por los aportes entregados.

A los instructores, aprendices y funcionarios del Servicio Nacional de Aprendizaje "SENA" por su apoyo incondicional en el desarrollo de mi formación.

A los profesores y directivas de la Maestría, especialmente a la Directora de la Tesis Dra. Doris Yaneth Herrera, por la paciencia, apoyo incondicional, dedicación y conocimientos transferidos. 
iv

A mi familia, quienes con su amor y paciencia me impulsaran a finalizar can éxita esta etapa de mi vida. 


\section{TABLA DE CONTENIDO}

Pág.

INTRODUCCIÓN

1.PLANTEAMIENTO DEL PROBLEMA

1.1 Innovación social: una necesidad para el desarrollo humano 3

1.2 Objetivos

1.2.1 Objetivo general

$\begin{array}{ll}\text { 1.2.2 Objetivos específicos } & 7\end{array}$

1.3.Justificación

2.MARCO NORMATIVO

3.1 Desarrollo Humano 18

3.1.1 Desarrollo incluyente 22

3.2.Innovación 23

3.2.1 Modelos de innovación $\quad 27$

3.2.1.1 Modelo de innovación tradicional 27

3.2.1.2 Modelo de innovación abierta 28

3.2.2 Tipos de innovación $\quad 30$

3.2.3 Características de la innovación por sectores 30

3.2.4 Factores relacionados con los objetivos y efectos de la 32 innovación: impulsos y barreras 
3.2.5 Métodos de protección de la innovación 35

3.2.6 Condiciones para que una institución acepte la novedad 36

3.3 Innovación social 37

3.3.1 Principios y características de la innovación social 42

3.3.2 Entornos de la innovación social 43

3.3.3 Enfoques de la innovación social 44

3.3.4 Fases de la innovación social 47

3.3.5 Barreras y facilitadores de la innovación social 49

3.3.6 Actores claves $\quad 50$

3.3.7 La cadena de valor $\quad 52$

3.3.8 Indagaciones de innovación social a nivel mundial $\quad 57$

3.4 La innovación social como eje central para el desarrollo 59 humano

4.MARCO CONTEXTUAL 62

4.1 Modelo estratégico SENA 62

4.2 Reglamentación y otras disposiciones para SENA 66

4.3 Aprendizaje en el SENA 66

4.4 Programas de formación profesional SENA 67

4.4.1 Competencias laborales $\quad 69$

4.5 Caracterización del programa de formación " diseño y 72 adaptación de prótesis y órtesis"

4.6 La innovación en el SENA $\quad 75$

5. METODOLOGÍA 78

$\begin{array}{ll}5.1 \text { Instrumentos } & 80\end{array}$ 
$\begin{array}{ll}\text { 5.1.1 Encuestas } & 80\end{array}$

5.1.1.1 Cuestionario a instructores $\quad 81$

5.1.1.2 Cuestionario a aprendices $\quad 82$

5.1.2 Entrevista 83

$\begin{array}{ll}\text { 5.1.3 Testimonio } & 84\end{array}$

5.1.4 Observación de campo $\quad 84$

5.2 Variables $\quad 85$

5.2.1 Innovación $\quad 85$

5.2.2 Generación de valor social $\quad 85$

5.2.3 Participación de la comunidad 86

5.2.4 Potencial de sostenibilidad 86

5.2.5 Potencial de escalabilidad 86

$\begin{array}{ll}\text { 5.2.6 Potencial de replicabilidad } & 87\end{array}$

$\begin{array}{ll}\text { 5.2.7 Colaboración intersectorial } & 87\end{array}$

6.RESULTADOS $\quad 88$

6.1 Sistematización de los resultados $\quad 89$

$\begin{array}{ll}6.1 .1 \text { Instructores } & 89\end{array}$

6.1.1.1 Información demográfica 90

6.1.1.2 El programa de formación 91

6.1.1.3 Aspectos de investigación, fortalecimiento y 96 desarrollo humano

6.1.2 Aprendices 99

6.1.2.1 Información demográfica 100

de vida

6.1.2.2 El programa de formación y su enfoque en calidad 102 
6.1.2.3 Desarrollo humano 105

$\begin{array}{ll}\text { 6.1.3 Personal administrativo } & 108\end{array}$

6.1.4 Actores beneficiados con el proyecto (testimonio de 115 aprendiz)

6.1.5 Observaciones efectuadas en campo

6.1.5.1 Estrategia SENNOVA

6.2 Contextualización y análisis, a partir de la triangulación de la

122 información

6.2.1 Análisis dado bajo las tres etapas determinadas por los objetivos específicos planteados

6.2.1.1 Etapa A: análisis del estado real del programa de formación

6.2.1.2 Etapa B: niveles de participación en la ejecución 123 de la formación

6.2.1.3 Etapa C: elementos de innovación social del 123 programa de formación

6.2.2 Análisis etapa A: nociones de innovación en la 125 comunidad académica

6.2.3 Análisis etapa B: niveles de participación de actores $\quad 135$

6.2.4 Análisis etapa C: descripción bajo elementos de 139 innovación social definidos

\section{CONCLUSIONES}

7.1 La caracterización del programa de formación

7.2 Frente a los hallazgos evidenciados en la investigación

153

7.3 Presentación de propuestas 


\section{ÍNDICE DE TABLAS Y FIGURAS}

TABLAS

Pág.

Tabla 01. Diferencias entre innovación abierta e innovación 29 cerrada.

Tabla 02. Aporte pioneros sobre innovación social. 41

Tabla 03. Diferencias entre cadena de valor y cadena productiva. 53

Tabla 04. Niveles de los programas de formación SENA, y su 68 correspondiente duración en la misma entidad.

Tabla 05. Matrículas SENA. $\quad 69$

Tabla 06. Aprendices matriculados en el programa de formación 74 de órtesis y prótesis - SENA.

Tabla 07. Consolidación información demográfica, encuesta a 90 instructores.

Tabla 08. Consolidación resultados respecto al programa de 92 formación, encuesta a instructores.

Tabla 09. Consolidación resultados respecto a las condiciones 95 para la formación, encuesta a instructores.

Tabla 10. Consolidación de resultados en cuanto a los aspectos 96 de investigación y fortalecimiento del programa, encuesta a instructores.

Tabla 11. Consolidación resultados respecto a información 100 demográfica, encuesta a aprendices.

Tabla 12. Consolidación resultados respecto al programa de 103 formación, encuesta a aprendices. 


\section{FIGURAS}

Pág.

Figura 01. Marco conceptual de la investigación, con enfoque en el desarrollo humano.

Figura 02. Características de la innovación por sectores.

Figura 03. Factores que obstaculizan las empresas para innovar. $\quad 34$

Figura 04. Concepto de innovación social.

Figura 05. Principios de la innovación social.

Figura 06. Fases de la innovación social.

Figura 07. Cadena de valor de la innovación social. 55

Figura 08. Eslabones reflejados por la cadena de valor en la 56 innovación social.

Figura 09. Perspectivas, objetivos e iniciativas estratégicas SENA.

Figura 10. Estructuración del aprendizaje por medio del desarrollo de competencias.

Figura 11. Elementos de innovación - SENA.

Figura 12. Componentes del sistema de gestión del conocimiento. 77

Figura 13. Relación de instrumentos y objetivos de la 80 investigación.

Figura 14. Sistematización resultados de información demográfica y otros, instructores.

Figura 15. Sistematización de resultados de información respecto al programa de formación, encuesta a instructores.

Figura 16. Sistematización resultados de información respecto a 
las condiciones para la formación, encuesta a instructores.

Figura 17. Sistematización de resultados de información respecto

a los aspectos de investigación y fortalecimiento, encuesta a instructores.

Figura 18. Sistematización resultados respecto a información 102 demográfica, encuesta a aprendices.

Figura 19. Sistematización resultados respecto al programa de 104 formación, encuesta a aprendices.

Figura 20. El SENA, motor de la innovación en Colombia.

Figura 21. Actividades y procesos que estructuran el sistema SENNOVA.

Figura 22. Estructura de la triangulación de datos, a partir de las categorías establecidas.

Figura 23. Características del programa de prótesis y órtesis. 


\section{ANEXOS}

ANEXO N ${ }^{\circ} 1 \quad$ Reglamentación y otras disposiciones.

ANEXO N ${ }^{\circ} 2$ Relación de actividades incorporadas a nuevos aprendizajes, como ejes de actividades innovadoras.

ANEXO N 3 Tipos de innovación.

ANEXO N ${ }^{\circ} 4$ Factores que impulsan los efectos de innovación.

ANEXO N 5 Factores que obstaculizan a las empresas para innovar.

ANEXO N ${ }^{\circ} 6$ Entidades gubernamentales que impulsan la innovación social en Colombia.

ANEXO N ${ }^{\circ} 7$ Características en materia de innovación social.

ANEXO N ${ }^{\circ} 8$ Enfoques de la innovación social.

ANEXO $\mathrm{N}^{\circ} 9$ Especificaciones de los países que adoptan la estructura de innovación social a nivel mundial.

ANEXO N 10 Cuestionario de la encuesta aplicada a los instructores. 
ANEXO $\mathrm{N}^{\circ} 11$ Cuestionario de la encuesta aplicada a los aprendices.

ANEXO N ${ }^{\circ} 12$ Cuestionario de la entrevista aplicada al personal administrativo.

ANEXO N ${ }^{\circ} 13$ Resultados encuesta a instructores.

ANEXO N 14 Resultados de la encuesta aplicada a los aprendices.

ANEXO N ${ }^{\circ} 15$ Ambientes de aprendizaje donde se imparte la formación de prótesis y órtesis. 


\section{SIGLAS}

ANSPE

BID

CEPAL

CINTERFOR

COLCIENCIAS

CONPES

$\mathrm{CT}+\mathrm{I}$

DNP

DANE

GIZ
Agencia Nacional para la Superación de la Pobreza Extrema

Banco Interamericano de Desarrollo

Comisión Económica para América Latina y el Caribe

Centro Interamericano para el Desarrollo del Conocimiento en la Formación Profesional

Departamento Administrativo de Ciencia, Tecnología e Innovación

Consejo Nacional de Política Económica y Social

Ciencia, Tecnología e Innovación

Departamento Nacional de Planeación de Colombia

Departamento Administrativo Nacional de Estadística

Deutsche Gesellschaft für Internationale Zusammenarbeit (Agencia de Cooperación Técnica Alemana) 
INNOBASQUE

ISPO

OCDE

OIT

OMS

ONGs

PIB

PNUD

SENA

SENNOVA
Agencia Vasca de la Innovación

Sociedad Internacional de Órtesis y Prótesis

Organización para la Cooperación y el Desarrollo Económicos

Organización Internacional del Trabajo

Organización Mundial de la Salud

Organizaciones No Gubernamentales

Producto Interno Bruto

Programa de las Naciones Unidas para el

Desarrollo

Servicio Nacional de Aprendizaje

Sistema de Investigación, Desarrollo Tecnológico

e Innovación del SENA 


\section{RESUMEN}

La innovación social da lugar a un cambio transformador en el mejoramiento de la calidad de vida de la comunidad abriendo espacio al desarrollo humano, específicamente en áreas como la formación profesional donde las adversidades sociales están agudizándose y las soluciones no son suficientes para atender de manera efectiva las dificultades que se enfrentan; así la situación, con esta investigación se analizan las causas que impiden visibilizar los factores de innovación social necesarios para el fortalecimiento de la formación profesional, especialmente, el programa "desarrollo y adaptación de prótesis y órtesis" implementado en el Servicio Nacional de Aprendizaje -SENA-. La metodología utilizada fue de enfoque mixto que integra sistemáticamente las fases de recolección, análisis y vinculación de datos cualitativos y cuantitativos, para la obtención de nuevos procesos concebidos por medio de la identificación y estudio de factores que implican, entre otros, la intensificación de transferencia de conocimiento y la consolidación de capacidades a través del desarrollo de competencias, aumentando de manera progresiva el cambio para mejorar los resultados.

Palabras claves: desarrollo humano, innovación social, cadena de valor, desarrollo de competencias. 


\begin{abstract}
Social innovation leads to a transformation and change in the improvement of the quality of life of the community, opening space to human development. The variation is evident in areas such as professional training which has lots of social issues and there are not enough solutions to deal with the difficulties in them effectively. This research aims to determine the causes that make difficult to visualize the social innovation factors which are required to enhance the professional formation, especially the training program: "development and adaptation of prostheses and orthoses", which is implemented by the National Training Service "SENA". This research follows the methodology mixed approach, which integrates systematically the phases of collecting, analyzing and combination quantitative and qualitative data, in order to get new processes created by the identification and study of issues, such as the enforcement of knowledge transfer and the consolidation of abilities through the development of skills, increasing the change progressively to obtain better results.
\end{abstract}

Keywords: human development, social innovation, value chain, skills development. 


\section{INTRODUCCIÓN}

La creciente importancia que ha tenido en los últimos años la innovación social, además de su amplia evolución en concepto y aplicación, incita a concebirla como protagonista central del desarrollo humano a través de la transformación y/o activación de las áreas en las que se han concentrado diversos actores, así como procesos ejecutados alrededor de necesidades sociales latentes con importantes retos a nivel regional.

En tal contexto, y a fin de lograr el mejoramiento de condiciones de vida contribuyendo al desarrollo social, es necesario que entremos a profundizar en áreas que imponen desafíos que van desde la desarticulación entre el sistema de ciencia, innovación y tecnología con el sector productivo, hasta la desigualdad de oportunidades y ausencia de innovación social en servicios como la formación profesional; ésta es la oportunidad de explorar, transformar y dinamizar los escenarios colombianos que implican formación, insertando iniciativas que determinen factores para visibilizar y fortalecer la innovación con el propósito de hacer frente en forma segura a los problemas que nos afectan.

Por otra parte, la estructura del documento se presenta en cinco capítulos, de los cuales: el primero consiste en el planteamiento del problema dado a partir de la necesidad de la innovación para el desarrollo social; el segundo capítulo comprende el marco normativo y detalla una 
serie de disposiciones dirigidas a la ciencia, tecnología e innovación, relacionadas con la cualificación del recurso humano; el tercer capítulo establece el marco conceptual presentado desde las categorías de desarrollo humano, innovación, innovación social y cadena de valor; el cuarto capítulo implica el marco contextual identificando aspectos institucionales de la entidad donde se realizó el estudio de caso; el quinto capítulo consta de la metodología, instrumentos y variables utilizadas para el desarrollo de la investigación; en el sexto capítulo se entregan los resultados diferenciando la sistematización y contextualización a partir del análisis por el método de triangulación; y finalmente están las conclusiones especificadas por aportes, lecciones aprendidas y reflexiones finales. 


\section{PLANTEAMIENTO DEL PROBLEMA}

\subsection{Innovación social: una necesidad para el desarrollo humano}

El concepto de innovación entendido en su dimensión social implica un proceso de creación, difusión y puesta en marcha de respuestas a las necesidades de la comunidad, en búsqueda de la transformación de prácticas y la reducción de brechas sociales; estas soluciones se centran particularmente y en forma detallada en diferentes sectores, estableciendo los factores que pueden contribuir en el fortalecimiento y capacidad direccionada a la innovación en el área de estudio, como es el caso de la formación.

A su vez, estudios hechos por la Comisión Económica para América Latina y el Caribe -CEPAL- presentados en su documento "Claves de la innovación social en América Latina y el Caribe", han evidenciado que la desarticulación entre economía y bienestar social como bases para el desarrollo de una comunidad, no han podido ser tomadas de forma efectiva siendo indispensable la incorporación de soluciones sociales innovadoras que se encaminen, particularmente y en forma detallada en cada país, para identificar factores a escala zonal que lleguen a influir en el desarrollo humano vinculado a la capacidad de innovación.

Igualmente, el Foro Económico Mundial sobre Latinoamérica efectuado en el año 2012 se encausó a la formación de nuevos modelos 
orientados a productos de crecimiento equilibrado y sostenible, arrojando como elemento clave el impulso de la innovación social.

Por otra parte, la investigación denominada "The global innovation index 2014", además de acentuar el factor humano como único conductor de la innovación, da a conocer los resultados de la clasificación de los índices de innovación efectuada en ciento cuarenta y tres (143) países, donde se tuvieron en cuenta aspectos como inversión del Producto Interno Bruto -PIB- en actividades de Ciencia, Tecnología e Innovación -CT+Iasí como número de patentes registradas por millón de habitantes, entre otros, posicionando a Colombia por debajo de países como Chile, Barbados, Brasil, Costa Rica y Panamá; la ubicación dentro de este listado evidencia la necesidad de cualificación del capital humano, al igual que la insuficiente inversión en investigación y desarrollo que se asigna en Colombia, frente a otros países a nivel mundial, en los cuales la inversión del PIB sí está por encima del dos (2) por ciento.

Es así como Colombia, a pesar de ser una de las pocas naciones a nivel mundial que cuenta con un centro de innovación social en el interior de una institución pública del sector gubernamental denominada Agencia Nacional para la Superación de la Pobreza Extrema-ANSPE-, reconoce en su documento Pre-CONPES de innovación social 2014, la necesidad de fortalecer en el país cuatro componentes claves para el cubrimiento de las necesidades sociales en pro del desarrollo humano, que son: el marco institucional y la política pública, las dinámicas culturales, los servicios de 
soporte a la innovación social y los procesos de gestión del conocimiento. (BID, 2015, p. 9).

Desde esa perspectiva, la complejidad y urgencia que han adquirido para Colombia los problemas sociales como la desigualdad, el desplazamiento interno y el conflicto armado, entre otros, ha conllevado a que las propuestas, planes, programas y proyectos de innovación social ocupen un papel protagónico en todas las áreas, especialmente en el sector educativo, productivo y gubernamental; como consecuencia se está buscando no sólo el aumento en la asignación de recursos para CT+I y la apertura de proyectos liderados por entes gubernamentales para promover la participación en nuevas alternativas encaminadas al desarrollo, sino también la potenciación del capital humano a través de la formación para el trabajo, como condición de vida que alivie las poblaciones más necesitadas.

Por ende, la potenciación del recurso poblacional con rumbo al desarrollo social entendido desde la innovación como producto de la cualificación del capital humano, se robustece a través de los procesos de gestión del conocimiento encauzados a las comunidades incluida la académica, con base en la visibilización de los factores de innovación social que apuntalan la ejecución de los programas de formación que se ejecutan a través del desarrollo de competencias, como es el caso del programa de formación denominado "desarrollo y adaptación de prótesis y órtesis", curso de formación titulada único en Colombia, diseñado en el 2009, impartido en el Servicio Nacional de Aprendizaje -SENA-; para el 
Departamento Administrativo de Ciencia, Tecnología e Innovación COLCIENCIAS-, la apropiación social del conocimiento es el fundamento de cualquier forma de innovación (BID, 2015, p. 25).

De ahí que, surge la necesidad de realizar la investigación, cuya pregunta es la siguiente: ¿qué características permiten identificar los factores de innovación social para el fortalecimiento del programa de formación en tecnología de prótesis y órtesis del $\mathrm{SENA}^{1}$, por parte de la comunidad académica?, si la comunidad académica (estudiantes, instructores y funcionarios administrativos), llega a visibilizar plenamente las características que identifican los factores de innovación social presentes en los programas de formación, sería posible percibir resultados de innovación que generen valor social integrando procesos, mecanismos e instrumentos consolidados a fin de permitir la sostenibilidad, implicando un crecimiento continuo del servicio (escalabilidad) el cual puede ser divulgado e imitado por otras comunidades (replicalibidad).

Esta investigación, realizada entre los años 2012 y 2015, época de gran auge de la innovación social (BID, 2015), se enfocó en el análisis del programa de formación denominado "desarrollo y adaptación de prótesis y

\footnotetext{
1 El SENA es una entidad pública tripartita: gobierno, empresa y trabajadores, que contribuye a la competitividad de Colombia a través del incremento de la productividad de las empresas y las regiones, la inclusión social de personas y comunidades vulnerables, y, mediante transferencia de conocimiento y tecnologías; esta entidad contempla además, dentro de su misión, el diseño y ejecución de programas de formación profesional, para la incorporación y desarrollo de los colombianos (SENA, 2015). Según informe de la Organización para el Comercio y el Desarrollo Económico "OCDE" y el Banco Mundial publicado en el año 2012 denominado "La Educación Superior en Colombia", confirma que la formación del SENA representa el $55 \%$ de la cobertura total de estudiantes de formación profesional en Colombia, específicamente en niveles técnico profesional y tecnólogo.
} 
órtesis"2 impartido en los ambientes de aprendizaje del Centro de Formación de Diseño y Metrología, perteneciente al SENA (ubicado en la carrera 31 No. 14-20, ciudad Bogotá), con el propósito de establecer las características que puedan identificar los factores de innovación social, por parte de los actores de la comunidad académica.

\subsection{Objetivos}

\subsubsection{Objetivo general}

Realizar una caracterización del programa de formación denominado "desarrollo y adaptación de prótesis y órtesis" nivel tecnólogo, implementado en el SENA, que permita identificar los factores de innovación social para su fortalecimiento.

\subsubsection{Objetivos específicos}

- Determinar las nociones de innovación social en la comunidad académica del programa de formación titulada "desarrollo y

\footnotetext{
2 El programa de formación, modalidad presencial, denominado "desarrollo y adaptación de prótesis y órtesis, es el único programa de formación del SENA relacionado con la fabricación de dispositivos médicos, el cual pretende a través del desarrollo de competencias, elevar la cualificación del recurso humano dedicado a atender usuarios en condición de discapacidad para así mejorar su calidad de vida; este programa fue diseñado en el año 2009, y tiene una duración de 30 meses (SENA, 2015). En el mismo contexto, respecto a los dispositivos médicos denominados órtesis y prótesis, catalogados por el Ministerio de Salud como tecnología que mejora la calidad de vida, para el caso, de personas discapacitadas víctimas del conflicto armado que pierden uno de sus miembros en combate, se debe anotar que según la Dirección para la Acción Integral contra Minas Antipersonal (2.014), Colombia ha ocupado durante los últimos años los primeros lugares en el mundo, en víctimas de minas antipersonales y artefactos sin explotar; en el periodo comprendido entre 1990 y Septiembre de 2014 se registraron en éste país un total de 10.847 víctimas por minas antipersonal "MAP" y municiones sin explotar "MUSE"; de éstas, el 39\% (4.196) son civiles y el $61 \%(6.651)$ miembros de la Fuerza Pública.
} 
adaptación de prótesis y órtesis", y la manera en que estas nociones afectan la intervención en la población beneficiaria.

- Especificar los niveles de participación en la ejecución de la formación a partir de variables de innovación social, de los actores del programa "desarrollo y adaptación de prótesis y órtesis", y su impacto institucional.

- Describir el programa de formación titulada "desarrollo y adaptación de prótesis y órtesis", bajo los elementos de innovación social definidos.

\subsection{Justificación}

La necesidad de crear capacidades para mejorar las condiciones de vida induce a elevar la importancia de la innovación social, incitándola a evolucionar en su concepción y en su práctica, y aunque no haya consenso unánime sobre su concepto, hay acuerdo en que la innovación social da lugar a un giro transformador en la calidad de vida de la comunidad conllevando al desarrollo humano, por tanto, se requiere dedicación para enfrentar los desafíos sociales.

Para avanzar en el campo de la innovación social es importante la exploración y el análisis en todos los sectores ya sea político, social, económico, entre otros, puesto que han resultado ser insuficientes las 
soluciones a los problemas que están intensificándose, especialmente en áreas como la formación profesional ${ }^{3}$ donde nuevas posibilidades de visibilización y afianzamiento aún no han sido explotadas.

Además, la CEPAL (2008) enuncia que los gobiernos tienen la obligación de apoyar las diferentes soluciones que nacen en la innovación social, puesto que son retos para replicar acciones relacionadas con experiencias subjetivas y procesos de aprendizaje colectivo.

Del mismo modo, en el Plan Nacional de Desarrollo con vigencia 2010 - 2014 así como el de vigencia 2014 - 2018, incluyen la innovación social como herramienta fundamental de la sostenibilidad, del crecimiento y desarrollo de los procesos sociales que impulsarán la competitividad y el progreso de Colombia. A continuación se presenta aparte textual de enunciado hecho en el Plan Nacional de Desarrollo 2014 - 2018, denominado "Todos por un nuevo país":

Para facilitar estos procesos, las entidades del sector de la inclusión social y reconciliación deben mejorar su coordinación estratégica y

\footnotetext{
3 La formación profesional es el proceso educativo teórico-práctico de carácter integral, orientado al desarrollo de conocimientos de nivel técnico, tecnológico y de actitudes y valores para la convivencia social, desarrollando destrezas y aptitudes para la realización humana y la participación activa en el trabajo productivo y en la toma de decisiones sociales. Dicha formación implica el dominio operacional e instrumental de una ocupación determinada, la apropiación de un saber técnico y tecnológico integrado a ella, y la capacidad de adaptación dinámica a los cambios constantes de la productividad. Estatuto de Formación Profesional Integral (Marzo. 1997). Ley 119 de 1994. Para el Ministerio de Educación Colombiano la educación superior se imparte en dos niveles que son pregrado y postgrado, en cuanto al nivel de pregrado se comprenden tres niveles específicos: nivel técnico profesional, nivel tecnológico y nivel profesional. La normativa que regula al SENA desde 1957, lo constituye como la institución encargada de ofrecer y ejecutar la formación profesional en el país.
} 
operativa. Para ello será clave incorporar la innovación social como herramienta de gestión pública de las políticas, así como el uso de prácticas y metodologías asociadas, lo cual permitirá aumentar la eficiencia y pertinencia del gobierno en la prestación de servicios que mejoren el bienestar la población en situación de pobreza y vulnerabilidad. (DNP, 2014, p. 29).

Por consiguiente, en un impacto potencial hacia la población vulnerable, en los dos planes se establece la innovación como la plataforma principal para dar soluciones enfocadas a la eficiencia del gasto social (DNP, 2010, p. 107), encaminando al país hacia la consolidación de proyectos, espacios y oportunidades sociales en los cuales se plasmen esquemas de monitoreo público, para lograr mejores estándares de calidad en la entrega de servicios promoviendo la formación de capital humano, a través de modelos de aprendizaje que incluyen el desarrollo de competencias, y bienes de carácter público a los ciudadanos. (DNP, 2014, p. 41).

Continuando, la ANSPE (2014) presenta la innovación como pieza medular del progreso social y gestión del desarrollo sostenible, contribuyendo a la solución de problemas específicos de la sociedad. La innovación está en la agenda pública en todas las formas: tecnológica, social, institucional y organizacional, entre otras.

De igual forma la Dirección de Innovación Social en Colombia liderada desde la ANSPE, ha reconocido la importancia de la academia como agente de desarrollo y actor fundamental en la generación de 
iniciativas y proyectos de innovación social. Además, COLCIENCIAS también ha manifestado en diversos escenarios la necesidad de impulsar proyectos de investigación enfocados hacia la innovación social, en aras de contribuir con soluciones a las dificultades sociales que aqueja la comunidad (BID, 2015).

Por lo anterior, el desarrollo de esta investigación constituye una oportunidad para aportar al desarrollo y progreso social de la comunidad, como es el caso de la académica, especialmente de los actores del SENA, donde las características para establecer los factores de innovación social generados en los diferentes programas de formación, aún no son claramente identificadas para el respectivo fortalecimiento y visibilización. Por lo tanto, se necesita ahondar sobre la innovación social en pro de solucionar las necesidades aún no resueltas de la población, explorando y aportando a las necesidades educativas, de salud, laborales de los colombianos, basadas en el desarrollo de capacidades que aporten a un cambio de vida.

De tal forma, a partir de las áreas temáticas que se plantean en la maestría, las cuales son: políticas públicas con enfoque de derechos, descentralización y ordenamiento territorial, planeación participativa y planeación ciudadana, pobreza e inequidad; esta investigación se enmarca en la dimensión de políticas públicas con enfoque de derechos, y de pobreza e inequidad, eje y principio orientador que fortalece la implementación de acciones estratégicas que aportan a la construcción de políticas de 
innovación social, actualmente en agenda pública, dirigidas a la generación de servicios y soluciones efectivas a los que puedan tener acceso las comunidades, especialmente poblaciones en condiciones de pobreza a fin de superar dichas circunstancias, conllevando a un escalamiento de oportunidades y retos con un criterio de equidad que es impulsado por las instituciones gubernamentales. 


\section{MARCO NORMATIVO}

En materia de innovación social, tal como lo señala COLCIENCIAS, los actuales retos del gobierno colombiano son numerosos y complejos, razón por la cual el país ha ingresado en una transformación de estructuras de política pública articuladas al Sistema de $\mathrm{CT}+\mathrm{I}$, enfatizando en el desarrollo social, con influencia para los próximos veinticinco años; existen nuevos actores, nuevas inversiones y están cambiando las líneas de acción a nivel regional.

No obstante, y con el fin de enfrentar los desafíos para solucionar los problemas sociales como la pobreza y la inequidad, se han expedido una serie de disposiciones dirigidas a la CT+I y al SENA; el SENA es la entidad donde se efectuó el trabajo de campo, siendo una institución gubernamental vinculada a la cualificación del recurso humano que entrega directrices de creación, ejecución e inversión, amplias en contenido pero con algunas dificultades para la realización, especialmente en ciertos entes territoriales debido al desconocimiento y no apropiación por parte de las regiones, entre las disposiciones están: decreto ley 118 de 1957, "por la cual se decretan aumentos de salarios, se establece el subsidio familiar y se crea el Servicio Nacional de Aprendizaje - SENA -"; Comisión Nacional de Proyectos - SENA, con asignación como órgano asesor del Consejo Directivo Nacional en la Estrategia de Innovación; ley 29 de 1990, por la cual se dictan disposiciones para el fomento de la investigación científica y el desarrollo tecnológico y se otorgan facultades extraordinarias (SENA, 
2014). La norma establece acciones del Estado colombiano en materia de $\mathrm{CT}+\mathrm{I}$. Posteriormente se efectúa desarrollo normativo que establece tareas concretas para el SENA.

En la misma dirección, están otras disposiciones incluidas como el decreto ley 585 de 1991 que indica para el SENA "adelantar actividades de formación profesional de conformidad con las normas vigentes, dirigida a transferir tecnología de utilización inmediata en el sector productivo, realizar programas y proyectos de investigación aplicada y desarrollo tecnológico, y orientar la creatividad de los trabajadores colombianos" (diario oficial, 1991, p. 1), es así como se asigna al SENA el rol principal de la investigación aplicada en el país; decreto 2149 de 1992, por la cual se reestructura el SENA; ley 119 de 1994, que determina objetivos al SENA, a saber "participar en actividades de investigación y desarrollo tecnológico, ocupacional y social, que contribuyan a la actualización y mejoramiento de la formación profesional integral" (SENA, 2014). En vista de ello, no podemos dejar de lado la identificación de otras normativas las cuales pueden conocerse en el Anexo No. 1, denominado como SENA: Reglamentación y otras disposiciones.

Por otra parte, respecto al Consejo Nacional de Política Económica y Social -CONPES-, como organismo asesor del gobierno en aspectos sociales y económicos, y actuando bajo la dirección de la Presidencia de la República, ha emitido los siguientes CONPES relacionados con la materia en estudio: CONPES 3527 de 2008 que especifica la política nacional de 
competitividad y productividad, y consta de quince (15) planes de acción ubicando la Innovación en el sexto plan para el desarrollo de la política; CONPES 3582 de 2009, consistente en la Política Nacional de Ciencia, Tecnología e Innovación, como resultado de la identificación de los bajos niveles de innovación y la insuficiencia de recursos asignados a la CT+I; CONPES 3668 de 2010 el cual es el informe de seguimiento a la política nacional de competitividad y productividad, ley 1253 de 2008, donde se especifican aspectos de $\mathrm{CT}+\mathrm{I}$ estableciendo el requerimiento de intervención de múltiples entidades gubernamentales. Igualmente, desde el año 2012, se inició el diseño de una línea de política pública de innovación social con la participación del Departamento Nacional de Planeación DNP-, de COLCIENCIAS, de la ANSPE y del SENA, entre otros, encaminado al apuntalamiento de la innovación social del país; esta política se encuentra actualmente en construcción. (DNP, 2015).

En este sentido, también hay que mencionar otros entes y documentos establecidos como medios para dar resultados, donde están: el Plan Nacional de Desarrollo 2014-2018, que se enfoca en la contribución a la innovación como plataforma de respuesta a necesidades sociales y económicas de las comunidades; la ANSPE y su Centro de Innovación Social - Nodo de Innovación Social, creado en el año 2013, con enfoque de promoción de actores para generar soluciones de innovación social.(ANSPE, 2014). 
Así mismo, el conjunto normativo permite reconocer la innovación social como una apuesta de país, dada a partir de la consolidación de lineamientos direccionados al desarrollo de la comunidad con énfasis en el bienestar social, regulando igualmente derechos y responsabilidades de las entidades gubernamentales con mira a una cultura en innovación social. 


\section{MARCO CONCEPTUAL}

En este capítulo se presenta un conjunto de categorías conceptuales que se encuadran en el contexto y la base estructural del proceso de la investigación, en el marco de la innovación social y su dimensión del desarrollo humano, abordando fundamentos de relevancia como las competencias laborales y las actividades de aprendizaje; para esta investigación las categorías son desarrollo humano, innovación, innovación social y cadena de valor, las cuales se presentan en la siguiente figura mostrando la interacción entre ellas.

Figura 1: Marco conceptual de la investigación, con enfoque en el desarrollo humano.

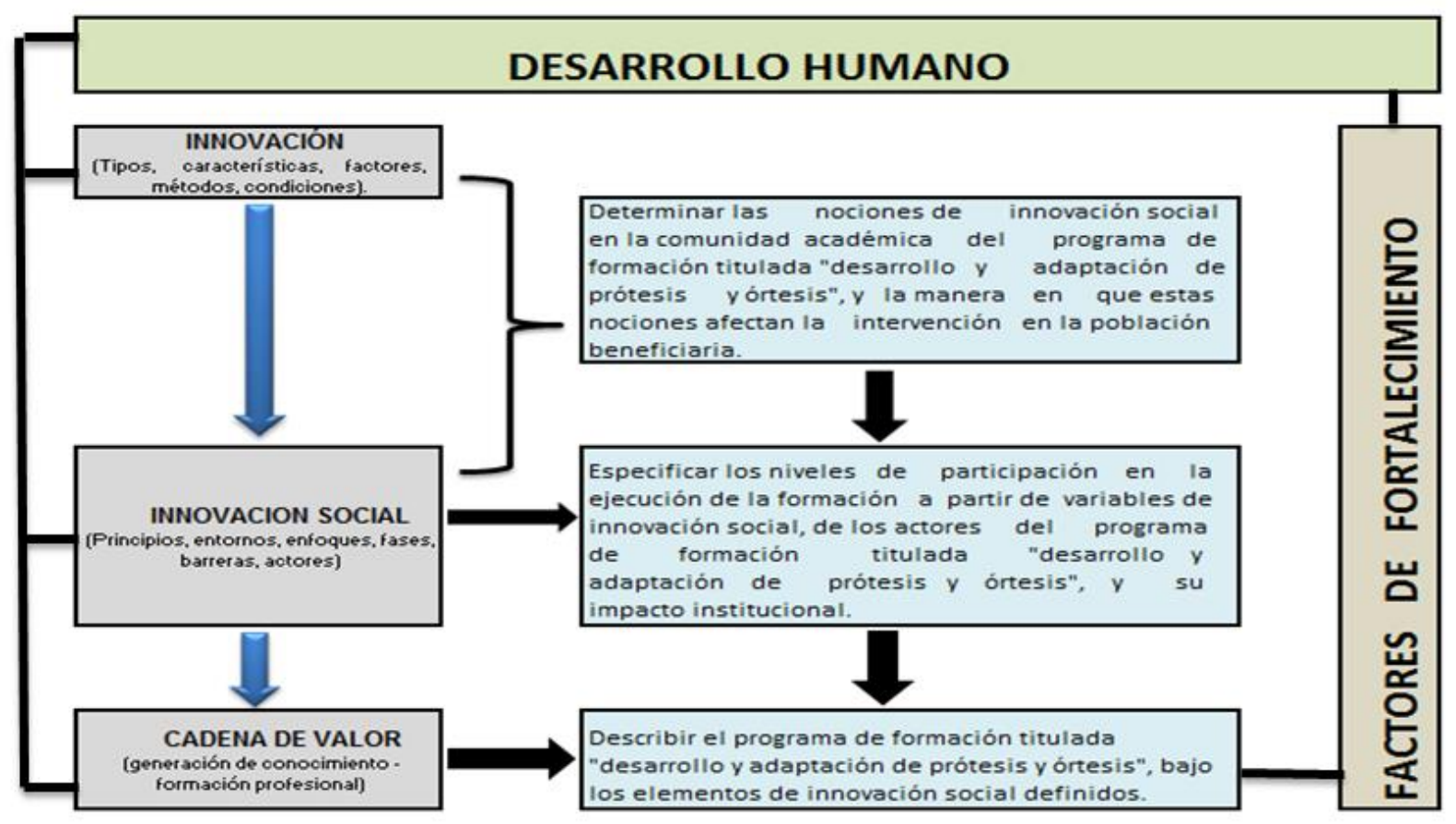

Fuente: Elaboración propia a partir de la estructura dada en la investigación. 
A partir de la articulación presentada en la figura dada entre desarrollo humano e innovación social, y tomando como base la innovación y sus conceptos, se identifican las tipologías, características y condiciones necesarias que originan el punto de partida para el análisis de las nociones en el programa de formación en órtesis y prótesis ${ }^{4}$, seguido del proceso de innovación social y la determinación de factores para el potenciamiento de la innovación, estableciendo de forma alterna las causas que obstaculizan la visibilización de estos factores y las características de innovación social que generan desarrollo humano. Desde esta perspectiva, el análisis es pertinente para abordar la cadena de valor dada en el proceso, estableciendo puntos críticos enlazados con los eslabones; así mismo, a continuación se realizará una discusión de la noción de desarrollo humano en clave del concepto de innovación.

\subsection{Desarrollo Humano}

El desarrollo es un término utilizado en diferentes escenarios de múltiples gobiernos y entidades internacionales, que ha evolucionado de acuerdo al pensamiento y los valores dominantes en la sociedad; el concepto de desarrollo ha ido cambiando a lo largo del tiempo, donde cada sociedad y

4 Órtesis, según la Norma UNE 11-909-90/1, acogida de la ISO 8549/1, es un dispositivo aplicado de manera externa sobre el cuerpo humano, y es utilizado para cambiar las particularidades estructurales o funcionales del sistema neuro-músculo-esquelético, a fin de mantener, mejorar o recuperar la función; se diferencia de los demás productos de apoyo porque está en contacto permanente con el cuerpo humano (órtesis - son ayuda y/o soporte en el campo de la ortopedia). En cuanto a la prótesis, desde la Norma UNE 11-909-90/1, adoptada de la ISO 8549/1, es un dispositivo externo (extensión artificial) que aplicado al cuerpo reemplaza total o parcialmente un miembro o parte del mismo. 
cada época tienen su propia formulación según convicciones, expectativas y posibilidades predominantes en ellas, en resumen el concepto se relaciona con la idea del futuro que cada sociedad se propone como meta para el colectivo humano (Dubois, 2002, p. 3). El desarrollo caracteriza igualmente una parte significativa de las escuelas de sociología en América Central y América del Sur, con análisis de diferentes aspectos de la interacción social a partir de causas y efectos vinculados al criterio de desarrollo, el cual se fortalece en la última década (Roitman, 2008, pp. 31-60).

Además, refiriéndonos puntualmente al desarrollo humano orientado al cambio transformador de una comunidad que mira hacia la construcción de una sociedad incluyente, puede ser pensado como un proceso en el que se maximizan y perfeccionan las libertades de las cuales disfruta un individuo (Sen, 2000), tiene relación directa con el desarrollo de capacidades, entendidas como el conjunto de herramientas, recursos y actitudes necesarias para desempeñar una labor (SENA, 2015), encaminadas al mejoramiento del nivel de vida de los individuos, donde, dicha cualificación es fundamental para el apuntalamiento de la innovación social (PNUD, 2013).

A continuación se presentan los conceptos dados por académicos que han hecho contribuciones importantes en la temática de desarrollo humano, y coinciden en la condición de enfoque y potencialización de capacidades, además de la búsqueda de la libertad humana con opciones de participación en decisiones de vida, a saber: 
Nussbaum (2007), señala que el desarrollo humano se basa en la presunción de las capacidades, porque cada individuo tiene un interés sobre él mismo y no se pregunta únicamente por el bienestar sino también por la oportunidades dispuestas para cada ser humano; en consecuencia, la libertad se convierte en el estándar para medir la calidad de vida y el desarrollo de la gente. (Nussbaum, citado por Gough, 2007, p. 178)

Sen (2000), afirma que el desarrollo humano comprende la creación de un entorno propicio para que las personas desarrollen su máximo potencial, en el camino de la libertad humana, incluyendo la mayor cantidad de oportunidades (aumento) como producto del desarrollo de las capacidades humanas.

Además, Sen plantea una agencia personal como eje del cambio social en el cual una persona tiene la libertad de hacer y lograr en búsqueda de valores e intereses valorados como significativos (competencia y deseo), relacionando el desarrollo con una vida de bienestar y producción de acuerdo a necesidades e intereses, yendo más allá de un crecimiento económico debido a que el desarrollo de una región no se refleja en los datos producto del análisis económico sino en la forma como se interpretan las oportunidades reales para lograr la calidad de vida anhelada. Por tanto, hay que agregar que las oportunidades para formarse, la atención en aspectos de salud, la cobertura de necesidades básicas (vivienda, 
alimentación, otros), además de la opción de emplearse, son libertades que conllevan al desarrollo humano.

En otras palabras, tanto para Sen como para Nussbaum, los fundamentos del desarrollo humano se cimientan en criterios de equidad y justicia, donde su potenciación produce avances en el desarrollo y su carencia conlleva a la pobreza.

Del mismo modo, el Programa de las Naciones Unidas -PNUD(2014), institución que tiene como misión, entre otras, apoyar el sistema de Naciones Unidas para impulsar el desarrollo humano de los países en esta vía, al igual que Amartya Sen (2000) y Martha Nussbaum (2007), conciben el desarrollo humano como la indagación de garantías en un ambiente adecuado donde los individuos pueden desarrollar sus capacidades y así ampliar sus opciones de llevar una vida cálida y productiva, con énfasis en la dignidad y el respeto, de acuerdo con sus necesidades e intereses primarios. Entre las capacidades primarias para el desarrollo humano están: acceder a recursos que permitan poseer un buen nivel de conocimiento, vivir honrosamente, tener salud y longevidad.

Desde esta lógica, la cualificación del ser humano debe basarse en el hecho que las personas son protagonistas de su propio desarrollo, propiciado por un ambiente favorable con aproximación de oportunidades y recursos hacia quienes más los necesitan y en interacción con la comunidad, reflejando así la conexión de otras variables. 
En este horizonte, el desarrollo humano conlleva al estudio de piezas concretas como el desarrollo incluyente, una unidad fundamental en el bienestar de la población.

\subsubsection{Desarrollo incluyente}

El concepto de desarrollo incluyente trascendió entre investigadores y Organizaciones No Gubernamentales -ONGs- a finales de los años noventa, asociando la reducción de la pobreza y la reducción de la desigualdad a un desarrollo que puede contribuir a la inclusión, en la medida que se aumenten los beneficios para mejorar la calidad de vida de la población con discapacidad u otros grupos poblacionales que requieren una garantía de derechos a partir de la inclusión.

En el mismo sentido, para Weigt (2014), “el enfoque del desarrollo incluyente se basa en la comprensión de la discapacidad desde el punto de vista de los derechos humanos, y coloca en primer plano los aspectos de la igualdad de oportunidades y de la participación equitativa de las personas con discapacidades" (p. 12).

De ahí que, el desarrollo incluyente sólo es posible si se otorga a las personas discapacitadas la oportunidad de ganarse la vida en condiciones de equidad e igualdad, y esto se logra con opciones como la cualificación del recurso humano, para el caso a través del desarrollo de competencias 
direccionadas a la innovación, que impulsen la posibilidad de superación en sectores como el laboral.

\subsection{Innovación}

La innovación es de gran importancia para la planificación y organización de los pueblos junto con su desarrollo humano integral, donde al ser considerada como fenómeno social promueve la integración en una invariante común de la evolución en la conciencia ciudadana (Carrero, 2011, p. 53). Entonces, al ser la innovación considerada eslabón clave del desarrollo humano, nace la importancia de estudiar su concepto encontrando que origina su evolución en la última década y ha sido analizada por diferentes entes como la CEPAL, DNP y la Organización para la Cooperación y el Desarrollo Económicos -OCDE-; a continuación se exponen algunas percepciones:

En el estudio de la CEPAL denominado "Claves de la innovación social en América Latina y el Caribe", caracterizan la innovación de la siguiente manera:

La innovación es el resultado de un largo proceso histórico, de un cúmulo de intentos fallidos y pequeñas mejoras que en un momento crítico cambian el signo de la tendencia, la dirección de un proceso, la calidad de un producto o la técnica de un procedimiento. Dado que aparecen de manera impetuosa y hasta transgresiva, con frecuencia se pasa por alto que cada innovación depende del cambio que se ha venido gestando en el marco de una determinada cultura tecnológica, 
artística, científica, filosófica u organizativa. (Rodríguez y Alvarado, 2008, p. 23)

Según Moreira y Frías (2013), la innovación se define como:

Innovación es la capacidad y el proceso de generación, transferencia y aplicación del conocimiento científico y/o empírico, dentro y fuera del ámbito del mercado, que incrementa la productividad o la efectividad de una comunidad, organización o empresa en forma sostenible, permitiéndole alcanzar sus objetivos, satisfacer sus necesidades o incrementar su bienestar. La innovación crea valor a partir del conocimiento y se generan externalidades positivas de carácter económico y social. Es aplicar el conocimiento a la solución de problemas o a incrementar la competitividad de una empresa o el bienestar de una comunidad de forma sostenible. (p. 7)

Por otro lado, en el Plan Nacional de Desarrollo (2010), se refiere a la innovación como un proceso que consiste en convertir una idea en un producto que sea aceptado. Por su parte, la Organización para la Cooperación y el Desarrollo Económicos (2005), conceptúa a la innovación como la introducción de un nuevo producto, generado a partir de un proceso de comercialización en las prácticas internas de la empresa.

Adicionalmente, según el Manual de Oslo (OCDE, 2005), la definición de innovación es la siguiente:

Se entiende por innovación la concepción e implantación de cambios significativos en el producto, el proceso, el marketing o la organización de la empresa con el propósito de mejorar los resultados. Los cambios innovadores se realizan mediante la 
aplicación de nuevos conocimientos y tecnología que pueden ser desarrollados internamente, en colaboración externa o adquiridos mediante servicios de asesoramiento o por compra de tecnología. Las actividades de innovación incluyen todas las actuaciones científicas, tecnológicas, organizativas, financieras y comerciales que conducen a la innovación. Se consideran tanto las actividades que hayan producido éxito, como las que estén en curso o las realizadas dentro de proyectos cancelados por falta de viabilidad (p. 39)

En ese mismo orden de ideas, entre las coincidencias de los conceptos presentados están: concepción de nuevas formas de hacer las cosas (procesos, productos), introducción de un nuevo o significante mejorado, generación, transferencia y aplicación de conocimiento científico. La innovación constituye uno de los principales elementos para el aceleramiento de la competitividad.

Así mismo, el manual de Bogotá en el estudio de normalización de indicadores de innovación tecnológica en América Latina y el Caribe (2001) y el manual de Oslo (OCDE, 2005), el cual es una guía para la realización de estudios científicos, estudios tecnológicos, investigaciones y mediciones, siendo también referencia para diferentes organismos públicos, coinciden en que la innovación incluye actividades incorporadas directamente en la adquisición de nuevos aprendizajes. Por otra parte, a continuación se indica la relación de las actividades, dividida en dos grupos: "investigación y desarrollo", conceptuadas como investigación fundamental y aplicada para adquirir nuevos conocimientos, desarrollo de nuevos conceptos de productor, procesos o métodos para evaluación de factibilidad y viabilidad, y, "otras actividades innovadoras", concebida 
como definición de conceptos y procesos de comercialización, o cambios organizativos, inversión en equipos y reorganización de sistemas (OCDE, 2005, p. 23). En el mismo sentido, en el Anexo No. 2, se presenta la relación de actividades incorporadas a nuevos aprendizajes, como ejes de actividades innovadoras.

Dentro del contexto, las empresas y organizaciones innovan introduciendo por primera vez cambios significativos, a través de la inclusión de una estructura organizativa flexible y plana, con bajo número de niveles jerárquicos, con toma de decisiones en diferentes niveles de la organización, llevando proyectos con tecnología multifuncional para optimizar los resultados, disponiendo de herramientas apropiadas de comunicación, con espacios que desarrollen la creatividad y apalanquen los comportamientos innovadores enriqueciendo así las capacidades de la organización, especialmente de su capital humano (EUSKADI, 2015, p. 5).

De otra parte, están también las actividades que no se consideran innovación, las cuales se encuentran distribuidas en los siguientes parámetros: dejar de realizar un ejercicio obsoleto, cambiar y ampliar equipos, trasladar las variaciones de costo de los precios, efectuar cambios por estacionalidad, vender algo nuevo con el método habitual (OCDE, 2005, p. 25).

En cierto modo se resume que la innovación es percibida por diversos autores como un cambio novedoso que responde a una solución de 
cualquier necesidad, motivo por el cual se considera relevante la identificación de los modelos de innovación.

\subsubsection{Modelos de innovación}

Los modelos de innovación existentes son el tradicional y el abierto, en esta vía, a continuación se especifica cada uno de ellos con el planteamiento de su concepción.

\subsubsection{Modelo de innovación tradicional}

Este modelo concibe una imagen de control total en dirección a la protección y cuidado de la propiedad intelectual, regido por los aportes y desarrollos que surgen de diversas fuentes como los centros de innovación, las universidades y los propios individuos.

Pascale (2015), en su artículo publicado en el diario Economía y Mercado de Uruguay, identifica la innovación cerrada como punto de convergencia en el desarrollo al interior de las instalaciones de una entidad donde se generan sus propias ideas, las cuales surgen después de desarrollarlas, manufacturarlas y comercializarlas; este modelo funcionó altamente en el siglo XX, se invertía en investigación y en desarrollo con el ánimo de superar a los competidores, vinculando a la institución aquel personal talentoso que se encontraba en el mercado. 


\subsubsection{Modelo de innovación abierta}

A partir de la última década, la innovación abierta ha cambiado el modo de pensar de diversas instituciones con respecto al desarrollo de los productos que de ellas se emanan, razón por la cual debe ser aplicada también a los servicios, incluida la educación (Chesbrough, 2011, p. 2).

Además, para autores como Moreira (DNP, 2013), la conceptualización de innovación abierta se define como:

La innovación abierta aprovecha la inteligencia colectiva distribuida en las masas, implicando el reconocimiento del potencial de las comunidades como aliados estratégicos, permitiendo así generar la confianza en las comunidades para que sean conscientes de sus capacidades y conocimientos para liderar sus propios procesos de desarrollo y solventar sus propias necesidades. Este modelo de innovación se basa en una serie de principios entre los que se destacan la colaboración, la auto-organización, la descentralización, la transparencia y la pluralidad de los participantes. (p. 3)

La innovación abierta concibe una corriente de diseño hacia el paradigma de la colaboración, el co-diseño y co-creación de código abierto para el trabajo directivo en las entidades de cada sector (Ramírez, 2012, p. 11).

Por la misma línea, en la siguiente tabla se plasman las diferencias entre innovación abierta e innovación cerrada, determinadas por Mónica Edwards, investigadora del Instituto de Innovación y Gestión del Conocimiento en España, en su artículo "Nuevos Paradigmas en Innovación”, publicado en el año 2008. 
Tabla 1. Diferencias entre innovación abierta e innovación cerrada.

\begin{tabular}{|c|c|}
\hline $\begin{array}{l}\text { Concepciones de la institución que aplica la } \\
\text { innovación cerrada. }\end{array}$ & $\begin{array}{l}\text { Concepciones de la institución que aplica la } \\
\text { innovación abierta. }\end{array}$ \\
\hline $\begin{array}{l}\text { La mejor gente en este campo trabaja con } \\
\text { nosotros. }\end{array}$ & $\begin{array}{l}\text { No toda la gente experta en este campo trabaja } \\
\text { con nosotros. Necesitamos trabajar con ella } \\
\text { dentro y fuera de la empresa. }\end{array}$ \\
\hline $\begin{array}{l}\text { Para aprovecharnos de nuestra investigación y } \\
\text { desarrollo, tenemos que descubrirlo, } \\
\text { desarrollarlo y distribuirlo por nosotros } \\
\text { mismos. }\end{array}$ & $\begin{array}{l}\text { La investigación y desarrollo externos pueden } \\
\text { crear valor de forma significativa: necesitamos } \\
\text { nuestra investigación y desarrollo internos } \\
\text { para reclamar parte de ese valor. }\end{array}$ \\
\hline $\begin{array}{l}\text { Si lo descubrimos por nosotros mismos, } \\
\text { llegaremos de primeras al mercado. }\end{array}$ & $\begin{array}{l}\text { No tenemos por qué iniciar la investigación } \\
\text { para aprovecharnos de ella. }\end{array}$ \\
\hline $\begin{array}{l}\text { La primera empresa que introduce una } \\
\text { innovación en el mercado ganará. }\end{array}$ & $\begin{array}{l}\text { Es mejor construir mejores modelos de } \\
\text { negocio que llegar de primero al mercado. }\end{array}$ \\
\hline $\begin{array}{l}\text { Si somos quienes más y mejores ideas } \\
\text { creamos en el mercado, ganaremos. }\end{array}$ & $\begin{array}{l}\text { Si somos quienes mejor usamos las ideas, } \\
\text { internas y externas, ganaremos. }\end{array}$ \\
\hline $\begin{array}{l}\text { Deberemos controlar nuestras patentes } \\
\text { industriales para que la competencia no se } \\
\text { aproveche de ellas. }\end{array}$ & $\begin{array}{l}\text { Deberemos aprovecharnos del uso que otros } \\
\text { hagan de nuestras patentes y comprar otras si } \\
\text { nos ayudan a mejorar nuestro modelo de } \\
\text { negocio. }\end{array}$ \\
\hline
\end{tabular}

Como se puede observar en la tabla anterior, el concepto de innovación abierta está involucrando la masa colectiva, sin dejar de lado ningún actor, para lograr un máximo de aprovechamiento intelectual hacia la innovación. 
A partir de los conceptos presentados por los diferentes autores, se destaca que la diferencia entre los dos modelos radica, entre otros, en la cantidad de actores que intervienen en cada uno de ellos, donde, contrario a la innovación tradicional, la innovación abierta involucra la mayor cantidad de actores posibles, implicando las masas colectivas.

\subsubsection{Tipos de innovación}

A continuación se establecen los tipos de innovación junto a especificaciones generales, dados en el Manual de Bogotá (2001) según documento de normalización de indicadores de innovación tecnológica de América Latina y el Caribe, y, constatados en el Manual de Oslo (OCDE, 2005, p. 23): innovación de producto (cambio en características técnicas o funcionalidades), innovación de proceso (cambios en técnicas, materiales,

programas, otros), innovación de marketing (área de comercialización: cambios en diseño, envasado, posicionamiento, otros), innovación en organización (cambios en prácticas y procedimientos). Para mayor ilustración puede referirse al Anexo No. 3 donde se especifican los tipos de innovación.

\subsubsection{Características de la innovación por sectores}

La clasificación que se describe a continuación, se funda en el sector de alta tecnología, en el sector servicios, en el sector de bajo o medio contenido 
tecnológico y las medianas empresas referido a patrimonio y trabajadores. (OCDE, 2005, p. 23).

Figura 2. Características de la innovación por sectores.
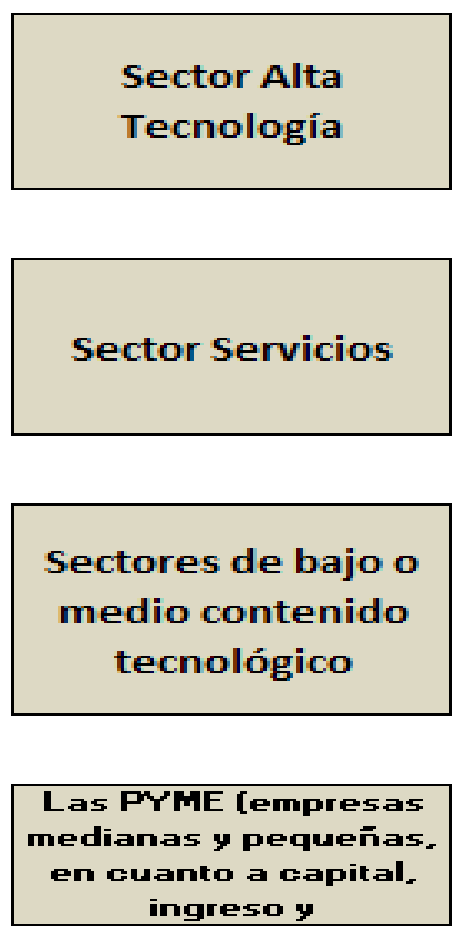

La investigación y el desarrollo desempeñan un papel central en las actividades de innovación

$\square$ tros sectores adaptan conocimientoy tecnología ya existente

Se innowa por proceso contínuo, introduciendo modificaciones progresivas en productos yen procesos. Esta característica puede complicar la identificación específica de las actividades vinculadas.

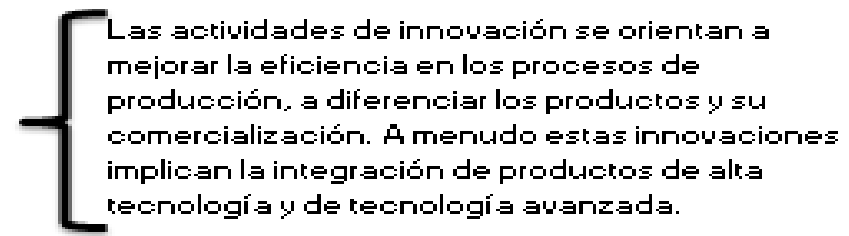

Necesitan compartir la tarea de innowación con otras empresas y con establecimientos públicos de investigación. La financiación de la innovación puede ser un obstáculo importante.

\section{La dimensión regional resulta significativa.}

Los procesos de innovación son, en muchos casos, internacionales.

Fuente: Elaboración propia a partir del manual de Oslo (OCDE, 2.005).

En la figura 2 se evidencia la importancia del desarrollo y el mejoramiento de procesos en las actividades de innovación, figurando con un papel protagónico en la intervención de los renglones presentados. El académico Tidd (2003), referenciado en el documento "Análisis prospectivo sobre Modelos de Innovación en el sector servicios", enuncia que la innovación en el sector de servicios, a diferencia del sector 
tecnológico, conlleva a un cambio de paradigma en el concepto donde se enlazan procesos de suministro y atención al cliente, distribución del producto, control de calidad y potencialidades a desarrollar para el futuro, los cuales agregan valor aportando nuevos métodos o mejoras para solucionar un problema (ISEA, 2008, p. 5).

3.2.4 Factores relacionados con los objetivos y efectos de la innovación: impulsos y barreras

Las instituciones pueden tener éxito o fracasar en el cumplimiento de los objetivos trazados al introducir una innovación, y a su vez las innovaciones pueden tener efectos inesperados o adicionales con relación a los planteados con su introducción. En ese mismo orden de ideas, se debe tener en cuenta que al iniciar el desarrollo de una innovación, un aspecto importante para impulsarla en el camino al éxito es dedicar tiempo y recursos necesarios para comprender el mercado e incluir a los clientes y consumidores en la creación de conceptos de solución (Elola, 2010, p. 10).

Según el Manual de Oslo, existen factores que interactúan en la actividad innovadora los cuales se relacionan con el objetivo que motivó el inicio de la innovación; algunos factores pueden afectar al objetivo y al efecto de la innovación (OCDE, 2005, p. 123). Por tal motivo, los factores que impulsan los objetivos enlazados con las motivaciones de las empresas para innovar según la OCDE (2005, p. 123), son: 
En cuanto al objetivo de la motivación para innovar denominado competencia, demanda y mercados, se tienen los siguientes factores: en el factor 1, reemplazar los productos progresivamente retirados; factor 2, aumentar la gama de los bienes y servicios; factor 3, desarrollar productos respetuosos con el medio ambiente; factor 4, aumentar o mantener la cuota de mercado; factor 5, introducirse en nuevos mercados; factor 6 , aumentar la visibilidad o la exposición de productos; factor 7 , reducir el plazo de respuesta a las necesidades de los clientes (p.123).

Para el objetivo de la motivación para innovar denominado producción y distribución, se tienen los siguientes factores: en el factor 1, mejorar la calidad de los bienes y servicios; factor 2, mejorar la flexibilidad de la producción o la prestación del servicio; factor 3, aumentar la capacidad de producción o de prestación del servicio; factor 4, reducir los costos laborales unitarios; factor 5, reducir el consumo de materiales y de energía; factor 6 , reducir los costos de diseño de los productos; factor 7, reducir las demoras en la producción; factor 8, cumplir las normas técnicas del sector de actividad; factor 9, reducir los costos de explotación vinculados a la prestación de servicios; factor 10, aumentar la eficiencia o la rapidez del aprovisionamiento y/o consumo del suministro de los bienes o servicios; factor 11, mejorar la capacidad en cuanto a tecnologías de información (p. 123).

Para el objetivo de la motivación para innovar denominado organización del lugar de trabajo, se presentan los siguientes factores: factor 1, mejorar la comunicación y la interacción entre distintas actividades de la empresa; factor 2, intensificar la transferencia de conocimientos con otras organizaciones y el modo de compartirlos; factor 3, aumentar adaptabilidad a las distintas demandas de los clientes; factor 4, establecer relaciones más estrechas con la clientela; factor 5, mejorar las condiciones de trabajo (p.123).

Lo que refiere al objetivo de la motivación para innovar denominado Varios, se precisa los siguientes factores: factor 1, minimizar el impacto 
medioambiental o mejorar la sanidad y la seguridad; factor 2, respetar las normas" (OCDE, 2005, p. 123). Ver Anexo No. 4, que plasma detalladamente los factores que impulsan los efectos de innovación.

A continuación se presenta la relación de los factores que, dependiendo el tipo de innovación, obstaculizan a las empresas para innovar. Los factores relacionados son de costo, de mercado, vinculados al conocimiento, institucionales y, otras razones para innovar.

Figura 3. Factores que obstaculizan a las empresas para innovar.

\begin{tabular}{|c|c|c|}
\hline \multirow{5}{*}{$\begin{array}{l}\text { FACTORES DE } \\
\text { COSTO }\end{array}$} & \multicolumn{2}{|c|}{ Riesgos percibidos como excesivos } \\
\hline & \multicolumn{2}{|l|}{ Costo demasiado elevado } \\
\hline & \multicolumn{2}{|l|}{ Falta de fondos propios } \\
\hline & \multirow{2}{*}{$\begin{array}{l}\text { Falta de financiación externa a } \\
\text { la empresa }\end{array}$} & Capital riesgo \\
\hline & & Financiación pública \\
\hline & \multicolumn{2}{|c|}{ Potencial de innovación insuficiente (investigación, diseño, desarrollo, otros) } \\
\hline & \multirow{2}{*}{ Falta de personal cualificado } & Dentro de la empresa \\
\hline & & En el mercado laboral \\
\hline & \multicolumn{2}{|c|}{$\begin{array}{l}\text { Falta de información sobre tecnología } \\
\text { Falta de información sobre los mercados }\end{array}$} \\
\hline \multirow{7}{*}{$\begin{array}{l}\text { FACTORES } \\
\text { VINCULADOS AL } \\
\text { CONOCIMIENTO }\end{array}$} & \multicolumn{2}{|c|}{ Insuficiencias en la disponibilidad de servicios externos } \\
\hline & \multirow{2}{*}{$\begin{array}{l}\text { Dificultad de encontrar socios } \\
\text { en cooperación para: }\end{array}$} & El desarrollo de productos o procesos \\
\hline & & Consorcios de comercialización \\
\hline & \multirow{3}{*}{$\begin{array}{l}\text { Rigideces organizativas } \\
\text { dentro de la empresa }\end{array}$} & Actitud del personal respecto al cambio \\
\hline & & Actitud de los gestores respecto al cambio \\
\hline & & Estructura de la dirección de la empresa \\
\hline & \multicolumn{2}{|c|}{$\begin{array}{l}\text { Incapacidad para afectar personal a las actividades de innovación debido a los requisitos de la } \\
\text { producción }\end{array}$} \\
\hline \multirow{2}{*}{$\begin{array}{l}\text { FACTORES DE } \\
\text { MERCADO }\end{array}$} & \multicolumn{2}{|c|}{ Demanda dudosa de bienes y servicios innovadores } \\
\hline & \multicolumn{2}{|c|}{ Mercado potencial dominado por empresas establecidas } \\
\hline
\end{tabular}



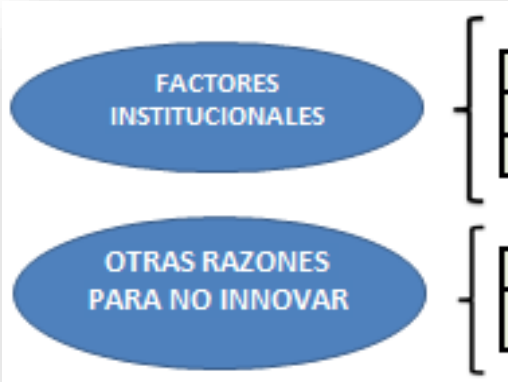

Falta de infraestructura

Debilidad de los derechos de propiedad

Legislación, reglamentos, normas, fiscalidad

No hay necesidad de innovar debido a innovaciones previas

No hay necesidad de innovar debido a una falta de demanda de innovación

Fuente: Elaboración propia a partir del Manual de Oslo (OCDE, 2005).

Son varios los factores que no permiten que las empresas innoven, entre ellos están: falta de fondos propios, costos demasiado elevados, poco personal cualificado, dificultad de encontrar socios de cooperación. Ver con mayor detalle el Anexo No. 5, que presenta los factores que obstaculizan a las empresas para innovar.

3.2.5 Métodos de protección de la innovación

Países como Colombia utilizan métodos formales como derechos de protección de las invenciones realizadas, llamadas patentes de innovación.

Entre los métodos formales tenemos: patentes las cuales se deben vincular al país donde se desarrolló y no al país donde se presentó, registro de modelos (método de protección de aspectos estéticos de los productos), marcas registradas (aspectos de imagen de la empresa), derechos de autor (utilización final de productos $\mathrm{y}$ derechos para exigir pago por su utilización), acuerdos de confidencialidad (protección de trabajos producto de investigación y desarrollo) y secreto comercial (OCDE, 2005, p. 132) 
En este contexto, en el documento denominado "generación y protección del conocimiento: propiedad intelectual, innovación y desarrollo económico" (CEPAL, 2008, p.21), subraya que, aunque la patente haya sido originada para motivar la innovación, puede llegar a convertirse en un obstáculo de entrada de otros innovadores y en un instrumento para conservar monopolios.

En consecuencia, todos los fundamentos planteados inciden en el incremento de las innovaciones, abriendo el campo a las condiciones que son necesarias para admitir la novedad.

\subsubsection{Condiciones para que una institución acepte la novedad}

La innovación considerada como factor crítico para mejorar la calidad de vida de una institución y de una sociedad (Pulido, 2005, p. 15), necesita de ciertas condiciones para ser aceptada como una novedad (OCDE, 2005, p. 24), a saber: la relevancia (que el efecto de la innovación tenga entidad), la ventaja (que los beneficios potenciales sean sensiblemente superiores a los aportados por otras disponibilidades accesibles en la empresa), la movilización (las actuaciones de quien vende o propone el cambio crean un estado de oportunidad e inquietud en el cliente o decisor), la especificidad (la propuesta se ajusta a su negocio), el riesgo controlado (resulta fácil tomar la decisión y ponerla en práctica con la probabilidad elevada de alcanzar los objetivos previstos). 


\subsection{Innovación social}

Algunos de los países más prósperos en recursos naturales y diversidad cultural están ubicados en América Latina y el Caribe, contrariamente también es la región con los más altos índices de pobreza que incluyen obstáculos para el progreso e ingreso a variados recursos (CEPAL, 2008, p. 12).

Así la situación, y a pesar de los grandes logros en crecimiento económico alcanzados en los últimos años, aún no hay señales de disminución de los problemas sociales como la exclusión social, discriminación y la inequidad, como tampoco hay lineamientos de desarrollo humano que consoliden la integración de la comunidad; se enfatiza en que, aunque existen algunas innovaciones en ejecución que cambian las acciones del esquema social en entornos como la capacitación, gran parte de esas innovaciones no son detectadas y registradas como tales. Las brechas sociales necesitan del surgimiento y multiplicación de innovaciones en el campo social, y únicamente efectuarse a través de la difusión de éstas (CEPAL, 2008, p. 17).

Por lo anterior se hace necesario centrarse en el concepto de innovación y sus orígenes en el campo social, aspectos que se exploran en la teoría dada por el sociólogo Ogburn en el año 1923, quien afirmó que el cambio social tiene lugar en la integración de la cultura material (tecnología y proyectos) y la cultura inmaterial a partir de reglas y prácticas que 
caracterizan la relación del ser humano con los equipos (citado en DNP, 2013, p. 4); sin embargo, a pesar de existir diversos conceptos respecto la materia en estudio, a la fecha no hay un consenso universal sobre el concepto de innovación social. De hecho, existen variadas definiciones que van desde las que se fundamentan en nuevas ideas enfocadas en prácticas sociales, hasta aquellas que se establecen en estructuras novedosas, todas orientadas a la generación de valores sociales. He aquí algunas de ellas:

El Plan Nacional de Desarrollo 2010 - 2014 (2010) define a la innovación como:

Proceso de diseño e implementación de ideas y proyectos que dan solución a problemas sociales, culturales, económicos o de medio ambiente. El concepto de innovación social implica, de este modo, el desarrollo de nuevas formas de pensar, operar, coordinar y/o escalar e involucra a muchos actores: la academia, las firmas, las organizaciones de base, los organismos multilaterales y el sector público. (p. 226)

Para el Nodo de Innovación Social, en Colombia, el concepto está representado en la siguiente figura: (innovación social- proceso mediante el cual se crea valor para la sociedad). 
Figura 4. Concepto de innovación social.

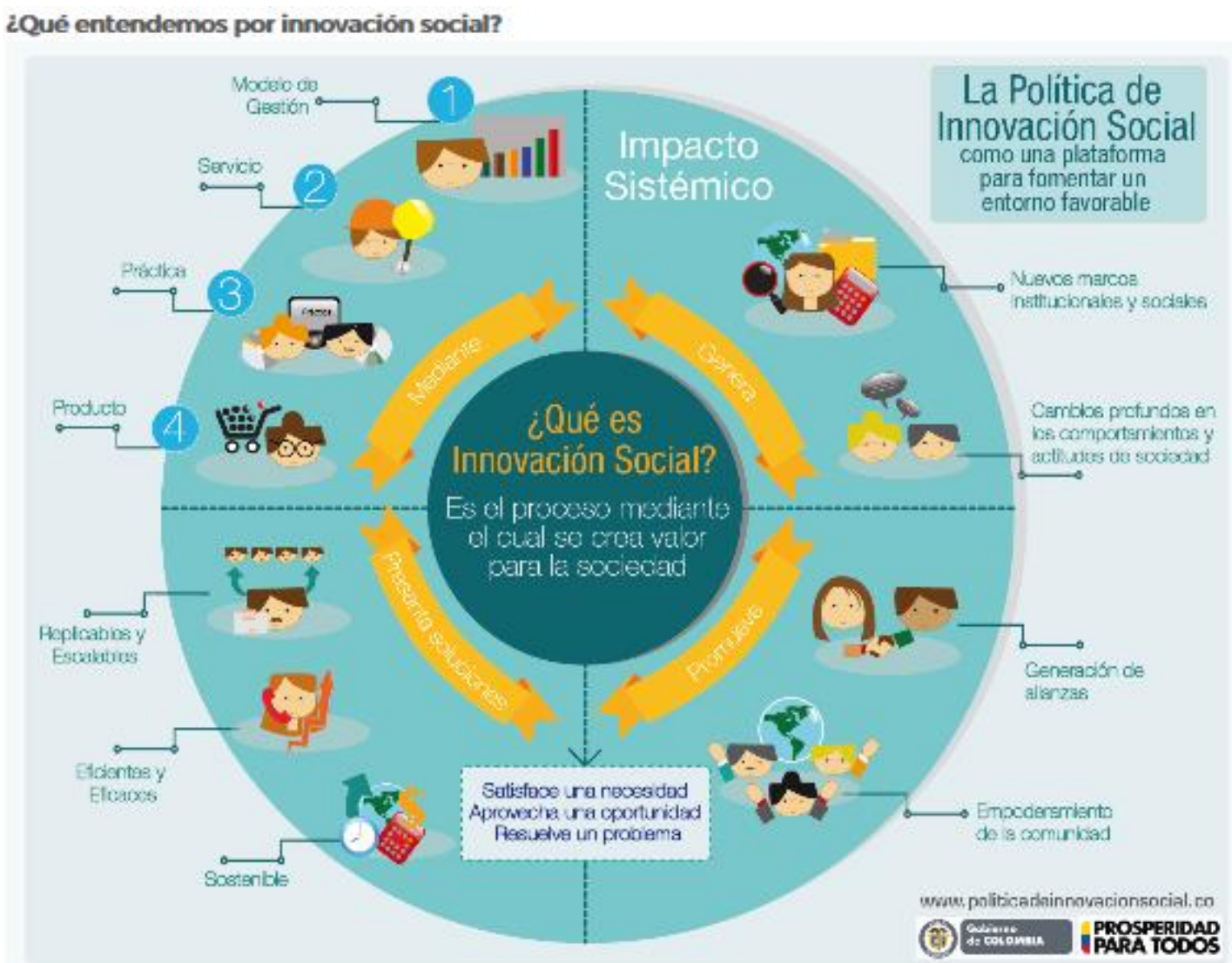

Fuente: Nodo de Innovación Social, ANSPE (2014). Recuperado de http://www.anspe.gov.co/

Por otro lado, según DNP (2013), la innovación social se entiende como:

Proceso a través del cual se crea valor para la sociedad mediante prácticas, modelos de gestión, productos o servicios novedosos que satisfacen una necesidad, aprovechan una oportunidad y resuelven un problema social de forma más eficiente y eficaz que las soluciones existentes, produciendo un cambio favorable en el sistema en el cual opera. La Innovación Social se caracteriza por tener potencial de escalabilidad, replicabilidad, ser sostenible, promover mayores niveles de empoderamiento de la comunidad y generar alianzas entre diferentes actores de la sociedad. (p. 2). 
Así pues, el concepto de Innovación Social para la Agencia Vasca de la Innovación -INNOBASQUE- (2011), es el siguiente:

Innovación social: proceso dado a partir de la concepción de la innovación social como elemento clave para innovar "en, cómo y para" la sociedad, INNOBASQUE considera las innovaciones sociales como procesos colaborativos de participación de personas con el objetivo de mejorar y/o transformar situaciones sociales a través de la co-creación de soluciones, la aportación de propuestas frecuentemente con visión de transversalidad no experimentadas anteriormente que obtengan la aceptación ciudadana. Estos procesos desencadenan aprendizajes, compromisos y transformaciones que impactan fuertemente a nivel local y deben construirse sobre tres pilares: la participación de los agentes locales guiada por el principio de subsidiariedad, el empoderamiento y el compromiso ciudadano, el proceso de abajo-arriba. (p. 20)

Además, Domanski \& Howaldt (2013), en el foro internacional de innovación social, expresan lo siguiente:

Innovación Social es una nueva combinación o nueva configuración de prácticas sociales en ciertas áreas de acción o contextos sociales, impulsada por ciertos actores o constelaciones de actores de una manera intencional concreta con el objetivo de cumplir mejor con necesidades, o responder lo mejor posible a los problemas, a base de las prácticas establecidas, aceptadas al nivel social y difundidas ampliamente por la sociedad o ciertas sub-áreas de la sociedad, finalmente institucionalizada como una nueva práctica social (p. 12).

Los conceptos plasmados anteriormente coinciden en varios aspectos como son: la innovación se establece como social cuando se vincula 
directamente a la comunidad, incluye la ejecución de nuevas prácticas sociales y tiene impacto en la sociedad; por tanto, el interés de la innovación social es optimizar la calidad de vida de un grupo específico, dando respuesta eficaz a través de soluciones a necesidades sociales generalmente urgentes, dentro de un proceso innovador, en busca del desarrollo humano.

Ahora bien, de acuerdo con Moreira y Frías (2013), el concepto de innovación social fue cultivado de manera importante en naciones con tradición anglosajona, y adoptado por diversos países a nivel mundial, así:

Tabla 2. Aportes pioneros sobre innovación social.

\begin{tabular}{|c|c|c|}
\hline Autor & Año & Contribución \\
\hline Gerhuny & 1983 & \multirow{5}{*}{ Aportes pioneros de conceptualización. } \\
\hline Kingston & 1984 & \\
\hline Rickards & 1984 & \\
\hline Wolfgang Zapf & 1990 & \\
\hline Geoff Mulgan & 2007 & \\
\hline Retegi \& Ullibarri & 2009 & $\begin{array}{l}\text { Los "espacios interactivos de } \\
\text { aprendizaje" son el máximo exponente de } \\
\text { entornos. }\end{array}$ \\
\hline Christopher Freeman & Sin especificación & \multirow{2}{*}{$\begin{array}{l}\text { Planteamientos generales del modelo } \\
\text { conceptual de innovación. }\end{array}$} \\
\hline Ben Ake Lundvall & Sin especificación & \\
\hline
\end{tabular}

Fuente: Elaboración propia, a partir de Moreira y Frías (DNP, 2013)

En la tabla presentada observamos que la mayor cantidad de aportes pioneros se dieron en la década de los años ochenta, orientados a un 
fortalecimiento de planteamientos generales del modelo conceptual después de la década de los años noventa.

Particularmente, en referencia a la innovación social a nivel del gobierno colombiano, es ubicada en uno de los ejes centrales del desarrollo de la población y aumento de la competitividad de la nación, destacando la necesidad de alianzas de cooperación entre los actores públicos y privados para el progreso de la sociedad; entre las entidades gubernamentales creadas para impulsar la innovación social están la ANSPE, el Departamento Nacional de Planeación y el Nodo de Innovación Social. (Ver Anexo No. 6. Entidades gubernamentales que impulsan la innovación social en Colombia).

3.3.1 Principios y características de la innovación social

A la innovación social se le atribuyen, entre otros, los siguientes principios:

Figura 05. Principios de la innovación social.

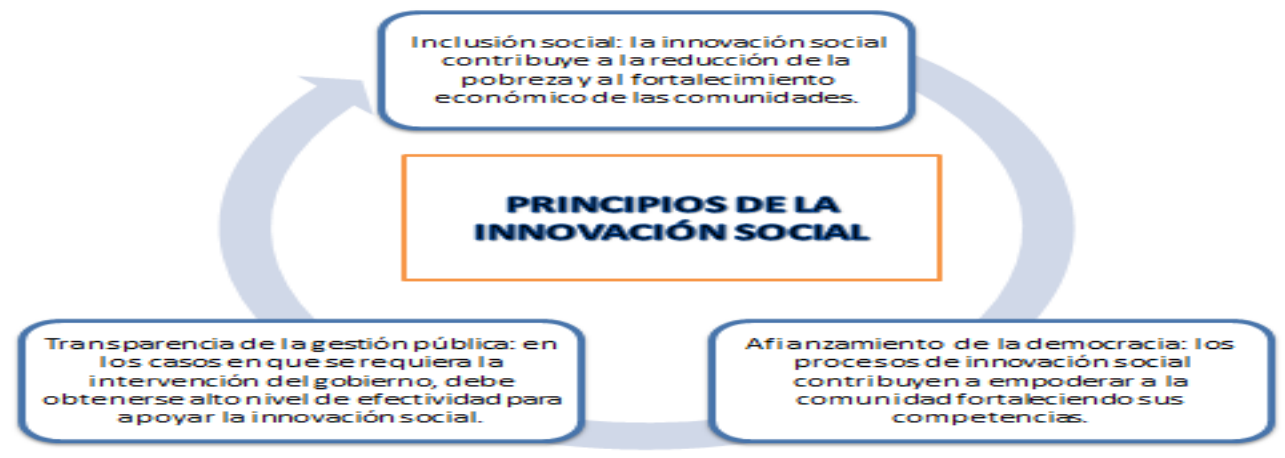

Fuente: Elaboración propia a partir de DNP, 2013 (p.4) 
Desde los principios de innovación social descritos en la figura anterior (DNP, 2013), donde se plasma la articulación entre innovación social, reducción de la pobreza, transparencia de la gestión pública y afianzamiento de la democracia, se establecen a continuación las características necesarias además de las anheladas en las innovaciones sociales, diferenciadas por categorías, a saber:

Características necesarias, categoría I: novedad, potencial de éxito, sostenibilidad, participación activa de la comunidad y/o población beneficiaria, generación de alianzas.

Características deseables, categoría II: potencial para la política pública, económicamente favorable, escrutinio público de los componentes de la calidad de vida, intercambio y transferencia contextualizada de conocimientos y experiencias. Ver Anexo No. 7, en el cual se presentan en detalle las características, en materia de la innovación social.

\subsubsection{Entornos de la innovación social}

El entorno que se perciba incide en el proceso de evolución y crecimiento de la innovación, haciendo que el nivel de ésta sea fomentado $u$ obstaculizado, tal como lo señala la Confederación Empresarial de Madrid (2000); además, “los entornos pueden ser dinámicos y ajustarse al mercado, pero la importancia radica en la disposición de una flexibilidad estratégica" (citado por Delgado et al, 2008, p.14). 
Por su parte, según Moreira y Frías (2013), quien coincide con la Confederación Empresarial de Madrid (2000), establece los entornos de la siguiente forma:

- Entorno de la comunidad: se origina del conocimiento empírico, esquemas y necesidades que tiene la comunidad (nuevas formas de intervención de la comunidad, organización de cadenas de producción a través de nuevas formas comunitarias).

- Entorno del sector público, gobierno: implica innovación en instituciones públicas, innovación en programas de intervención social (eficiencia, cobertura, impacto) y modernización del gobierno. Involucra componentes con estrategias de interacción con la comunidad y procesos para impulsar toma de decisiones, además de la innovación en gestión del conocimiento tal como el fortalecimiento de procesos de aprendizaje.

- Entorno de espacios de la sociedad civil: incluye todos los esquemas que no caben en los dos primeros entornos como las universidades, las organizaciones no gubernamentales, además de otras entidades del sector productivo y sector académico.

\subsubsection{Enfoques de la innovación social}

Partiendo de los conceptos de innovación social presentados anteriormente, los cuales se interceptan en aspectos como la vinculación directa a la comunidad, el interés en la optimización de la calidad de vida, la ejecución de prácticas sociales y el impacto en la sociedad, entre otros, se presentan a 
continuación los enfoques que atañen a la innovación social, basados en el esquema presentado por Moreira y Frías (2013):

Así pues, entre los enfoques de la innovación social están:

- Enfoque sociológico: innovación social como un cambio social sistémico en una sociedad, la comunidad tiene un rol principal como actor y generador de la demanda (DNP, 2013).

- Enfoque económico: innovación social como servicio o actividad con el propósito de satisfacer demanda social, con el rol principal para el emprendedor social y las organizaciones sociales (DNP, 2013).

- Enfoque gerencial: innovación social como solución novedosa a problemas sociales que crean valor y benefician la sociedad en su conjunto (DNP, 2013).

- Enfoque de la ciencia política: innovación social como proceso en un territorio local que se consolida cuando se producen cambios en las relaciones sociales y/o relaciones de poder, tomado como elemento de justicia social (DNP, 2013).

- Enfoque participativo: innovación social como elemento que genera confianza entre comunidades responsables de sus capacidades y sus propios desarrollos (DNP, 2013). 
En el Anexo No. 8, se especifican de forma detallada los enfoques de la innovación social, estableciendo para cada uno de ellos los roles principales y las características generales que implican el reconocimiento de acciones para el cubrimiento de necesidades.

En este propósito y según lo señalado por Finquelievich (2007), el progreso de los enfoques en procedimientos de innovación fortaleció la premisa que valida la innovación, para el caso social, como un proceso localizado además de sistémico, acumulativo y alineado a los límites de las regiones, sin un modelo establecido a seguir, en el cual cada suceso debe ser evaluado a partir de sus peculiaridades, sus características y su inclusión en el contexto de país, encaminado a la evaluación de formas de desarrollo y propias estrategias.

No obstante, la intención de los enfoques descritos es propiciar el cambio de la comunidad, impulsando la motivación de función social y creación de valor compartido donde se involucra la creación de beneficios (valores) para abordar necesidades y desafíos de la sociedad (Guía de la Innovación Social - Comisión Europea, 2013, p. 4).

En otras palabras, el hecho de tratar las innovaciones sociales a través de enfoques ayuda al estudio preciso desde los roles y características, despejando el espacio para la clasificación en fases. 


\subsubsection{Fases de la innovación social}

En el proceso de innovación social se identifican cuatro fases que se detallarán a continuación, cada una de ellas hace parte de éxitos y riesgos totalmente diferentes; las fases validadas en la figura No. 15 fueron presentadas en las Memorias del Seminario Taller "Los retos de la innovación social en Colombia" efectuado en la ciudad de Bogotá, en el año 2013.

De ahí se deduce que las fases se encuentran totalmente interconectadas hacia un fin necesario para el cumplimiento del propósito, aportando particularidades para el procedimiento.

Figura 6. Fases de la innovación social.

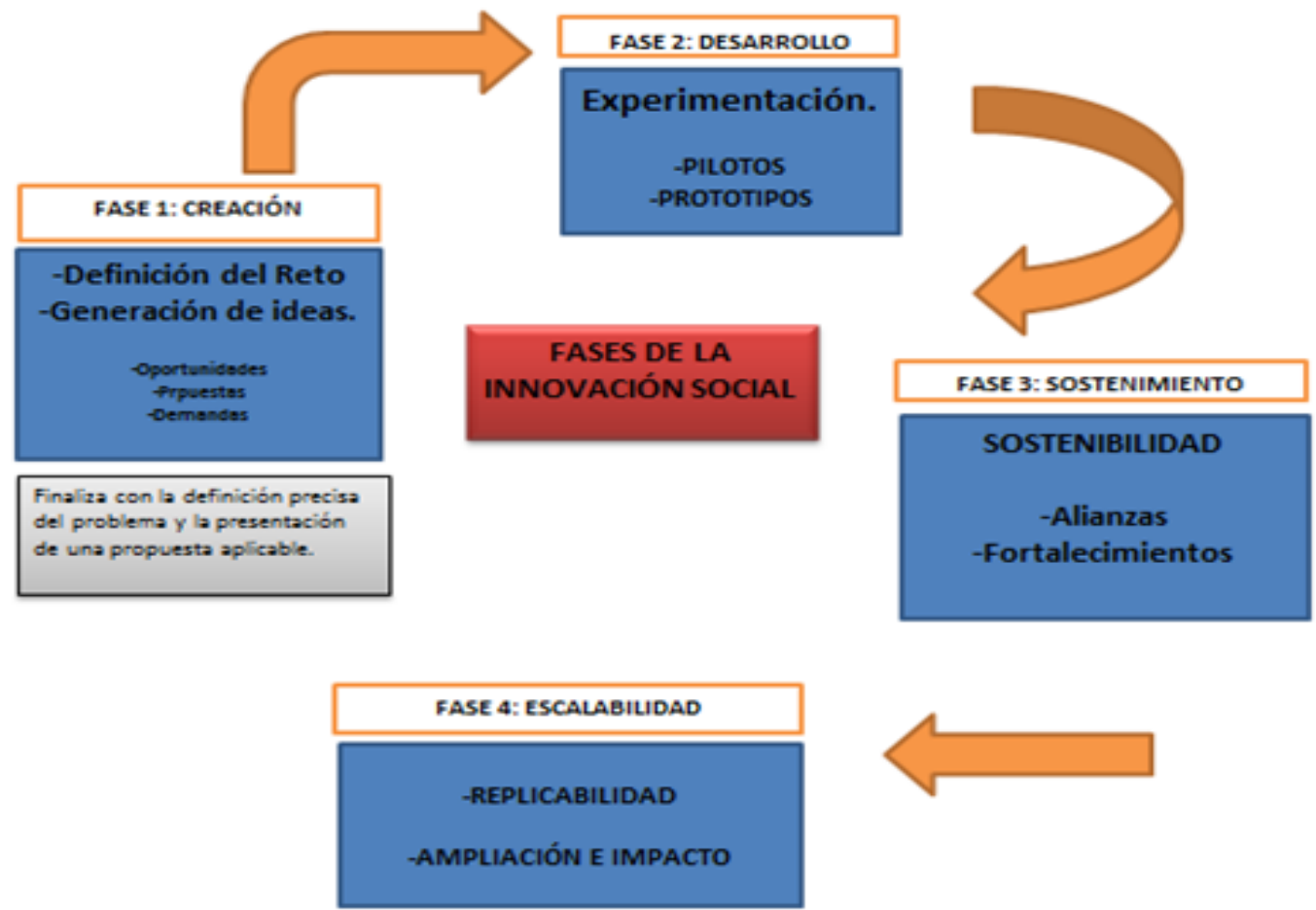

Fuente: Elaboración propia a parir de resultados del taller efectuado por ANSPE (2014). 
En la figura 6, concerniente a las fases de la innovación social se plasma la relación de las mismas, al igual que su posicionamiento en el proceso de ejecución de la innovación social.

La descripción de cada una de las fases, determinadas en la figura anterior:

- Fase 1: Creación. Surge con la percepción de necesidades sociales no resueltas, en esta fase se define el problema y el reto, se presentan las propuestas por los gestores, promotores, o líderes respectivos (generación de ideas). Memorias del Seminario Taller "Los retos de la innovación social en Colombia" efectuado en la ciudad de Bogotá (2013).

- Fase 2: Desarrollo. Constituye la experimentación y articula puesta en marcha de la propuesta, incluyendo ejercicios pilotos, construcción de prototipos, otros; en esta fase se consideran también las acciones experimentales, planeación de iniciativas, exploraciones y valoraciones, la ejecución de procesos de perfeccionamiento de ideas, ciclos de iteración, validaciones por parte de beneficiarios, aplicabilidad, entre otros. Memorias del Seminario Taller "Los retos de la innovación social en Colombia” (2013).

- Fase 3: Sostenimiento. Incluye la ejecución de estrategias para su sostenimiento, como son: mejorar el margen de ingresos, la conformación de alianzas y redes con otras instituciones o sectores 
que permitan el desarrollo, la implementación de mecanismos de financiación, difusión a menor escala, gobernabilidad, entre otros. Memorias del Seminario Taller "Los retos de la innovación social en Colombia" (2013).

- Fase 4: Escalabilidad. En esta fase se asume que la innovación social ha logrado tanto sus objetivos como tener sostenibilidad, por lo cual el paso a seguir es ampliar los impactos de la misma, ya sea a través de la replicación en otros escenarios, o la vinculación a iniciativas del orden estatal. Como formas para realizar el crecimiento significativo de la innovación social, están: licencias y franquicias, federaciones y estrategias de flexible difusión. Memorias del Seminario Taller "Los retos de la innovación social en Colombia” (2013).

\subsubsection{Barreras y facilitadores de la innovación social}

Las barreras son todos aquellos aspectos que dificultan la consecución de los objetivos y el desarrollo en sus distintas fases del proceso, interfiriendo en las acciones direccionadas a la innovación; las barreras pueden ser regionales o locales, e incluir aspectos financieros, culturales, administrativos, otros. Existen barreras de entrada, de sostenibilidad, de ampliación y de cambios (ANSPE, 2014). 
En este contexto, un punto importante es reconocer que debe disponerse de metodologías para innovar, recordando que los obstáculos siempre se van a presentar para dificultar la ejecución, reduciendo así la capacidad de innovar (Guerra, 2010, p. 252); por tal motivo es importante buscar el mejor de los escenarios para cualquier situación minimizando el riesgo hasta donde sea posible.

Por otra parte, los facilitadores formales e informales, son factores que estimulan y promueven el desarrollo de la innovación social en sus distintas fases (ANSPE, 2014). Así pues, según García (2012), la empresa debe establecer una estructura que inyecte fluidez y eficacia al proceso de innovación contemplando facilitadores de innovación y comités de innovación, que inyecten elementos de ideación e implementación, entre otros.

\subsubsection{Actores claves}

Desde los primeros conceptos dados a la innovación social, según lo describe el documento denominado "la innovación social en América Latina" (2014), se percibe una tendencia a relacionar la articulación entre diferentes actores, presentes en actividades interpersonales o interacciones de la sociedad para el cumplimiento de objetivos comunes.

Ahora bien, para la ANSPE (2014), los actores claves de la innovación social pueden darse desde la dimensión de personas, 
organizaciones o territorios; el tipo de actor y el rol a protagonizar varían según el contexto en el cual se desarrolle la innovación social. En esta innovación (social) se destaca el trabajo colaborativo y las alianzas entre diversos actores.

En este orden de ideas, entre los actores claves e interdependientes de la innovación social encontramos: la comunidad, el innovador social, actores centrales (actores protagónicos en el desarrollo de la innovación) y los actores de soporte (actores que apoyan la innovación fortaleciendo su replicabilidad y sostenibilidad). La comunidad, es uno de los actores más importantes del proceso innovador por su responsabilidad como gestor de su propio desarrollo y su capacidad para proponer soluciones a los problemas (CEPAL, 2014, p. 7).

Del mismo modo, está el innovador social quien lidera el proceso innovador desde una extensa mirada, él puede ser tomado como un emprendedor social; el innovador social puede ser tanto una persona, una organización pública o privadas, como un grupo de individuos que puedan actuar también como gestores y líderes de procesos de innovación (CEPAL, 2014). Así pues, los actores de soporte son personas y organizaciones que cumplen roles puntuales alrededor de las dinámicas de la innovación social y de la creación de un entorno favorable para su desarrollo, tales como la articulación y conformación de redes, la prestación de servicios de apoyo financiero y técnico, la generación y transferencia de conocimiento, entre otros. 
No obstante, los actores no deben ser considerados de manera independiente, es necesario analizar la relación de cada actor con los demás, para poder comprender los patrones de las relaciones entre los diferentes actores al igual que los puntos fuertes o débiles, como también si existen actores centrales en el funcionamiento del sistema y otros tienen un papel marginal. (Buckland et al, 2014, citando a Hanneman).

Finalmente, se especifica que los flujos de información entre diferentes actores llegan a potenciar los resultados de innovación, propiciando análogamente la cadena de valor.

\subsubsection{La cadena de valor}

La cadena de valor es un modelo teórico sugerido por Michael Porter (1985), que constituye un conjunto de actividades y procesos articulados estratégicamente, añadiendo valor a productos $\mathrm{y}$ servicios de una institución; es así como el modelo sirve de eje para el análisis estratégico que determina fundamentos por medio de la desagregación ordenada de actividades, integrado como base de articulación y flujo de relaciones colaborativas entre múltiples fuerzas y agentes que conjugan elementos para ejercer fuerzas catalizadoras hacia la resolución de retos de la sociedad y la transformación social deseada (INNOBASQUE, 2011). 
Por ende, tomando la generación de valor como eje institucional frente a la dinámica de la cadena, según el documento titulado "fases para el diseño y análisis de la cadena de valor en las organizaciones", en el modelo se separa la secuencia en las actividades estratégicas más importantes, eslabonadas unas a otras, con el ánimo de comprender comportamientos, fuentes de diferenciación existentes y fuentes latentes.

De esta manera se presentan a continuación las diferencias entre cadena de valor y cadena productiva, las cuales sirven de plataforma para identificar si la innovación se enfoca en alguno de esos modelos teóricos, así:

Tabla 3. Diferencias entre cadena de valor y cadena productiva.

\begin{tabular}{lll}
\hline \multicolumn{1}{c}{ Aspecto } & Cadena Productiva & \multicolumn{1}{c}{ Cadena de Valor } \\
\hline Orientación & Liderado por la oferta & Liderado por la demanda \\
Fundamento & Costo/precio & Valor agregado/calidad \\
Estructura & Actores & Actores dependientes \\
organizativa & independientes & \\
Estrategia & Productos básicos & Productos diferenciados \\
Relación entre actores & Informal & Formal \\
Visión de la relación & Corto plazo & Largo plazo \\
Nivel de confianza & Bajo/medio & Alto \\
Flujo de información & Escasa o ninguna & Extensiva \\
\hline
\end{tabular}


Incluso, INNOBASQUE (2011) especifica la cadena de valor de la innovación social, plasmando las actividades requeridas para el cumplimiento del reto donde los actores son dependientes y el flujo de información es extensiva contrario a la cadena productiva, de forma que se puntualiza la realidad de la sociedad, la generación del conocimiento y su aplicación posterior a la necesidad real, la difusión y/o sensibilización resultante de la transformación social.

La cadena de valor de la innovación social busca transmitir la interacción entre agentes y/o actividades claves para lograr la transformación social beneficiosa para el conjunto, como objetivo último de la innovación social. Así pues, como proceso de interacción y flujo de relaciones colaborativas entre múltiples fuerzas orientadas a las transformaciones sociales beneficiosas para el conjunto, se pretende mostrar un enfoque no lineal, en el que la innovación social puede surgir de forma espontánea desde cualquier eslabón del proceso y generar una verdadera transformación social, sin necesidad de completar todos los eslabones que refleja la propia cadena de valor (INNOBASQUE, 2011).

A partir de la cadena de valor establecida por INNOBASQUE, se construyó la cadena de valor para el proyecto de esta investigación. 
Figura 7. Cadena de valor de la innovación social.

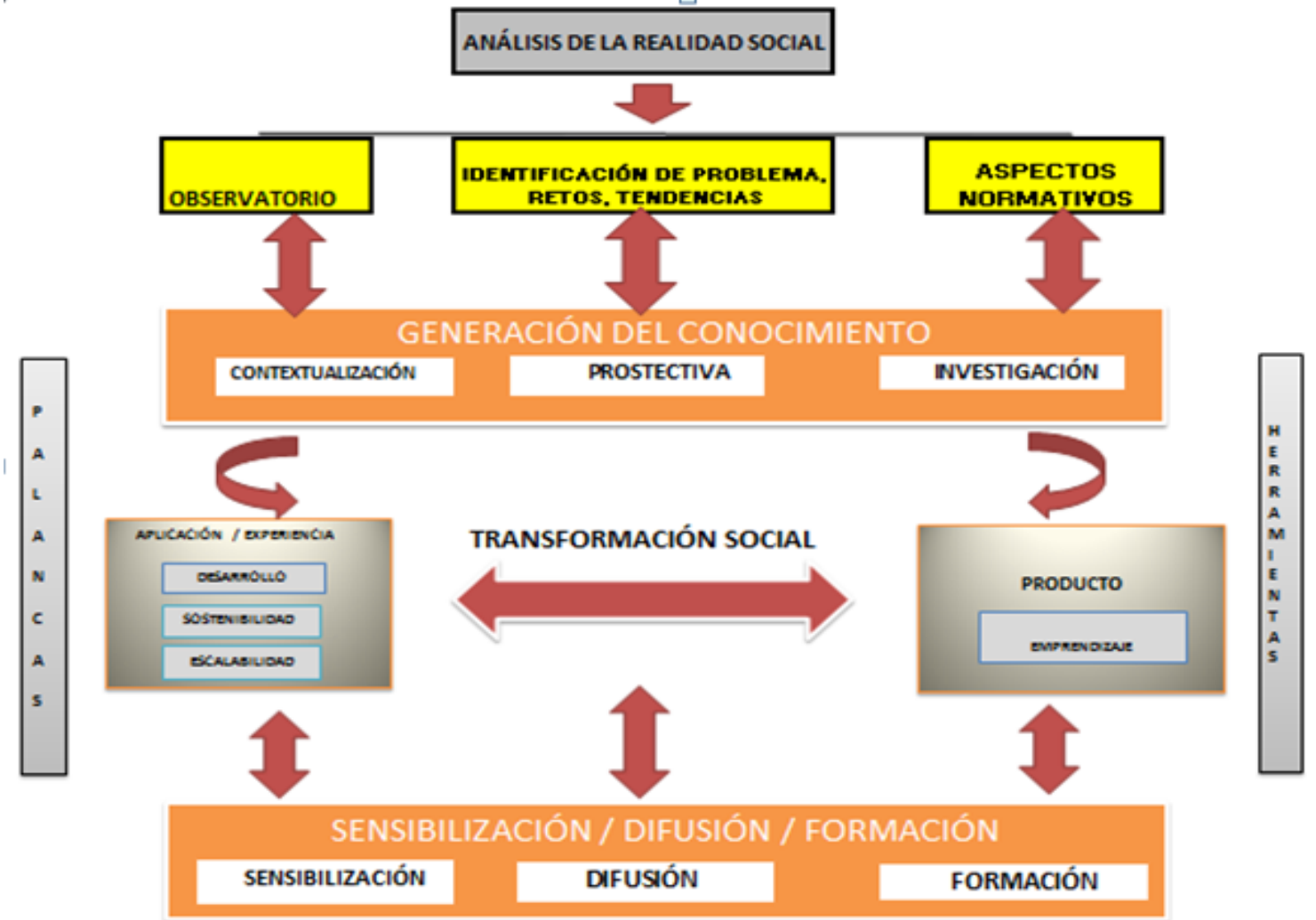

Fuente: Elaboración propia, a partir del documento "Estrategia de innovación social: una ventana de oportunidad para Euskadi" (2011).

Entre los riesgos indicados en el proyecto sistematizado a través de la cadena de valor están: las decisiones importantes necesitan más tiempo ya que incluyen varias personas, cada actor individual tiene un control parcial, cada actor parcial tiene un control individual sobre las actividades que se comparten, cada actor individual pierde algo de flexibilidad e independencia.

Así, se destaca que existen experiencias de innovación social que han surgido directamente desde la aplicación o la experiencia, como desarrollo 
de un proyecto de investigación, se considera posible y deseable desencadenar todas las fases de la cadena de valor, con el objetivo de incentivar y dinamizar acciones y experiencias desde un enfoque sistémico que posibilite desarrollar un modelo cultural y sistémico de experimentación que favorezca la innovación social (INNOBASQUE, 2011).

Figura 8. Eslabones reflejados por la cadena de valor en innovación social.

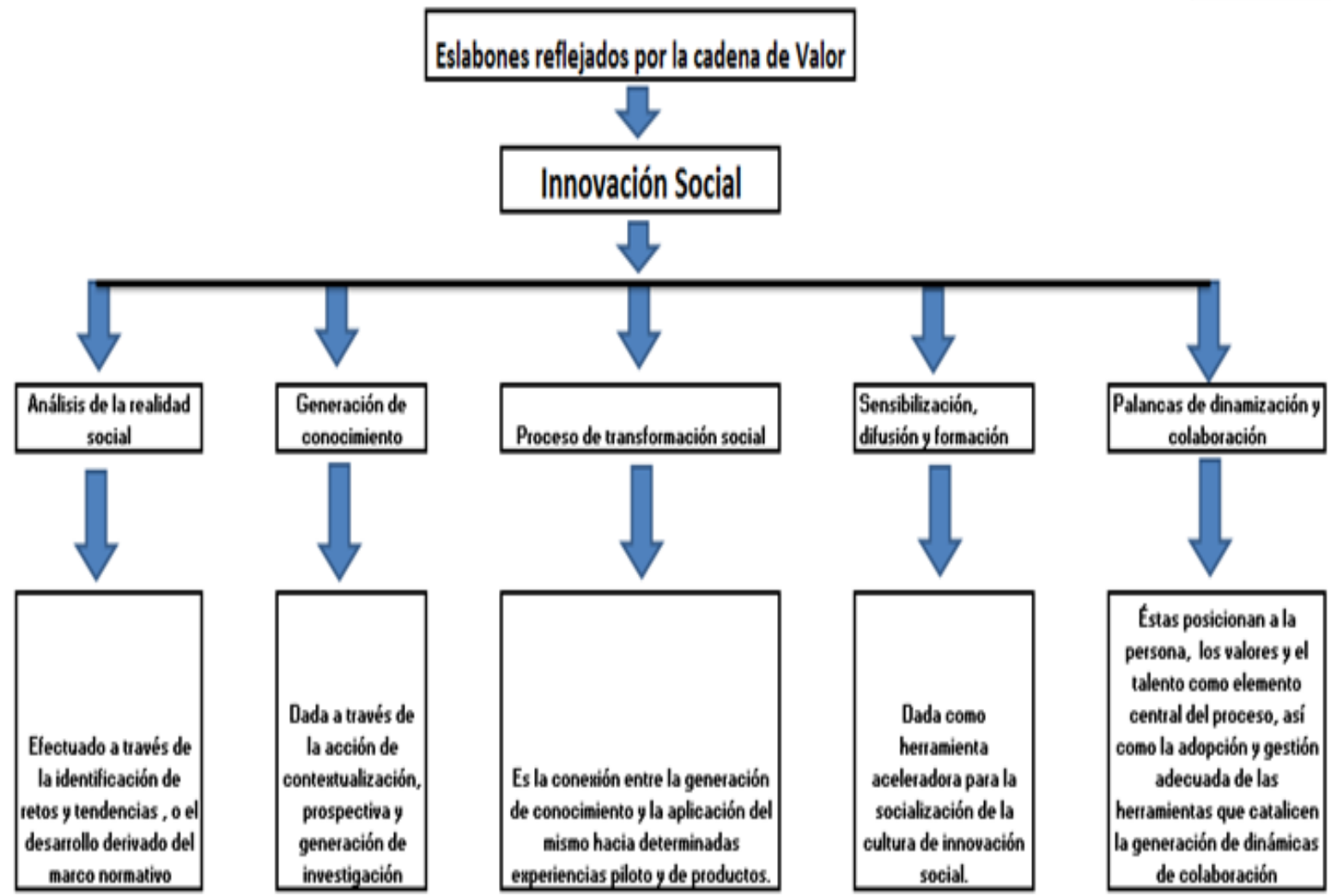

Fuente: Elaboración propia (2014), a partir del documento "Estrategia de innovación social: una ventana de oportunidad para Euskadi” (2011). 
Es importante que se estimulen todos los eslabones de la cadena de valor en el proceso de innovación social, para crear de esta forma un patrón de desarrollo de esta innovación.

Para resaltar se tiene que los pasos de la cadena de valor no son siempre secuenciales, la estructura no es siempre lineal, pueden suceder innovaciones que comiencen con la experimentación, donde se originarán actos de retroalimentación que dan lugar a traslapes entre etapas del proceso innovador.

La perspectiva utilizada en la orientación de cadena de valor compagina con los proyectos que se desarrollan en áreas de servicios encaminados a la innovación social, ya que el fundamento se da en valor agregado con la estrategia de producto diferenciado, además hay una visión de relación a largo plazo y un flujo de información extensiva.

\subsubsection{Indagaciones de innovación social a nivel mundial}

Iniciativas de países como Alemania, Estados Unidos, Dinamarca y Canadá, presentan la necesidad de entender la innovación como un sistema donde los procesos sociales que se dan al margen del contexto empresarial son un eje importante, corroboran la creciente importancia de la innovación social y refirman la idea que si bien es un proceso de normalización está aún en etapa temprana, lo cual no debe ser obstáculo para que sea abordado seriamente por los entes gubernamentales (DNP, 2013). 
Según el documento publicado en Bruselas en el año 2014 por la Comisión Europea denominado "Investigación e Innovación" (p. 4), se ratifica que "la investigación y la innovación inciden directamente en la prosperidad de Europa y en el bienestar de sus ciudadanos y su sociedad", también se detallan aspectos históricos relevantes, a saber:

- Hungría (Budapest), 2008: se funda el Instituto Europeo de Innovación y Tecnología (sede Budapest), primera iniciativa de la Unión Europea para integrar plenamente los tres lados del «triángulo del conocimiento» (educación superior, investigación y empresa), por medio de la colaboración a las comunidades de conocimiento e innovación. Inicia funcionamiento en el año 2010 (p. 04).

- Bélgica, ciudad Bruselas como sede de la Unión Europea, 2010: la Unión Europea pone en marcha la iniciativa «Unión por la Innovación», que cuenta con más de treinta líneas destinadas a optimizar el acceso y las condiciones de financiación de la innovación y la innovación en el continente europeo. La iniciativa es un elemento básico de la Estrategia "Europa 2020" y tiene por objeto facilitar que las ideas innovadoras puedan convertirse en productos y servicios que fomenten el empleo y el crecimiento. Para el año 2014, inicia la estrategia "Horizonte 2020", el mayor programa marco de investigación e innovación de la Unión Europea hasta la fecha e instrumento financiero de la iniciativa "Unión por la innovación". Contará con un presupuesto de casi 80.000 millones de euros del año 2014 al año 2020, y contribuirá igualmente a generar crecimiento y empleo en Europa (p. 04).

En concordancia se presenta a través del Anexo No. 9, la relación de algunos países a nivel mundial, entre los que están España, Austria, Grecia, 
Reino Unido, Alemania, Canadá, Francia, Finlandia y Dinamarca, que ya adoptaron esquemas de innovación social por medio de entidades establecidas.

3.4 La innovación social como eje central para el desarrollo humano

La innovación social es considerada una pieza fundamental en el proceso del desarrollo humano ya que el dinamismo de relación dado, encuadra tanto a los actores que trabajan guiados por diversos incentivos como a las entidades que actúan de acuerdo a procesos y reglas respondiendo a claros esquemas; los vínculos e interacción entre actores determinan su habilidad para capturar el impulso que el conocimiento da a la producción y la hace entrar en un círculo virtuoso de crecimiento (CEPAL, 2006). De esta manera, tanto el desarrollo humano como la innovación social son conceptos que se integran y retroalimentan en una relación trascendental con grandes implicaciones para el diseño, ejecución y evaluación de estrategias (Carrero, 2011, p. 54).

En esta dirección, se trae al escenario el hecho que la tecnología traslapada con la innovación, no tienen respuesta para muchos de los problemas prácticos que son necesarios de resolver, sobre todo en América Latina, y se debe entonces acoger una actitud ingeniosa y transformadora, para así construir los propios estilos de desarrollo humano y modelos innovativos a nivel social (Carrero, 2011, p. 54 citando a Varsavsky). Es 
de destacar que la relación entre desarrollo social e innovación fue antes de los años noventa un aspecto de segundo renglón para los latinoamericanos (Carrero, 2011, p. 55), en la cual la ciencia, la tecnología, la innovación y el desarrollo social, tuvieron como inicio la implementación de modelos extranjeros que se alejan de la realidad de esta comunidad.

Según el documento "Aspectos del desarrollo social para la innovación desde la perspectiva de la corriente del pensamiento creativo y transformador latinoamericano" (2011), se ilustran las siguientes características para las sociedades innovadoras:

Las sociedades innovadoras unen el potencial segregado en la sociedad, en camino al desarrollo humano a través de un sistema educativo de calidad, un sistema de políticas públicas, entornos institucionales que promuevan las nuevas y buenas ideas que deben ponerse a disposición de la sociedad, para socializar el conocimiento y poder estimular los procesos de innovación. Los individuos colectivamente organizados establecen la base de los procesos innovativos y a la vez son portadores del sentido social de las innovaciones generando así el desarrollo humano (p. 60).

En el mismo sentido, Herrera (2011) al igual que Carrero (2011), reconoce como la capacidad de una región para crear, adaptar y aplicar el conocimiento, está integrada a las posibilidades de desarrollo, de ahí el gran significado que tienen el conocimiento y la innovación en aspectos de cambio. 
En síntesis, la innovación social es un mecanismo de desarrollo humano, en el cual su victoria se articula con el mejoramiento en la calidad de vida proyectado hacia la transferencia de conocimiento a través del desarrollo, para el caso de competencias, con aspectos que proporcionan nuevas capacidades entre diferentes agentes sociales estructurándose para estimular el progreso social del entorno. 


\section{MARCO CONTEXTUAL}

\subsection{Modelo estratégico SENA}

El SENA es un establecimiento público de orden nacional que surge mediante el Decreto - Ley 118 del 21 de junio de 1957 como iniciativa entre trabajadores, empresarios, iglesia católica y Organización Internacional del Trabajo; esta institución cuenta con personería jurídica, patrimonio propio e independiente y autonomía administrativa, así mismo se encuentra adscrita al Ministerio del Trabajo de Colombia. Respecto a la función de la entidad, se encuentra plasmada en el Decreto 164 del 06 de agosto de 1957, la cual es ofrecer y ejecutar formación profesional a la población colombiana para el desarrollo social, económico y tecnológico del país (SENA, 2014).

La entidad en mención, actualmente cuenta con ambientes de aprendizaje en 117 Centros de Formación, entre los que se encuentra el Centro de Formación de Diseño y Metrología ubicado en el Distrito Capital ( sitio en el que se realizó el estudio de caso), los Centros son controlados por 33 oficinas regionales, ubicadas de forma estratégica en el territorio nacional, también se tienen 160 aulas móviles (vehículos que se movilizan con ambientes de formación). Existen también, dentro de la infraestructura planteada, 129 laboratorios (acuicultura, biotecnología, ciencias básicas, metrología, materiales y ensayos, salud, telecomunicaciones, entre otros), 15 tecnoparques (líneas de desarrollo en tecnologías virtuales, electrónica y 
telecomunicaciones, diseño e ingeniería, biotecnología y nanotecnología) y 3 tecnoacademias (unidades de base tecnológica), en los cuales se realiza la estrategia de desarrollo tecnológico e innovación, de nuevas tecnologías en productos, procesos y servicios. En el SENA ofrece una amplia variedad de programas de formación gratuitos a los alumnos y matrícula a millones de personas cada año. Dichos programas de formación se encuentran enlazados a redes de conocimiento con el objetivo de articular de una manera eficaz los nuevos diseños curriculares, administración de ambientes de aprendizaje, las necesidades del entorno productivo, capacitación del talento humano e incorporación de nueva tecnología (SENA, 2015, p. 02)

Así mismo, se tiene un modelo estratégico conformado por ejes que apuntan a la competitividad de Colombia, incluyendo aspectos como la fuerza laboral, la innovación social y tecnológica, la formación profesional y la atención a las poblaciones vulnerables; los ejes estratégicos son:

- Más productividad para empresas y regiones: dada dentro del propósito (conocimiento, tecnologías, fuerza laboral).

- Más inclusión social: dada dentro del propósito (formación profesional, ocupaciones laborales, emprendimientos sociales).

- Empleo y emprendimiento: dados dentro de los servicios y productos (atención a poblaciones vulnerables). 
- Sistema nacional de conocimiento: dado dentro del desarrollo institucional (redes de conocimiento, observaciones laborales, investigación para la formación profesional, innovación social y tecnológica, desarrollo tecnológico).

- Fortalecimiento institucional: dado dentro del desarrollo institucional (sistema integral de gestión, sistemas de información, planta física, excelencia del talento humano, servicio al ciudadano y financiación del plan estratégico). (SENA, 2014).

En cuanto a la articulación entre objetivos, perspectivas e iniciativas, se encuentran organizadas de la siguiente figura, detallando las perspectivas sociales de impacto a la comunidad, cliente, procesos, desarrollo organizacional y recursos. 
Figura 9. Perspectivas, objetivos e iniciativas estratégicas SENA.

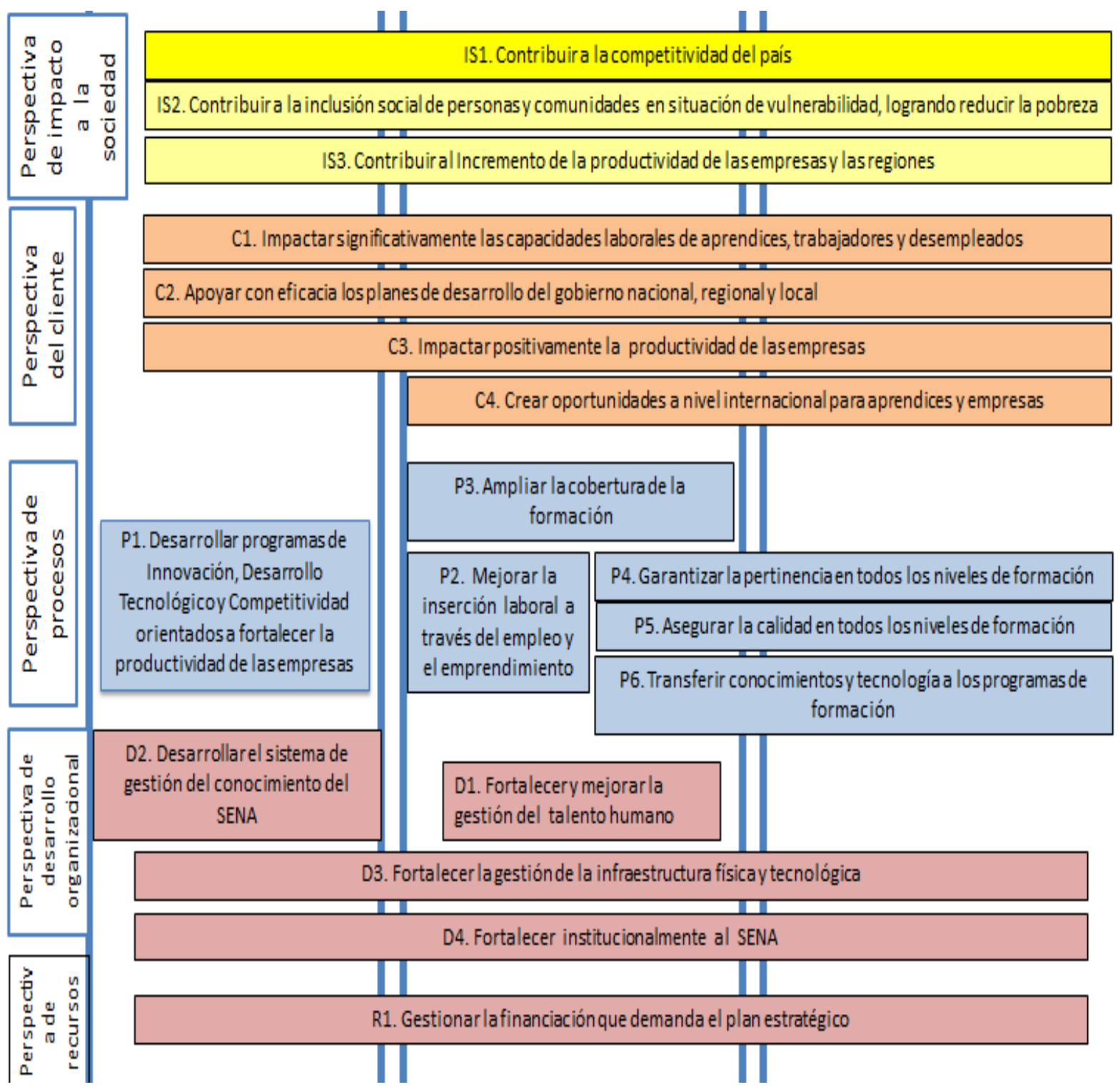

Fuente: Dirección de Formación Profesional-SENA. 2014

En esta gráfica evidenciamos la importancia que tiene para el SENA el aspecto de inclusión social de personas y comunidades en situación de vulnerabilidad, junto con el desarrollo de programas de innovación, 
ciencia y tecnología orientados a fortalecer los espacios laborales, asegurando niveles de formación con calidad que incluyan competencias transversales para apalancar la solución de necesidades sociales; en este caso identificando componentes de innovación social que fortalezcan la formación.

\subsection{Reglamentación y otras disposiciones para SENA}

A continuación se enuncian las disposiciones referentes a innovación, desarrollo y creación del SENA, entre otros: Decreto Ley 118 de 1.957, Comisión Nacional de Proyectos, Ley 29 de 1990, Decreto Ley 585 de 1991, Decreto 2149 de 1992, Ley 119 de 1994, Ley 344 de 1996, Ley 812 de 2.003, Decreto 249 de 2004, Acuerdo 8 de 2.005 del Consejo Directivo Nacional del SENA, Ley 1286 de 2.009, Acuerdo No. 007 de 2.010 y Acuerdo No. 003 de 2.012, Resolución 335 de 2.012 SENA, Acuerdo 016 de 2.012, Resolución 02406 de 2.013 SENA. Para mayor información puede referirse al Anexo No.1, denominado "Reglamentación y otras disposiciones".

\subsection{Aprendizaje en el SENA}

De acuerdo al SENA (2015), el aprendizaje es un proceso acumulativo que busca asimilar gradualmente conceptos y escalas de comportamiento para optimizar habilidades y capacidades. En este orden, aprender es un proceso continuo de captación, asimilación y evolución que le permite al 
estudiante modificar las estructuras mentales para perfeccionar la capacidad de realizar operaciones cognoscitivas, psicomotrices y actitudinales.

Igualmente, según el SENA, las actividades de aprendizaje son creadas como acciones integradas, realizadas por medio de una orientación y a lo largo del proceso formativo; por lo anterior, debe existir una articulación entre las competencias que se desarrollan en el proceso de formación y lo que posteriormente se efectuará en el mundo laboral.

\subsection{Programas de formación profesional SENA}

El SENA ofrece una amplia variedad de programas de formación gratuitos como el de "desarrollo y adaptación de prótesis y órtesis", y matricula a millones de personas cada año. Dichos programas de formación se encuentran enlazados a redes de conocimiento con el objetivo de vincular los nuevos diseños curriculares, administrar los ambientes de aprendizaje, incentivar la innovación y los proyectos de investigación, atender las necesidades del entorno productivo y de la población vulnerable, apuntalar la capacitación del talento humano e incorporar nueva tecnología.

Aunque existen algunas excepciones en programas de formación específicos de la red aeroespacial y la red salud, entre otros, debido a la normatividad nacional o exigencias internacionales, se tiene un estándar de 
duración de los programas de formación SENA según los niveles estipulados, así:

Tabla 4. Niveles de los programas de formación SENA, y su correspondiente duración en la misma entidad.

\begin{tabular}{lc}
\hline \multicolumn{1}{c}{ Nivel del programa } & Duración etapa lectiva + etapa práctica \\
\hline Operario & 2 Trimestres \\
Técnico Laboral & 4 Trimestres (265 programas) \\
Técnico Profesional & 6 Trimestres \\
Especialización Técnica & 1 Trimestre \\
Tecnólogo & 8 Trimestres \\
Especialización Tecnológica & 2 Trimestres (123 programas $)$ \\
Formación complementaria & 40 Horas a 440 Horas (150 programas a distancia) \\
\hline
\end{tabular}

Fuente: Dirección de Formación Profesional SENA (2014)

Los programas de formación están así mismo articulados con convenios y alianzas de cadena de formación con más de 30 universidades del país, para aquellos aprendices que desean continuar su formación profesional.

Continuando, el SENA ha ampliado notablemente su cobertura en la última década, consolidándose como el principal proveedor de servicios de formación profesional en Colombia. En la siguiente tabla podemos constatarlo con algunas cifras: 
Tabla 5. Matrículas del SENA.

Tipo de programa

Matrículas Matrículas Matrículas

Año 2009 Año 2010 Año 2011

Tecnólogo y Técnico Profesional

$255.422 \quad 296.686 \quad 353.104$

Técnico laboral

$509.463 \quad 667.544 \quad 666.389$

Formación complementaria

7.155 .388

7.251 .686

7.910.207

Total

7.920 .273

8.215.916

8.929 .700

Fuente: La educación superior en Colombia. OCDE-Banco Mundial. (2012)

Como se observa en la tabla anterior, el SENA ha tenido gran influencia en la educación profesional técnica y tecnológica de los colombianos durante la última década, resaltando que un promedio de 7 millones de colombianos pasan anualmente por la entidad.

\subsubsection{Competencias laborales}

Debido a que los programas de formación del SENA están compuestos por competencias laborales, se presenta a continuación el concepto respectivo de la competencia, así:

De acuerdo al Centro Interamericano para el Desarrollo del Conocimiento en la Formación Profesional -CINTERFOR- (2014), las competencias laborales se entienden como: 
Capacidad de una persona para movilizar los conocimientos, habilidades y actitudes necesarias para alcanzar los resultados pretendidos en un determinado contexto profesional, según patrones de calidad y productividad. Implica entonces, la capacidad de actuar, intervenir y decidir en situaciones imprevistas, movilizando el máximo de saberes y conocimientos para dominar situaciones concretas, aplicando experiencias adquiridas de un contexto para otro (CINTERFOR, 2014, p. 1).

Según el modelo pedagógico de la formación plasmado por SENA (2012), Páez y otros (2012), la formación por competencias es un enfoque que busca el desarrollo humano integral del aprendiz, enlazando un conjunto de capacidades socio-afectivas y habilidades sicológicas, cognoscitivas y motrices que permiten a la persona llevar a cabo de manera adecuada una actividad, un papel, una función, utilizando los conocimientos, actitudes y valores, originados de la articulación entre la tecnología y la sociedad; según el SENA, las competencias se incrementan de manera constante en el proceso de enseñanza, aprendizaje y evaluación, enmarcado igualmente en un programa de formación. 
Figura 10. Estructuración del aprendizaje por medio del desarrollo de competencias.

PROGRAIMA DE FORIMACIÓN Aprendizaje efectuado a través dell desarrollo de competencias

\begin{tabular}{|l|c|c|}
\hline \multicolumn{3}{|c|}{ COMPETENCIA 1 } \\
\hline \multicolumn{3}{|c|}{ Conocimientos de Principio } \\
Y de Proceso \\
\hline $\begin{array}{l}\text { Resultado de } \\
\text { aprendizaje 1 }\end{array}$ & $\begin{array}{c}\text { Resultado de } \\
\text { aprendizaje 2 }\end{array}$ & $\begin{array}{c}\text { Resultado de } \\
\text { aprendizaje 3 }\end{array}$ \\
\hline
\end{tabular}

\begin{tabular}{|c|c|c|}
\hline \multicolumn{3}{|c|}{ COMPETENCIA 2 } \\
\hline \multicolumn{3}{|c|}{$\begin{array}{c}\text { Conocimientos de Principio } \\
\text { Y de Proceso }\end{array}$} \\
\hline $\begin{array}{c}\text { Resultado de } \\
\text { aprendizaje 1 }\end{array}$ & $\begin{array}{c}\text { Resultado de } \\
\text { aprendizaje 2 }\end{array}$ & $\begin{array}{l}\text { Resultado de } \\
\text { aprendizaje 3 }\end{array}$ \\
\hline
\end{tabular}

\begin{tabular}{|c|c|c|}
\hline \multicolumn{3}{|c|}{ COMPETENCIA 3 } \\
\hline \multicolumn{3}{|c|}{ Conocimientos de Principio } \\
Y de Proceso \\
\hline $\begin{array}{l}\text { Resultado de } \\
\text { aprendizaje 1 }\end{array}$ & $\begin{array}{c}\text { Resultado de } \\
\text { aprendizaje 2 }\end{array}$ & $\begin{array}{c}\text { Resultado de } \\
\text { aprendizaje 3 }\end{array}$ \\
\hline
\end{tabular}

\begin{tabular}{|c|c|c|}
\hline \multicolumn{3}{|c|}{ COMPETENCIA 4 } \\
\hline \multicolumn{3}{|c|}{ Conocimientos de Principio } \\
Y de Proceso \\
\hline $\begin{array}{l}\text { Resultado de } \\
\text { aprendizaje 1 }\end{array}$ & $\begin{array}{c}\text { Resultado de } \\
\text { aprendizaje 2 }\end{array}$ & $\begin{array}{l}\text { Resultado de } \\
\text { aprendizaje 3 }\end{array}$ \\
\hline
\end{tabular}

Fuente: Elaboración propia, a partir de Páez -SENA (2012)

Con la figura de estructuración de aprendizaje, se establece como los programas de formación están esquematizados por competencias principalmente técnicas (definidas en mesas sectoriales conformadas por el sector productivo, SENA y academia), aunque también existen competencias básicas y competencias transversales que visualizan aspectos físicos y sociales (de bienestar), que incluyen los resultados a generar en el transcurso del aprendizaje. 
4.5 Caracterización del programa de formación "diseño y adaptación de prótesis y órtesis"

El programa de formación denominado "diseño y adaptación de prótesis y órtesis", tiene como objetivo general brindar al sector productivo la posibilidad de incorporar personal calificado en el área de prótesis y órtesis con el ánimo de contribuir al desarrollo económico, social y tecnológico de la nación; el programa es una formación relativamente nueva en Colombia y su fortalecimiento socio económico regional y nacional, dependen en parte de las alianzas y convenios, divulgación, captación de recursos, capital humano calificado y cualificado, que respondan integralmente a la dinámica del sector. El Centro de Formación donde se imparte el programa se encuentra ubicado en la ciudad de Bogotá, con dirección calle 15 No. 3142y es denominado de "Diseño y Metrología".

El programa de órtesis y prótesis se ejecuta basado en el aprendizaje por proyectos y el uso de técnicas didácticas activas que estimulan la resolución de problemas simulados y reales soportados en la utilización de tecnologías integradas, a través del desarrollo de competencias técnicas y transversales, que nacen a partir de una normas de competencia laboral que contienen los elementos y componentes normativos establecidos en la primera fase del proceso curricular desde la mesa nacional de diseño.

Las normas de competencia incluidas en el diseño son: desarrollar prótesis de acuerdo con el diagnóstico y la fórmula interdisciplinaria y 
especificaciones técnicas y normatividad vigente; desarrollar órtesis de acuerdo con el diagnóstico y la fórmula interdisciplinaria y especificaciones técnicas y normatividad vigente; desarrollar habilidades para interactuar con usuarios en situación de discapacidad física, teniendo en cuenta sus condiciones clínicas, psicológicas y del entorno; gestionar procesos para el desarrollo de órtesis y prótesis de acuerdo con los planes establecidos por la empresa; promover la interacción idónea consigo mismo, con los demás y con la naturaleza en los contextos laboral y social; comprender textos en inglés en forma escrita y auditiva; producir textos en inglés en forma escrita y oral. Por tanto encontramos que el programa de formación no contempla dentro de las competencias a desarrollar, aunque su espíritu sea ampliamente direccionado al beneficio de la comunidad, factores de innovación social que visibilicen fortalezcan e impulsen el programa a fin de escalarlo y replicarlo a las poblaciones.

Así mismo, el programa en mención tiene una duración de 30 meses, veintiún(21) meses de etapa lectiva y nueves (9) meses de etapa práctica, ejecutados por trimestres, atendiendo la normatividad del Ministerio de Educación Nacional, la Sociedad Internacional de Órtesis y Prótesis ISPO-, y de SENA; vale la pena destacar que el tiempo de duración del programa, atendiendo a su nivel tecnólogo, es mayor que los tecnólogos en general debido a solicitud efectuada por entes internacionales a fin de desarrollar todas las habilidades requeridas en búsqueda de la certificación internacional del programa. (SENA, 2014). En este orden de ideas, se especifican los requisitos académicos de ingreso al programa que son haber 
aprobado grado once (11), superar prueba de actitud, motivación, interés y competencias mínimas de ingreso.

Por otra parte, el equipo de instructores requeridos para impartir el programa deben tener perfiles específicos en ingeniería protesista ortesista registrada en ISPO con categoría I, ingeniería mecánica o metalúrgica, fisioterapia, psicología y medicina ortopédica, entre otros; la experiencia laboral del equipo debe ser mínima de cinco años con experiencia en clínica ortopédica.

Hay que mencionar que la evolución del programa de formación, que se adelanta desde el año 2007 y entra validado para formación en el año 2009, ha presentado la siguiente relación en ejecución:

Tabla 6. Aprendices matriculados en el programa de formación de órtesis y prótesis - SENA.

\begin{tabular}{lrrrrr}
\hline AÑO & $\mathbf{2 0 1 0}$ & $\mathbf{2 0 1 2}$ & $\mathbf{2 0 1 3}$ & $\mathbf{2 0 1 4}$ & Total Aprendices \\
Aprendices & 50 & 67 & 42 & 52 & 211 Aprendices \\
matriculados & & & & & \\
\hline
\end{tabular}

Fuente: Elaboración propia a partir del PE-04 SENA (2014)

Además, el perfil del egresado según el diseño es: ortesista protesistas, supervisores en el área de órtesis y prótesis, jefes de laboratorios de órtesis y prótesis; el egresado está capacitado para 
interactuar con usuarios en situación de discapacidad, al momento de hacer la toma de molde; alineación dinámica y estática; prueba de la prótesis; y gestión procesos de acuerdo a directrices nacionales e internacionales.

Para terminar la caracterización, se resalta que el SENA está buscando certificar internacionalmente el programa en mención a fin de posicionarlo ante entes externos.

\subsection{La innovación en el SENA}

Los productos de la investigación aplicada que se construyen en alianza con el sector productivo de forma cofinanciada y la que es desarrollada en los Centros de Formación del SENA, se fundamenta en tres pilares que son: innovación del capital humano, la innovación empresarial y emprendimiento innovador, ciencia y tecnología; es así como se genera conocimiento para retroalimentar los diferentes programas de formación profesional. (SENA, 2014).

Por tanto, existen también elementos de innovación establecidos hacia una mirada de investigación tecnológica y empresarial, más no social, que consolidan los servicios para el desarrollo de la formación, y se muestran en la figura siguiente. 
Figura 11. Elementos de Innovación - SENA

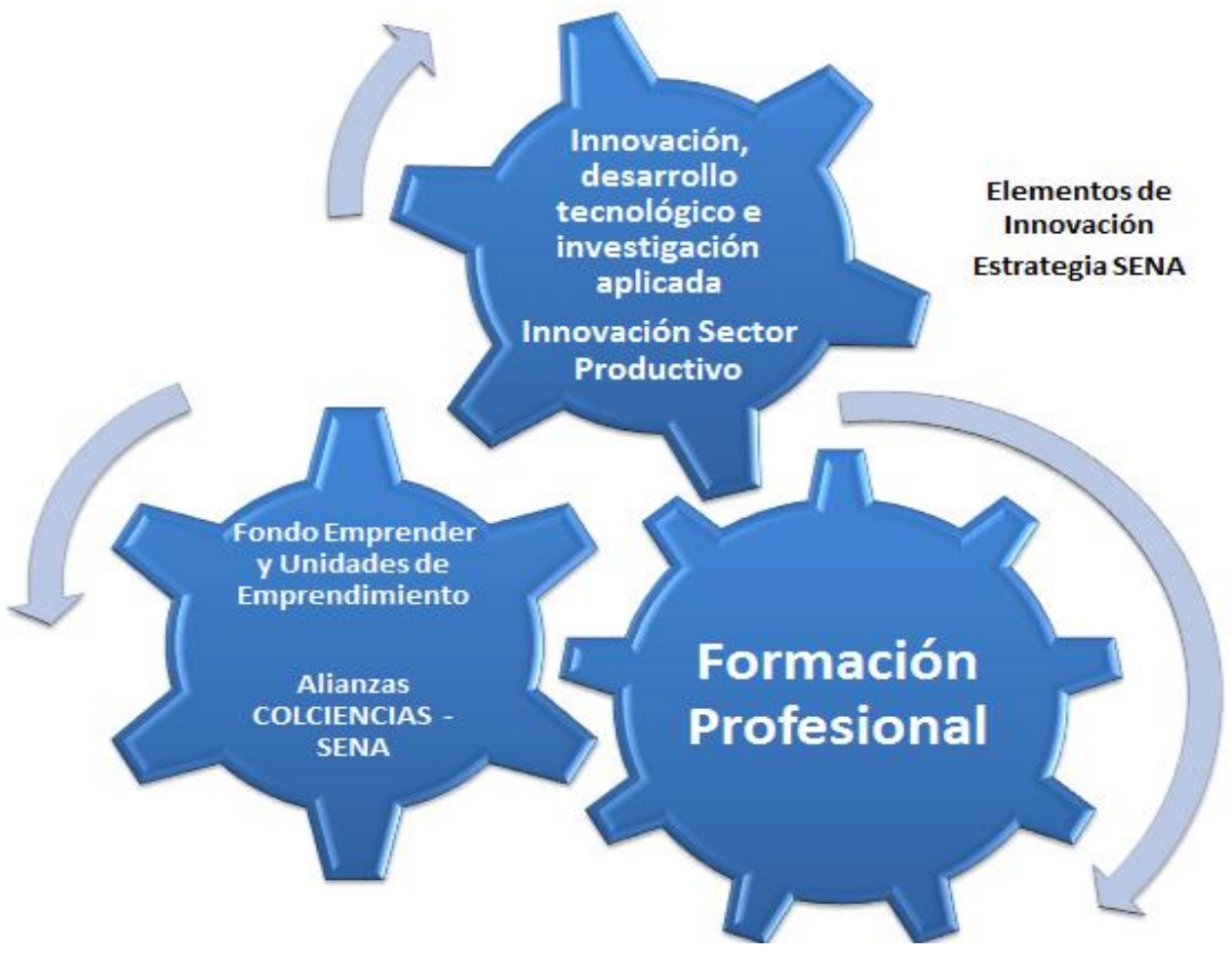

Fuente: Elaboración Propia a partir de SENA (2014)

Estos elementos, planteados en la figura de elementos de innovación, se engranan contribuyendo al desarrollo y competitividad del país, a través de programas de fomento a la innovación y el desarrollo tecnológico productivo, dirigido al sector empresarial colombiano y a los demás agentes del Sistema de CT+I.

Otros criterios claves, que no podemos dejar de mencionar, ya que también influyen en el desarrollo de competencias de innovación en la formación profesional, son: la actualización de programas de formación acordes con las necesidades del sector real, modernización de ambientes de aprendizaje SENA, formación especializada en las empresas, gestión de la 
innovación y desarrollo regional, colaboración a proyectos empresariales con centros de investigación y centros de desarrollo tecnológico, apoyo de proyectos a universidades, estandarización y acreditación de pruebas de laboratorio, proyectos de inversión para sectores de talla mundial, apoyo a la relación universidad- empresa-estado, fortalecimiento de propiedad intelectual, inversión privada para investigación y desarrollo.

También existen componentes del Sistema de Gestión del Conocimiento contemplados en el vector 5 del plan estratégico 2011-2014, que confirman la importancia de la innovación social y tecnológica para el SENA. Ver figura siguiente "Componentes del sistema de gestión del conocimiento".

Figura 12. Componentes del sistema de gestión del conocimiento

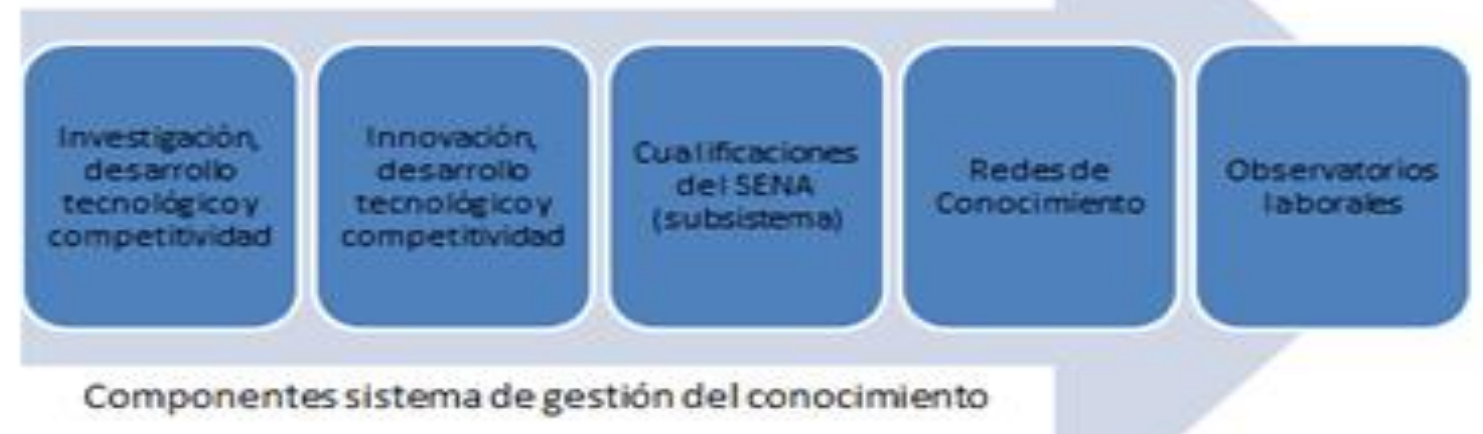




\section{METODOLOGÍA}

La investigación recoge el enfoque cualitativo y cuantitativo, y se centra en un estudio de caso que se vale de herramientas de la investigación mixta integrando sistemáticamente un proceso de recolección, análisis y vinculación simultánea de datos cuantitativos y cualitativos a fin de obtener una fotografía más completa del asunto en análisis, y así lograr hallazgos complementarios que permiten desarrollar el conocimiento relativo alrededor del tema en referencia (Hernández y Fernández, 2008, p. 26).

Por ende, las tres etapas para esta investigación se establecieron de la siguiente forma: la primera comprende el análisis del estado real del programa de formación profesional en órtesis y prótesis, según elementos de innovación e innovación social, determinando nociones de innovación social en la comunidad académica por medio de la identificación de los principales componentes de la innovación y cómo estas afectan su intervención en la población beneficiaria, dada a través de información procedente de las técnicas e instrumentos para la recolección de datos utilizados en la investigación; la segunda etapa consiste en la especificación de los niveles de participación de los actores del programa a partir del análisis de los resultados emanados; la tercera apunta a la descripción de los elementos de innovación social del programa de formación profesional referenciado teniendo en cuenta las variables establecidas, para finalmente determinar los factores de innovación social necesarios en el fortalecimiento del mismo. 
Por otra parte, la población de estudio abarca la comunidad académica plasmada en los actores del programa de formación titulada modalidad presencial "diseño, desarrollo y adaptación de prótesis y órtesis", impartido en el Centro de Formación de Diseño y Metrología - Regional Distrito Capital, del SENA.

Para el logro de los objetivos y debida recolección de datos, se utilizaron los siguientes instrumentos: la entrevista semiestructurada, encuesta aplicada a instructores a través de la herramienta del cuestionario, encuesta aplicada a aprendices a través de la herramienta del cuestionario, testimonio de aprendiz con discapacidad física y actualmente en formación, y la observación de campo.

A continuación se presenta la relación entre el marco conceptual, los instrumentos utilizados y los objetivos planteados para la investigación, resaltando la articulación entre innovación, innovación social y cadena de valor con las herramientas de investigación aplicadas. 
Figura 13. Relación de instrumentos y objetivos de la investigación

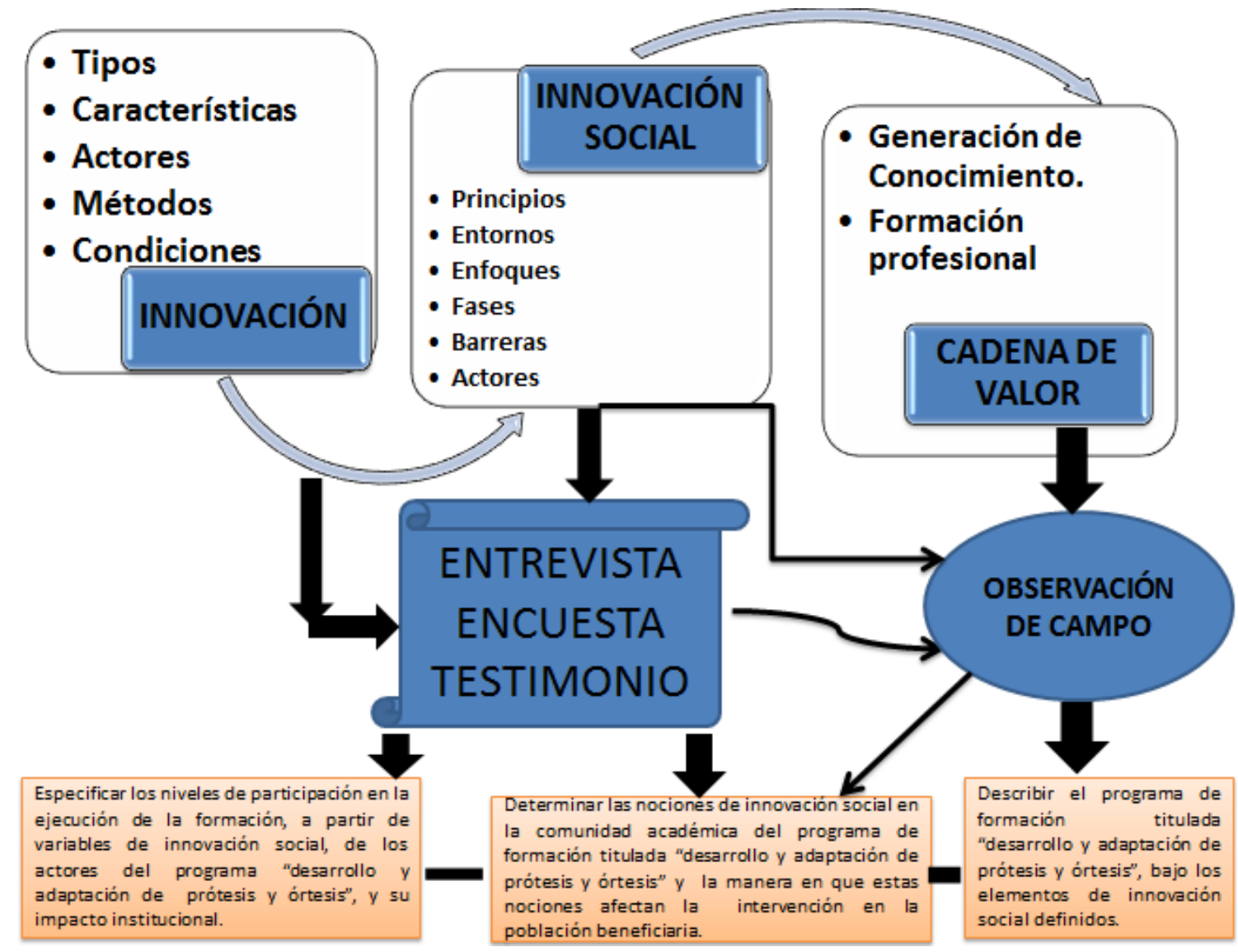

Fuente: Elaboración propia, a partir de los objetivos concertados y los instrumentos utilizados.

\subsection{Instrumentos}

\subsubsection{Encuestas}

Tomando la técnica de la encuesta, donde el instrumento es el cuestionario (Hernández y Fernández, 2008, p. 177), se efectuaron dos cuestionarios que incorporan tanto preguntas abiertas como preguntas cerradas, a fin de tener un completo panorama del problema en investigación. Es así como se diseñaron dos cuestionarios que buscan analizar diferentes aspectos de innovación social referentes al programa de formación titulada, modalidad 
presencial, nivel tecnólogo, Desarrollo y Adaptación de Prótesis y Órtesis, que se imparte en el Centro de Diseño y Metrología - Regional Distrito Capital, del SENA.

\subsubsection{Cuestionario a instructores}

Los actores fueron los instructores del programa de formación titulada, modalidad presencial, nivel tecnólogo, denominado "desarrollo y adaptación de prótesis y órtesis", del Centro de Formación de Diseño y Metrología de la Regional Distrito Capital, del SENA. Se aplicó la encuesta en el mes de octubre del año 2014, a tres de los cinco instructores (60\%) que conforman el equipo asignado al programa de análisis en la investigación.

En el mismo contexto, el objetivo de esta encuesta fue obtener información sobre el criterio, nociones y niveles referentes a la participación de los instructores asociados a la línea técnica de dispositivos biomédicos en la red de conocimiento de salud, respecto a variables de innovación social, enfocadas en el programa de formación titulada _ modalidad presencial, nivel tecnólogo, denominado "Desarrollo y adaptación de prótesis y órtesis", que se imparte en el Centro de Formación de Diseño y Metrología de la Regional Distrito Capital, del SENA. La encuesta incorpora aspectos referentes a componentes del programa de formación, actores junto con su desempeño dentro de la formación, 
acciones de intervención en la población beneficiada, elementos de innovación social.

En el Anexo No. 10, se encontrará el cuestionario de la encuesta aplicada a los instructores que desarrollan el programa de formación en el Centro de Diseño y Metrología (Bogotá D.C.).

\subsubsection{Cuestionario a aprendices}

Los actores fueron los aprendices del programa de formación titulada, nivel tecnólogo, modalidad presencial, denominado "Desarrollo y Adaptación de Prótesis y Órtesis", del Centro de Formación de Diseño y Metrología - Regional Distrito Capital, del SENA. Se aplicó la encuesta a veintiún aprendices, de los 22 que conformaban el grupo de formación seleccionado, equivalente al 95,5\% del total de estudiantes; estos aprendices se encontraban cursando el segundo trimestre de formación en el momento de la aplicación de la encuesta.

En este contexto, el objetivo fue obtener información sobre el criterio de los aprendices que están cursando el programa de formación titulada _ modalidad presencial, nivel tecnólogo, denominado "Desarrollo y adaptación de prótesis y órtesis", que se imparte en el Centro de Formación de Diseño y Metrología ubicado en la ciudad de Bogotá. La encuesta, al igual que la de instructores, incorpora aspectos como son, los componentes del programa de formación, actores junto con su desempeño dentro de la 
formación, acciones de intervención en la población beneficiada, elementos de innovación social. Ver el Anexo No. 11, la encuesta aplicada a los aprendices.

\subsubsection{Entrevista}

Con la entrevista, a través de las preguntas y respuestas, se logra una comunicación y la construcción conjunta de significados respecto a una tema (Alvarez et al, 2003). La entrevista diseñada se aplicó al Subdirector del Centro de Formación de "Diseño y Metrología", en el mes de octubre del año 2014; el lugar de realización fue la ciudad de Bogotá, en el complejo de Paloquemao, en las instalaciones del SENA.

Se construyó una entrevista semiestructurada, individual, en donde se efectuaron una serie de preguntas que variaron según las respuestas abiertas del entrevistado. La entrevista incluyó preguntas respecto a nacimiento y componentes del programa, actores y su rol dentro de la formación, población que puede acceder a la formación, e información respecto a convenios y alianzas, entre otros.

Por lo anterior, el objetivo de la entrevista hecha fue obtener información sobre aspectos generales del programa de formación titulada modalidad presencial, nivel tecnólogo, denominado "Desarrollo y adaptación de prótesis y órtesis", y resultados a nivel social, incluyendo elementos de pertinencia, participación, cobertura y accesibilidad, entre 
otros. Ver en el Anexo No. 12, cuestionario de la entrevista aplicada al personal administrativo SENA.

\subsubsection{Testimonio}

Se construyó un instrumento "testimonio", cuyo objetivo fue conocer las vivencias y experiencias personales de un alumno con discapacidad, el cual es a su vez beneficiado del producto del programa. La persona que entrega el testimonio es un aprendiz del programa de formación; el estudiante ejerce como Policía (Policía Nacional), tiene 24 años de edad, de origen bogotano, con discapacidad física, amputado transfemoral (amputación arriba de la rodilla), quien fue herido en el Cauca mientras prestaba servicio como funcionario vinculado de la Policía.

\subsubsection{Observación de campo}

Se buscó adentrarnos a profundidad en el problema social, manteniendo un papel activo de reflexión permanente, estando atento a detalles, sucesos e interacciones, entre otros (Hernández y Fernández, 2008, p. 260). Es así como, a partir de lo estipulado por Hernández, en la planificación del proceso dado para la observación fue el siguiente: el qué voy a observar y por qué, dada a través de la definición del problema; el cómo observar dado por la modalidad de observación; dónde observar, dado por el escenario; el qué observar dado a través del enfoque. Entre los componentes a identificar están el entorno físico, el entorno social y humano, las actividades 
(prácticas), acciones relevantes (actores, relaciones) y tecnología en uso, entre otros.

\subsection{Variables}

Las variables definidas en esta investigación se basan tanto en los criterios dados por la CEPAL para evaluar los proyectos de innovación social como en las fases establecidas en el seminario taller "Los retos de la innovación social en Colombia” efectuado en la ciudad de Bogotá, en el año 2013.

\subsubsection{Innovación}

Variable que se establece identificando el modelo de innovación, generalmente abierto, en el cual los actores tienen la libertad de utilizar y adaptar la idea o el modelo tradicional basado en el concepto de propiedad intelectual, donde el conocimiento se mantiene en las manos del creador.

\subsubsection{Generación de valor social}

Variable que mide la solución de problemas o retos sociales, encaminados al mejoramiento de la calidad de vida de la población que interviene. El valor social incluye los aspectos subjetivos del bienestar de la población, identificando nociones innovación social en la comunidad. 


\subsubsection{Participación de la comunidad}

Esta variable evalúa si existe colaboración activa entre actores, las comunidades y/o población beneficiaria, que permita que ésta se convierta en un actor protagónico de su propio bienestar, y no sólo en un receptor pasivo de beneficios. La amplia participación comunitaria emana pertenencia, capacidad para trabajar en equipo y resolver los problemas, identificar y aprovechar oportunidades y de esta manera superar las adversidades.

\subsubsection{Potencial de sostenibilidad}

Determina si se cuenta con procesos consolidados, mecanismos o instrumentos que permitan la sostenibilidad a nivel económico, social y cultural a largo plazo. Análisis de trayectoria destacada y articulación con la sociedad civil y/o con el gobierno. Empleabilidad e Internacionalización.

\subsubsection{Potencial de escalabilidad}

Calcula el crecimiento continuo del servicio, sin la pérdida de la eficiencia de éste. 


\subsubsection{Potencial de replicabilidad}

Establece resultados así como las formas efectivas de resolver problemas de diverso nivel, razón por la cual podrían ser calcados, divulgados, socializados y/o compartidos en otros lugares. Pertinencia.

\subsubsection{Colaboración intersectorial}

La innovación social pocas veces desarrolla su acción de forma aislada, la motivación varía según el tipo de participante (actor) y el sector, y dan lugar a organizaciones híbridas de gran interés para su observación.

Con estas variables se efectuará el análisis que corresponde para la determinación de características y posteriores resultados y de la investigación. 


\section{RESULTADOS}

A fin de aumentar la validación de los resultados obtenidos y disminuir los problemas de sesgo se utilizó la técnica denominada triangulación, la cual consiste básicamente en la combinación de diferentes fuentes de datos emanadas de los instrumentos utilizados, integrando resultados cuantitativos y cualitativos en el mismo estudio de investigación. Entre las ventajas de la técnica están la productividad en el análisis y recolección de datos para dar mayor validez de los resultados (Hernández y Fernández, 2008, p. 439), más proximidad del investigador al objeto de estudio, integración de métodos e instrumentos, aumentando la garantía de la investigación disciplinaria y aproximación al entendimiento de la realidad en los procesos dinámicos (Denzin y otros, 2005, p. 2).

De igual manera, el tipo de triangulación utilizada para esta investigación fue de métodos, basada en los instrumentos aplicados, el procedimiento y el tratamiento de la información, sumando productos cualitativos y cuantitativos de forma simultánea (intermétodos: método cualitativo y método cuantitativo), ya que mejoran el diagnóstico sintetizado en los resultados derivados del cruce de la información, en una interpretación válida y coherente. (Bericat, 1998, p. 372)

En el mismo contexto, entre los aspectos que se evitan con la aplicación de la técnica de triangulación, están: la dificultad para combinar 
datos textuales y numéricos, obstáculos en la interpretación de resultados divergentes del uso simultáneo de métodos cualitativos y cuantitativos, el no éxito en la delineación y la mezcla de conceptos, el bajo peso de la información procedente de diferentes fuentes de datos, la dificultad de acertar en la contribución de cada método cuando se asimilan los resultados.

\subsection{Sistematización de los resultados}

\subsubsection{Instructores}

Se utilizó la técnica de encuesta cuya herramienta fue el cuestionario; ésta se aplicó en el mes de octubre del año 2014, al $60 \%$ de los instructores (3 instructores de los 5 que se encuentran articulados al programa) que conforman el equipo asignado al programa de análisis en la investigación.

El cuestionario aplicado consta de tres partes, así: parte A, información demográfica; parte $\mathrm{B}$, relacionado con el programa de formación direccionados a la innovación social; parte $\mathrm{C}$, aspectos de investigación y fortalecimiento. El manual de Oslo (OCDE, 2005) coincide en el hecho que la investigación está relacionada con la innovación social, incorporando actividades que inciden directamente en la adquisición de nuevos aprendizajes. Así la situación, los resultados arrojados de la encuesta son los siguientes: (mayor especificación en el Anexo No.13. Resultados encuesta a instructores). 


\subsubsection{Información demográfica}

Tabla 7. Consolidación información demográfica, encuesta a instructores.

\section{ENCUESTA A INSTRUCTORES}

\begin{tabular}{|c|c|}
\hline Cantidad de instructores que contestaron el cuestionario: 3 & \\
\hline \multicolumn{2}{|c|}{ Lugar de realización: Centro de Diseño y Metrología_Regional Distrito Capital. Servicio Nacional de } \\
\hline \multicolumn{2}{|l|}{ Fecha de diligenciamiento: 24 Octubre 2.014} \\
\hline \multicolumn{2}{|l|}{ Nivel del Programa de Formación: Titulada - Tecnólogo } \\
\hline \multicolumn{2}{|c|}{ Nombre del Programa de Formación: Desarrollo y adaptación de prótesis y órtesis } \\
\hline \multicolumn{2}{|l|}{ Número de Ficha en Plataforma "SOFIA PLUS" 781379} \\
\hline \multicolumn{2}{|l|}{ Cantidad de Aprendices de la Ficha 22 Aprendices } \\
\hline \multicolumn{2}{|l|}{ INFORMACIÓN DEMOGRÁFICA } \\
\hline Sexo: & Femenino: cant. $1 \quad-\quad$ Masculino: cant. 2 \\
\hline Especifique su lugar de nacimiento: & $\begin{array}{l}\text { A.tlántico (Barranquilla): cant. } 1 \text { - Meta (Vista Hermosa): cant. } 1 \\
\text { Sin especificación: cant. } 1\end{array}$ \\
\hline Indique su edad (en años): (marque con una $X$ según corresponda) & Entre 25 y 30 : cant. 1 Entre 30 y 35 : cant. 1 - 45 Años o más: cant. 1 \\
\hline Profesión: & $\begin{array}{l}\text { Rta. 1: Tecnóloga en órtesis y prótesis categoría ISPO 2, Universidad Don Bosco - Pais El } \\
\text { Salvador: cant. } 1 \\
\text { Rta. 2: Ingeniero Mecánico Industrial - Universidad El Bosque: cant. } 1 \\
\text { Rta. 3: Licenciado en órtesis y prótesis, categoría ISPO 1 - Universidad Don Bosco - País El } \\
\text { Salvador: Cant. } 1\end{array}$ \\
\hline Tiempo de experiencia general como docente: (en años) & $\begin{array}{l}\text { Rta 1.: } 3 \text { Años de docencia - Rta. 2: } 14 \text { Años de docencia - Rta. 3: } \\
\text { 3 Años de docencia }\end{array}$ \\
\hline Fecha de Ingreso al Servicio Nacional de Aprendizaje "SENA" & Rta. 1: 20 Enero 2.012 - Rta. 2: 1.990 - Rta. 3: Enero de 2.012 \\
\hline Indique el tiempo que Ileva en el "SENA" como Instructor: & Rta.1: 3 Años - Rta.2: 17 Años - Rta. 3: 3 Años \\
\hline
\end{tabular}

Fuente: Elaboración propia, a partir de la encuesta aplicada a los instructores.

Los docentes que imparten el programa de formación tienen como lugares de origen Atlántico (Barranquilla), Meta (Vista Hermosa) y otro no especificado, sus edades oscilan entre 25 y más de 45 años; respecto a la experticia adquirida en el área de órtesis y prótesis, un porcentaje mayor del cincuenta por ciento de los entrevistados obtuvo experiencia fuera de Colombia, ya que no encontraron la opción de formación en el país, por 
falta de oferta en los entes académicos, lo que evidencia la necesidad de fortalecer el programa en Colombia.

Figura 14. Sistematización resultados de información demográfica y otros, instructores.

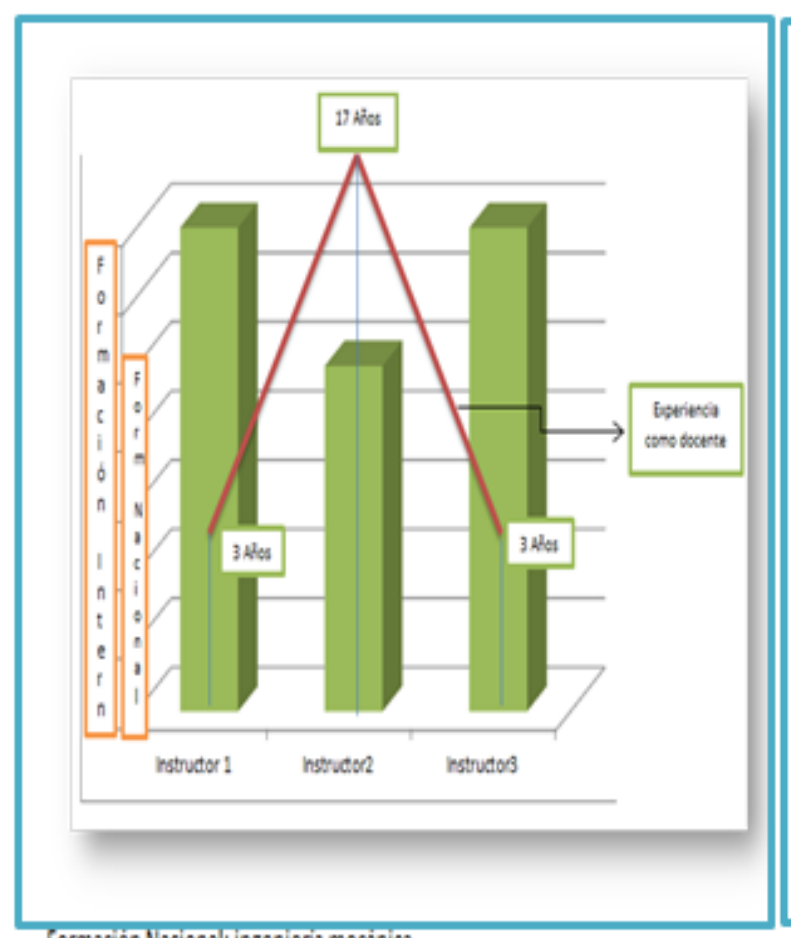

La formación pedagógica de los docentes oscila entre los tres y catorce años, lo que fortalece los aspectos de innovación específicamente en la consolidación de mecanismos para la sostenibilidad del proyecto; el tiempo de permanencia en el SENA es mayor para los instructores que tienen formación nacional que para los que tienen formación internacional, por otra parte la experiencia adquirida como docentes se ha dado de manera permanente en la misma entidad.

Formacion Nacional: ingentieria mectinica

Formación Internacional: licenciados y tecnólogos en órtesis y prótesis

Fuente: Elaboración propia, a partir de la encuesta aplicada a los instructores

\subsubsection{El programa de formación}

A continuación se presentan los resultados obtenidos en cuanto al programa de formación, incluyendo aspectos entre los cuales están la cobertura, alianzas e impacto social, entre otros. Para el DNP (2013), la innovación social incluye el promover mayores niveles de empoderamiento de la 
comunidad relacionando la cobertura, y el generar alianzas entre diferentes actores de la sociedad.

Tabla 8. Consolidación resultados respecto al programa de formación, encuesta a instructores.

\begin{tabular}{|c|c|c|c|c|c|}
\hline RESPECTO AL PROGRAMA DE FORMACIÓN & $\begin{array}{l}\text { Totalmente de } \\
\text { acuerdo }\end{array}$ & De acuerdo & $\begin{array}{l}\text { Parcialmente de } \\
\text { acuerdo }\end{array}$ & En desacuerdo & \\
\hline $\begin{array}{l}\text { El programa de formación junto con sus perfiles de ingreso y egreso, } \\
\text { oportunidad laboral y proyectos formativos que lo conforman son } \\
\text { divulgados por diferentes medios a la población, para su respectivo } \\
\text { acceso e inclusión? }\end{array}$ & 2 & 1 & & & 1 \\
\hline $\begin{array}{l}\text { La cobertura que tiene el programa de formación titulada en } \\
\text { referencia es nacional e internacional? (marque con una X según } \\
\text { corresponda) }\end{array}$ & 1 & 1 & 1 & & 2 \\
\hline $\begin{array}{l}\text { El programa de formación cuenta con convenios y alianzas } \\
\text { nacionales? }\end{array}$ & 2 & 1 & & & 3 \\
\hline $\begin{array}{l}\text { El programa de formación cuenta con convenios y alianzas } \\
\text { internacionales? }\end{array}$ & 2 & 1 & & & 4 \\
\hline $\begin{array}{l}\text { Identifica contribución del programa de formación al desarrollo } \\
\text { productivo y social del sector y del país? }\end{array}$ & 3 & & & & 5 \\
\hline $\begin{array}{l}\text { Identifica con el programa de formación y resultados obtenidos del } \\
\text { mismo, ideas y nuevas oportunidades para resolver necesidades del } \\
\text { entorno (emprendimiento, desarrollo de proyectos sociales)? }\end{array}$ & 2 & 1 & & & 6 \\
\hline $\begin{array}{l}\text { El programa de formación en referencia y logros presentados, } \\
\text { impactan en el sector social? }\end{array}$ & 3 & & & & 7 \\
\hline
\end{tabular}

Fuente: Elaboración propia, a partir de la encuesta aplicada a los instructores.

Se observa que el $100 \%$ de los instructores establecen el programa como un impacto en el área social con potencial de escalabilidad y replicabilidad, direccionado hacia la innovación y el desarrollo humano. Como se indicó en el marco teórico, la innovación social se caracteriza por tener potencial de escalabilidad, replicabilidad, ser sostenible, promover 
mayores niveles de empoderamiento de la comunidad y generar alianzas entre diferentes actores de la sociedad según el DNP (2013).

Figura 15. Sistematización de resultados de información respecto al programa de formación, encuesta a instructores.

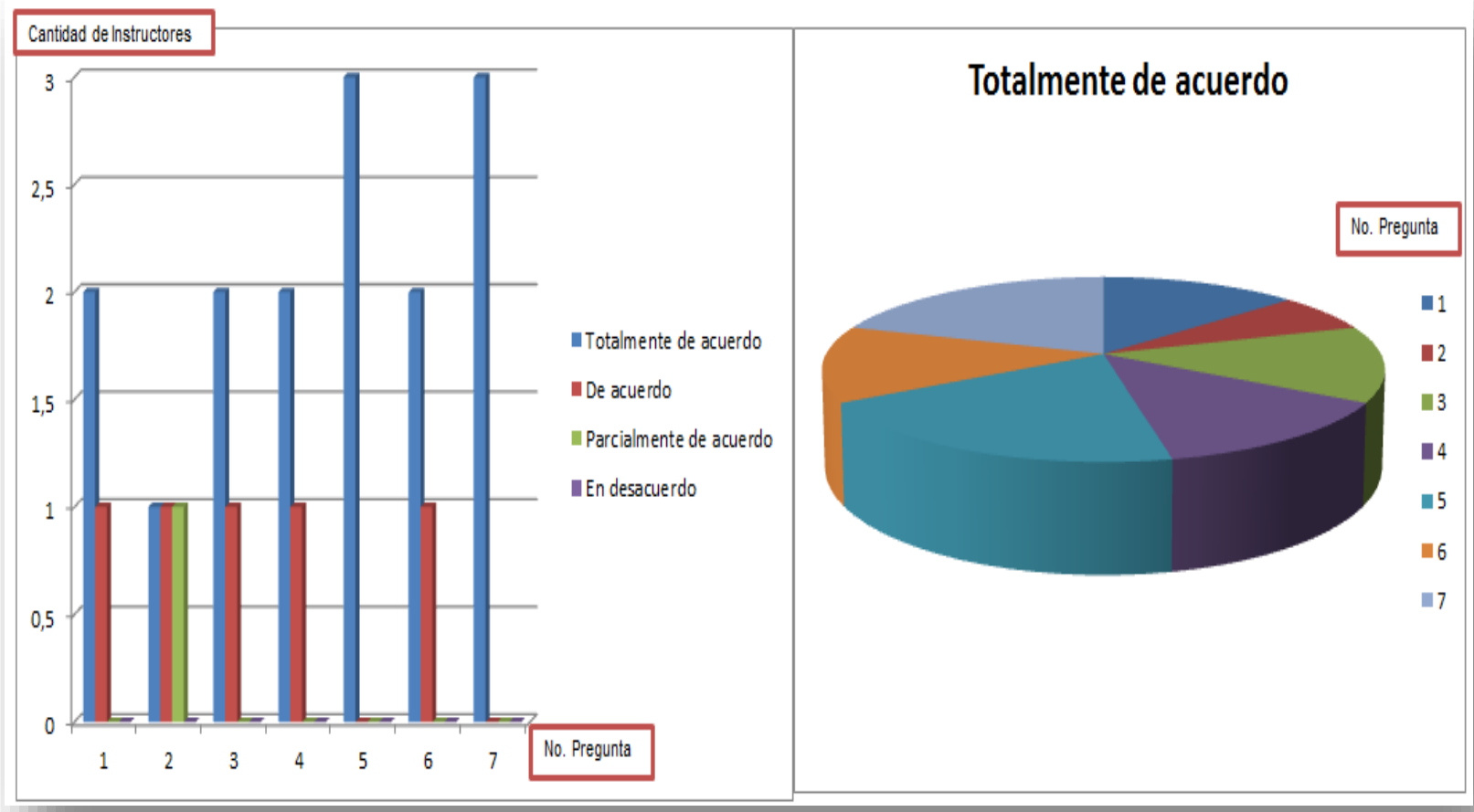

Fuente: Elaboración propia, a partir de la encuesta aplicada a los instructores.

En la gráfica anterior se observó que más del 50\% de los instructores que participaron de la investigación están de acuerdo o totalmente de acuerdo con las preguntas realizadas, confirmando la existencia de los siguientes elementos para el programa de formación: divulgación a la población por diferentes medios pero no de forma masiva, éste curso tiene 
cobertura nacional e internacional, además cuenta con algunos convenios y alianzas de cooperación tanto nacionales como internacionales (colaboración intersectorial); hay contribución del programa al desarrollo productivo y social del sector y del país encaminado al potencial de sostenibilidad; aspectos importantes a tener en cuenta para identificar la innovación social según la CEPAL (2014).

Además, se confirmó que a través del desarrollo del programa y los resultados de éste, surgieron nuevas ideas y nuevas oportunidades para resolver las necesidades del entorno, incluidos el emprendimiento y el desarrollo de proyectos sociales, caso enunciado en el Pre CONPES de Innovación Social (2014).

El $100 \%$ de las personas encuestadas (cuestionario que incluyó preguntas abiertas y cerradas), coincidieron en el hecho que los logros presentados por el programa de formación profesional impactan en el sector social (potencial de escalabilidad), dando un crecimiento continuo y ampliando la calidad del servicio por medio del aumento en cobertura, la suscripción de más convenios y alianzas, y la identificación de nuevas oportunidades en el entorno, elementos que se subrayan por el DNP (2014) enfatizando en la calidad y potenciación de la formación del capital humano en búsqueda del desarrollo. 
En cuanto a las condiciones para la formación:

Tabla 9. Consolidación resultados respecto a las condiciones para la formación, encuesta a instructores.

\begin{tabular}{|l|l|l|l|l|}
\hline \multicolumn{1}{|c|}{ CONDICIONES PARA LA FORMACIÓN } & $\begin{array}{c}\text { Totalmente de } \\
\text { acuerdo }\end{array}$ & De acuerdo & $\begin{array}{c}\text { Parcialmente de } \\
\text { acuerdo }\end{array}$ & En desacuerdo \\
\hline $\begin{array}{l}\text { La capacidad de los Ambientes de Aprendizaje asignados para } \\
\text { impartir el programa de formación titulada en referencia, incluyen la } \\
\text { tecnología adecuada y espacios físicos requeridos para el desarrollo } \\
\text { de la formación? (marque con una X según corresponda) }\end{array}$ & & 3 & \\
\hline $\begin{array}{l}\text { Accede a las herramientas, recursos y elementos necesarios para } \\
\text { lograr los resultados de aprendizaje del programa? }\end{array}$ & & 2 & 1 \\
\hline $\begin{array}{l}\text { Conoce y emplea los recursos tecnológicos que tiene el Centro de } \\
\text { Formación disponibles para impartir el programa, incluídos } \\
\text { infraestructura y tecnología? }\end{array}$ & & & & 2 \\
\hline
\end{tabular}

Fuente: Elaboración propia, a partir de la encuesta aplicada a los instructores.

Figura 16. Sistematización resultados de información respecto a las condiciones para la formación, encuesta a instructores.

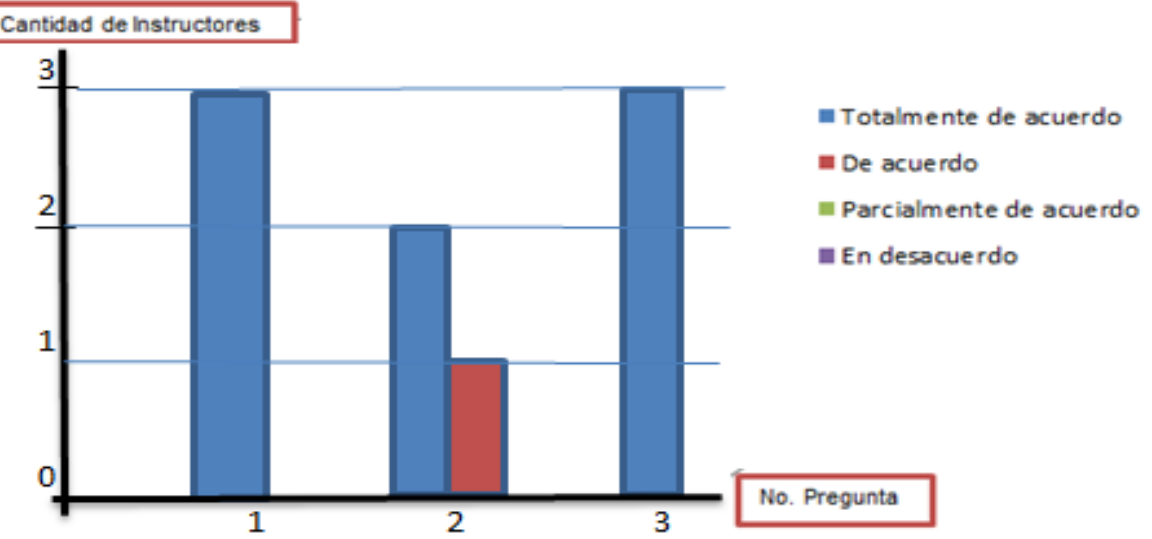

Fuente: Elaboración propia, a partir de la encuesta aplicada a los instructores. 
Los resultados emanados en relación a las condiciones de la formación determinan que el contexto incluye la tecnología adecuada y espacios físicos requeridos para el desarrollo del programa; también se confirmó que el acceso a las herramientas, recursos y elementos necesarios para lograr los resultados de aprendizaje se dan en un alto porcentaje, ampliando así los espacios para la innovación, ya que el $67 \%$ de los encuestados estuvieron "totalmente de acuerdo", $33 \%$ estuvo en sólo "de acuerdo" у 0\% “en desacuerdo". Para Retegi \& Ullibarri (Moreira y Frías, DNP, 2013), los espacios interactivos de aprendizaje son el máximo exponente de los entornos.

\subsubsection{Aspectos de investigación, fortalecimiento y desarrollo humano}

Tabla 10. Consolidación de resultados en cuanto a los aspectos de investigación y fortalecimiento del programa, encuesta a instructores.

\begin{tabular}{|c|c|c|c|c|c|}
\hline ASPECTOS DE INVESTIGACIÓN Y FORTALECIMIENTO & $\begin{array}{l}\text { Totalmente de } \\
\text { acuerdo }\end{array}$ & De acuerdo & $\begin{array}{l}\text { Parcialmente de } \\
\text { acuerdo }\end{array}$ & En desacuerdo & \\
\hline $\begin{array}{l}\text { En el Centro de Formación se han generado escenarios de atención } \\
\text { para transmitir y retroalimentar inquietudes, en pro del } \\
\text { mejoramiento y consolidación del programa de formación? }\end{array}$ & 2 & 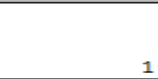 & & & \\
\hline $\begin{array}{l}\text { En su papel de Instructor del Programa de Formación, le es asignado } \\
\text { tiempo para el desarrollo de la Investigación? (marque con una X } \\
\text { según corresponda) }\end{array}$ & 1 & 1 & 1 & & 2 \\
\hline $\begin{array}{l}\text { Ha recibido acciones de capacitación para fortalecimiento de su perfil } \\
\text { como profesional en el área? }\end{array}$ & 2 & & 1 & & 3 \\
\hline $\begin{array}{l}\text { Existe transferencia de tecnología y de conocimientos dentro del } \\
\text { programa en referencia? }\end{array}$ & 3 & & & & 4 \\
\hline $\begin{array}{l}\text { Ha tenido la oportunidad de socializar el proyecto formativo con entes } \\
\text { externos al SENA? }\end{array}$ & 1 & 1 & 1 & & \\
\hline $\begin{array}{l}\text { Considera que las personas beneficiadas de los dispositivos médicos } \\
\text { que ustedes desarrollan en su proyecto formativo, mejoran su calidad } \\
\text { de vida familiar? }\end{array}$ & 3 & & & & 5 \\
\hline $\begin{array}{l}\text { Considera que las personas beneficiadas de los dispositivos médicos } \\
\text { que ustedes desarrollan en su proyecto formativo, tienen nuevas } \\
\text { posibilidades laborales? }\end{array}$ & 3 & & & & 7 \\
\hline $\begin{array}{l}\text { Cree que el programa de formación referenciado es una solución al } \\
\text { problema social en este tiempo de postconflicto? }\end{array}$ & 3 & & & & 8 \\
\hline $\begin{array}{l}\text { Para usted, el programa de formación en referencia además del } \\
\text { proyecto formativo que lo compone y resultados del desarrollo, } \\
\text { incluye componentes de innovación social? }\end{array}$ & 3 & & & & al \\
\hline
\end{tabular}


Figura 17. Sistematización de resultados de información respecto a los aspectos de investigación y fortalecimiento, encuesta a instructores.

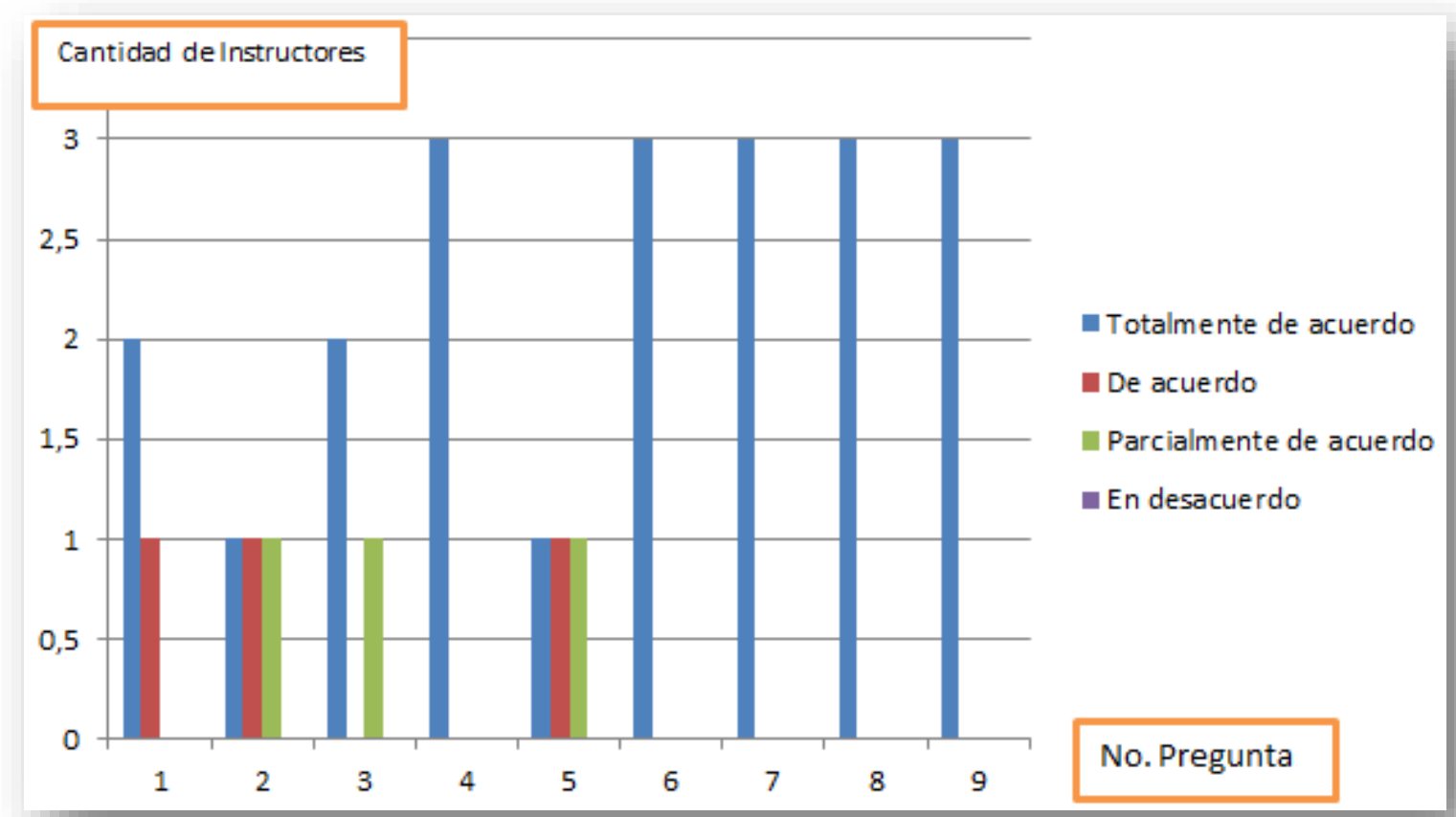

Fuente: Elaboración propia, a partir de la encuesta aplicada a los instructores.

Como resultado arrojado de los aspectos de investigación y fortalecimiento que comprende escenarios para transmitir y retroalimentar inquietudes, tiempo para el desarrollo de la investigación, capacitación para la consolidación del perfil, transferencia de tecnología y conocimientos, aspectos de posibilidades laborales, elementos de mejoramiento de calidad de vida y componentes de innovación social, se determinó que: todos los encuestados (100\%) consideran que las personas beneficiadas de los 
dispositivos médicos que se desarrollan en el Centro de Formación, dentro del programa en el proyecto formativo, mejoran la calidad de vida de las familias (desarrollo humano), dan nuevas posibilidades laborales, son solución al problema social e incluyen componentes de innovación social.

Por otra parte, el $37 \%$ de los instructores encuestados consideran que no se les asigna el suficiente tiempo para el desarrollo de la investigación, que no han recibido acciones de capacitación para el fortalecimiento de su perfil como profesional en el área y que no han tenido la oportunidad de socializar el proyecto formativo con entes externos al SENA; para la OCDE (2005) la investigación es fundamental para la generación de nuevos conceptos, procesos y métodos en pro de la optimización de la innovación. Continuando con los resultados, en cuanto a la transferencia a nivel interno del programa, se arrojó que el 100\% de los instructores estiman que existe transferencia interna de tecnología y conocimientos, elementos fundamentales de la innovación según la CEPAL (2014).

Entre las debilidades presentadas para el desarrollo de la formación están la falta de pacientes para efectuar las prácticas, el poco personal preparado para impartir la formación, los obstáculos para adquirir ciertos materiales para el desarrollo de la formación y el acceso limitado para comunicarse con el personal directivo; además solicitan la realización de nuevos convenios y/o alianzas con entidades gubernamentales para fortalecer el proceso. Según Guerra (2010), los obstáculos siempre se van a 
presentar para dificultar la innovación, reduciendo así la capacidad de innovar.

Los instructores creen en el programa de formación y los beneficios que el mismo aporta a la comunidad, admitiendo que la necesidad en el sector es amplia y que todos los esfuerzos para mejorar e impulsarlo realmente valen la pena; según la ANSPE (2014), los actores claves de la innovación social pueden darse desde la dimensión de personas, organizaciones o territorios, para el caso es de organizaciones, de la mima manera el tipo de actor y el rol a protagonizar varían según el contexto en el cual se desarrolle la innovación social. En esta innovación social, se destaca el trabajo colaborativo y las alianzas entre diversos actores, confirmando el protagonismo de los actores en la transformación social incidiendo en el impacto a la comunidad.

\subsubsection{Aprendices}

Se aplicó la encuesta ${ }^{5}$, cuya herramienta fue el cuestionario (Hernández y Fernández, 2008, p. 177), a veintiún aprendices, de los 22 que conformaban el grupo de formación seleccionado, equivalente al 95,5\% del total de estudiantes.

La encuesta aplicada a los aprendices consta de tres partes, así: parte A-información demográfica; parte B- relacionados con el programa de

${ }^{5}$ La encuesta aplicada a los aprendices se realizó en el mes de octubre (24) del año 2014. 
formación y enfoque en calidad de vida (desarrollo humano); parte Cdesarrollo humano. Sen (2000), afirma que el desarrollo humano comprende la creación de un entorno propicio para que las personas desarrollen su máximo potencial, para en caso articulado con la innovación social.

Los resultados arrojados de la encuesta son los siguientes (en el Anexo No. 14, se especifican los resultados de la encuesta aplicada a los aprendices):

\subsubsection{Información demográfica}

Tabla 11. Consolidación resultados respecto a información demográfica, encuesta a aprendices.

ENCUESTA A APRENDICES

Cantidad de aprendices que contestaron la encuesta: 21

Lugar de realización: Centro de Diseño y Metrología_Regional Distrito Capital. Servicio

Fecha de diligenciamiento: 24 de Octubre 2.014

Nivel del Programa de Formación: Titulada

Nombre del Programa de Formación: Desarrollo y adaptación de prótesis y órtesis

Número de Ficha en Plataforma "SOFIA PLUS" 781379

Cantidad Total de Aprendices del Grupo: 22 Aprendices

\begin{tabular}{|c|c|c|c|}
\hline \multicolumn{4}{|c|}{ INFORMACIÓN DEMOGRÁFICA } \\
\hline \multirow[b]{2}{*}{ Especifique su lugar de nacimiento: } & \multirow[b]{2}{*}{\begin{tabular}{|l} 
Femenino: cant. 0 \\
Valle del Cauca (Cail): cant. 1 \\
Antioquia (Uramita): cant.1. \\
Bogotá D.C.: cant.5 \\
Cundinamarca (Mesitas del colegio): cant.1 \\
Cundinamarca (Fusagasuga): cant.1 \\
Cesar (Aguachica): cant.1 \\
\end{tabular}} & \multicolumn{2}{|c|}{ Masculino: cant: 21} \\
\hline & & $\begin{array}{l}\text { Bolivar (San Martín de Loba): cant.1 } \\
\text { Bolivar (Carmen de Bolivar): cant. } 1 \\
\text { Tolima (Cajamarca): cant.1 } \\
\text { Nariño (Funes): cant.1 } \\
\text { Boyacá (Tota): cant. } 1 \\
\text { Boyacá (Sativa sur): cant.1 } \\
\end{array}$ & $\begin{array}{l}\text { Norte de Santander (Cúcuta): cant.2 } \\
\text { Magdalena (Banco): cant. 1 } \\
\text { Casanare (Yopal): cant. } 1 \\
\text { Santander (San Gil): cant. } 1\end{array}$ \\
\hline $\begin{array}{l}\text { Indique su edad (en años): (marque con una } X \text { según } \\
\text { corresponda) }\end{array}$ & Entre 20 y 25 : cant. 5 Entre 25 y 30 & cant. 12 Entre 30 y 35 : cant. & \\
\hline Profesión & $\begin{array}{l}\text { EJÉRCITO: } \\
\text { Soldado profesional: cant. } 11 \\
\text { Sub-oficial del ejército: cant. } 4\end{array}$ & $\frac{\text { POLICÍA NACIONAL: }}{\text { Policía: cant. } 3}$ & $\frac{\text { SIN ESPECIFICACIÓN: }}{\text { Cant.. } 3}$ \\
\hline
\end{tabular}


En relación con los lugares de nacimiento, vemos que los veintiún (21) aprendices provienen de diferentes regiones del país, 12 departamentos del país que son Valle, Antioquia, Cundinamarca, Cesar, Bolívar, Tolima, Nariño, Boyacá, Norte de Santander, Santander, Magdalena y Casanare. Según la CEPAL(2014), la dinámica nacional, asociada entre otros al desarrollo humano, dada en un proceso de diferenciación con confluencia en los niveles medios y bajos, determina a Bogotá D.C., Cundinamarca, Antioquia y Risaralda con el nivel más alto, siguen con un nivel más constante Caldas y Risaralda, luego están Boyacá y Quindío con un nivel medio; así mismo, Tolima, Meta, Norte de Santander aparecen con progresos inestables, y, Cauca, Cesar, Casanare y Nariño se posicionan en progresos relativos; finalmente en los puestos más bajos están Córdoba, Magdalena, Sucre, Caquetá y Arauca.

No obstante, los aprendices en formación confirmaron que retornarán a sus lugares de origen para ejercer su profesión en el momento que reciban su título en el SENA, factor que amplía la cobertura de beneficios del programa de formación. 
Figura 18. Sistematización resultados respecto a información demográfica, encuesta a aprendices.

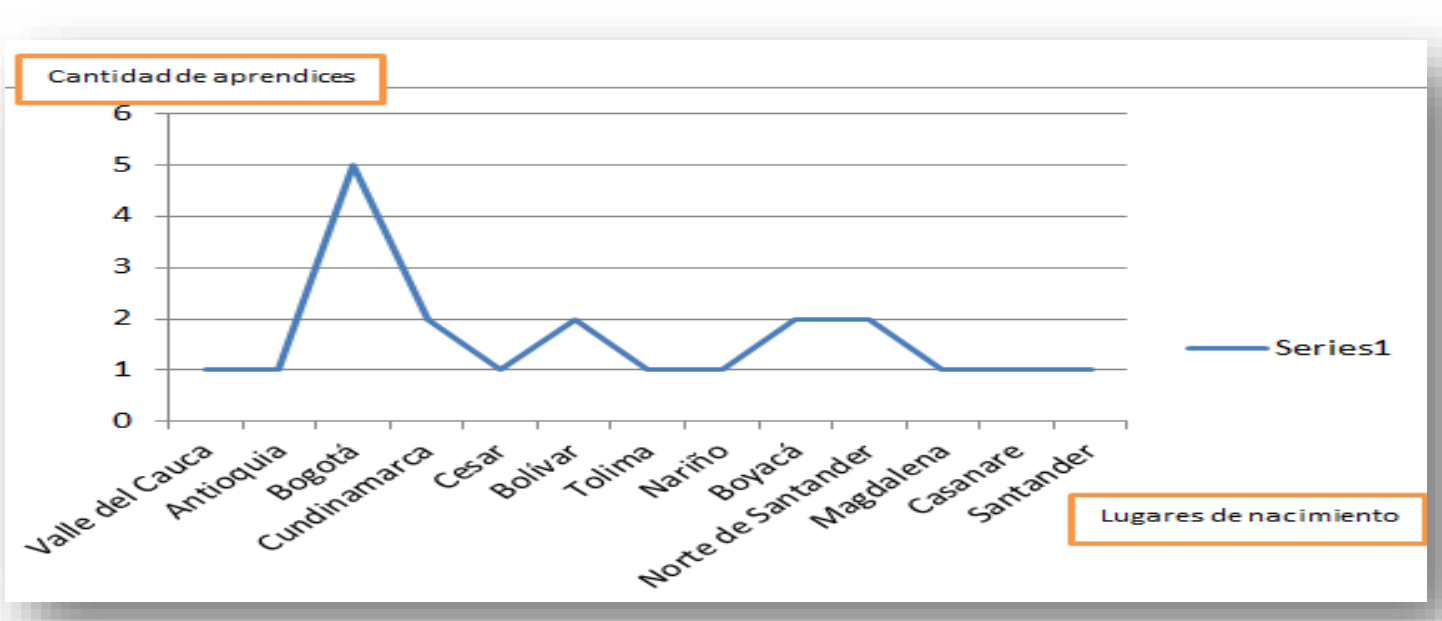

Fuente: Elaboración propia, a partir de la encuesta aplicada a los aprendices.

El 100\% de los aprendices encuestados son de sexo masculino, y sus edades oscilan entre los 20 y los 35 años; el $86 \%$ de los encuestados, expresaron que están vinculados a las fuerzas militares, donde: 15 aprendices están vinculados al Ejército, 3 a la Policía Nacional, y 3 aprendices no especificaron su asociación.

6.1.2.2 El programa de formación y su enfoque en calidad de vida 
Tabla 12. Consolidación resultados respecto al programa de formación, encuesta a aprendices.

\begin{tabular}{|c|c|c|c|c|c|c|c|}
\hline \multicolumn{7}{|c|}{ RESPECTO AL PROGRAMA DE FORMACIÓN } & \\
\hline $\begin{array}{l}\text { Indique la modalidad de formación: (marque con una X } \\
\text { según corresponda) }\end{array}$ & Presencial: $\mathrm{X}$ & & Virtual: -..-- & & & & \\
\hline Indique la fecha de inicio de la formación: & 1.Día: (07) & 2.Mes: (07) & 3.A & : (2.014) & & & \\
\hline $\begin{array}{l}\text { Indique la etapa en formación: (marque con una X según } \\
\text { corresponda) }\end{array}$ & Lectiva: & & Práctica: & & & & \\
\hline $\begin{array}{l}\text { Indique trimestre en el cual se encuentra formado, } \\
\text { teniendo en cuenta la fecha de inicio de su formación : } \\
\text { (marque con una } X \text { según corresponda) }\end{array}$ & $\begin{array}{l}\text { Primer Trimestre 1.( } \\
\text { Tercer Trimestre 3.( }\end{array}$ & & $\begin{array}{l}\text { Segundo T } \\
\text { Tercer Tri }\end{array}$ & lestre 2.1 & & & \\
\hline CONDICIONES PARA LA FORMACIÓN & Siempre & Casi siempre & Algunas veces & Nunca & Sin respuesta & \begin{tabular}{|l} 
Total \\
Respuestas
\end{tabular} & \\
\hline $\begin{array}{l}\text { El Servicio Nacional de Aprendizaje "SENA" Io ha motivado } \\
\text { en el cambio para ser actor principal en su proceso de } \\
\text { formación? }\end{array}$ & 16 & 4] & $1]$ & & & 21 & 1 \\
\hline $\begin{array}{l}\text { Tiene acceso a todos los ambientes de aprendizaje } \\
\text { asociados al programa de formación titulada, nivel } \\
\text { tecnólogo en prótesis y órtesis? }\end{array}$ & 17 & 3 & 1 & & & 21 & 2 \\
\hline $\begin{array}{l}\text { Los ambientes de aprendizaje y las instalaciones del Centro } \\
\text { de Formación facilitan su proceso formativo? }\end{array}$ & 13 & 7 & 1 & & & 21 & 3 \\
\hline $\begin{array}{l}\text { El tiempo que lleva en la formación a cumplido con las } \\
\text { expectativas que usted tenia generadas? }\end{array}$ & 17 & 3. & 1 & & & 21 & 4 \\
\hline
\end{tabular}

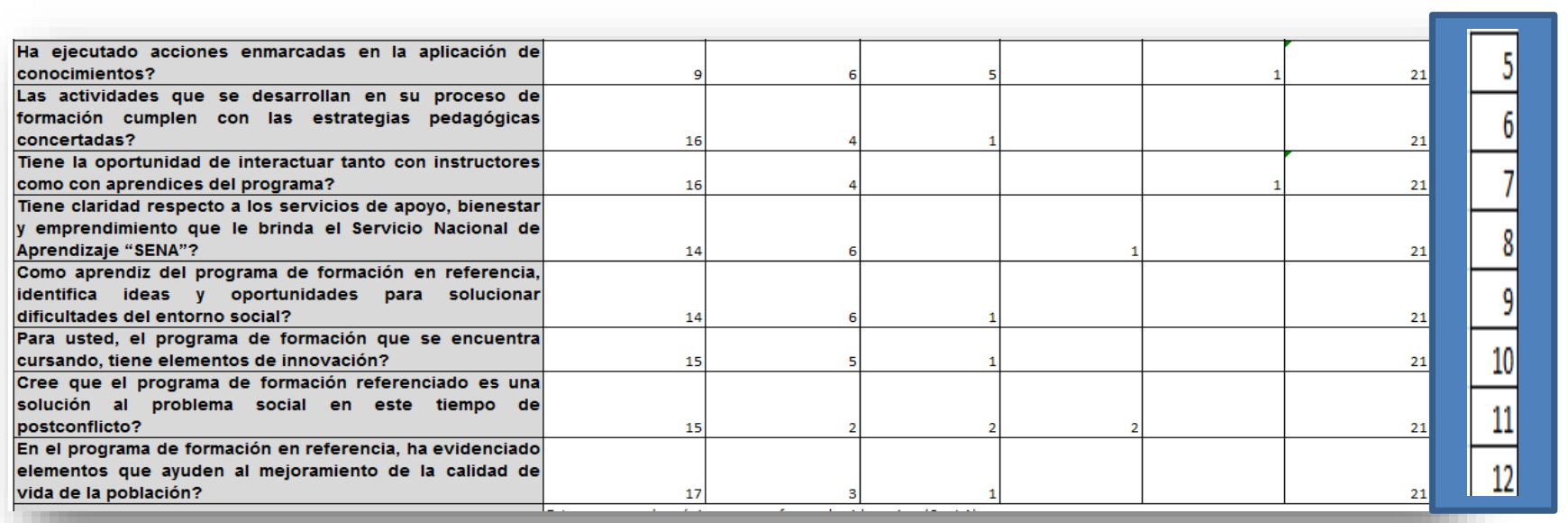

Fuente: Elaboración propia, a partir de la encuesta aplicada a los aprendices.

Se resalta que para el momento de la aplicación del instrumento, los aprendices encuestados se encontraban cursando el segundo trimestre de la etapa lectiva, aplicación dada en el mes de octubre de 2014, modalidad 
presencial; aclarando que el programa de formación consta de siete y trimestres de etapa lectiva y tres trimestres de etapa práctica.

Figura 19. Sistematización resultados respecto al programa de formación, encuesta a aprendices.

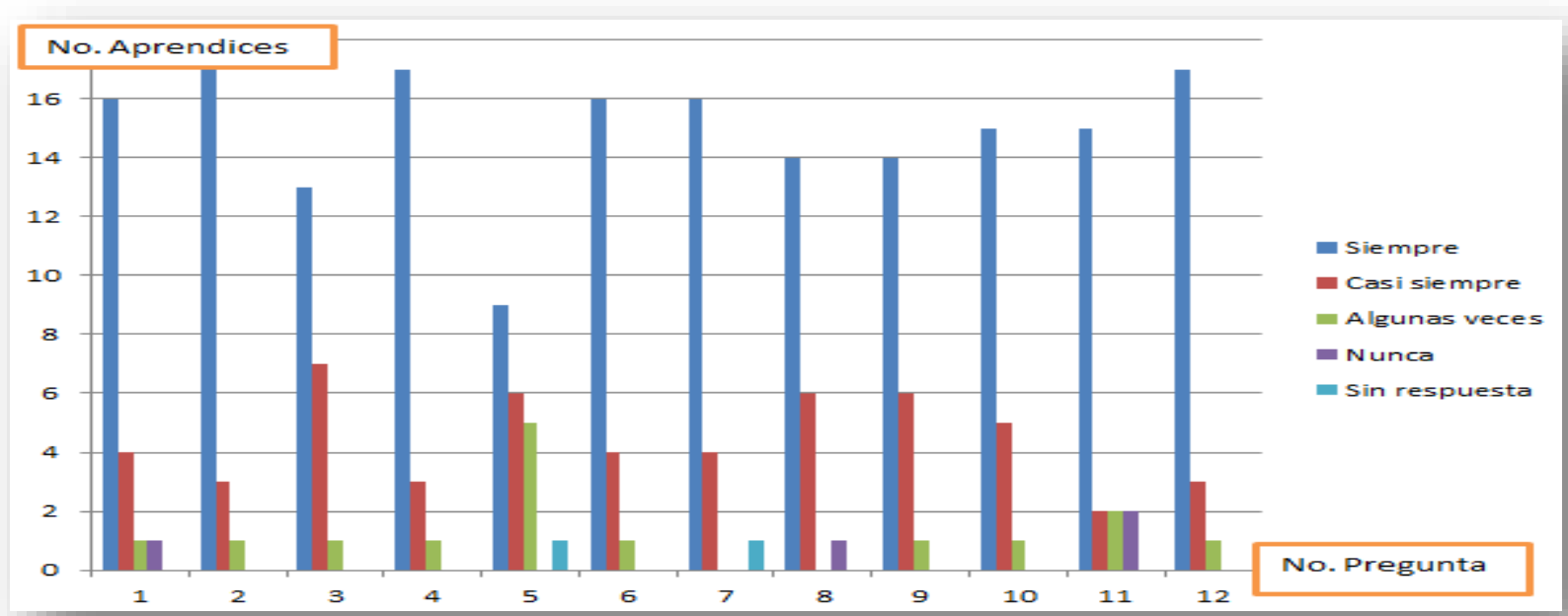

Fuente: Elaboración propia, a partir de la encuesta aplicada a los aprendices.

Más del 50\% de los aprendices encuestados coinciden en el hecho que existen las condiciones para la formación del programa incluída la motivación, se tiene acceso a los ambientes de aprendizaje asociados al programa (potencial de sostenibilidad), se cumplen con las expectativas generadas, se afianzan las estrategias pedagógicas concertadas, hay oportunidad de interactuar con los instructores, claridad en los servicios de apoyo, bienestar y emprendimiento, a través del programa se identifican oportunidades para solucionar dificultades del entorno social (potencial de escalabilidad), también hay en el curso elementos de innovación, el 
programa es una solución al problema social (potencial de replicabilidad), y hay elementos que ayudan al mejoramiento de la calidad de vida de la población (desarrollo humano); con estas evidencias se reconoce que hay condiciones para el desarrollo de la formación, incluyendo espacios para la innovación los cuales originan respuesta a problemas de la comunidad. Para la ANSPE (2014) y para la CEPAL (2014), tanto el potencial de sostenibilidad como el de replicabilidad y escalabilidad, entre otros ya nombrados, son características necesarias para que un proyecto se considere innovación social.

En el mismo contexto, en relación a la ejecución de acciones enmarcadas en la aplicación de los conocimientos, el $42 \%$ identificó su respuesta como "siempre", el $29 \%$ como "casi siempre", $24 \%$ como "algunas veces", y un 5\% no respondió; se valida el hecho que la aplicación de conocimientos no es dada solamente desde la interacción del conocimiento con la práctica, sino que también incluye las actividades que generan exclusivamente la adquisición de nuevos aprendizajes (SENA, 2015).

\subsubsection{Desarrollo humano}

El desarrollo humano asociado a la categoría de análisis en la investigación, evidencia que los aprendices tienen diversos conceptos o nociones para definir la calidad de vida a partir del estudio de la técnica profesional junto con los elementos identificados; como aportes del programa al 
mejoramiento de la calidad de vida están: colaboración y apoyo para la población por el conflicto armado, son nuevos programas de formación para la población colombiana, se fortalece la formación intelectual y el desarrollo de nuevas competencias, mejora la calidad de vida de las personas amputadas de cualquier extremidad, ayuda a la recuperación de personas afectadas por cualquier accidente, es una oportunidad para la población colombiana, dado que habrá mayor número de profesionales en el área. Según Nussbaum (2007), cada individuo tiene un interés sobre él mismo y no se pregunta únicamente por el bienestar sino también por las oportunidades dispuestas para cada ser humano, convirtiendo la libertad en un estándar para medir la calidad de vida y el desarrollo de la comunidad.

A continuación se presentan apartes textuales de los argumentos dados por los aprendices, plasmados de forma escrita como respuestas a las preguntas abiertas que se presentaron en los cuestionarios, respecto al enfoque del programa en el mejoramiento de la calidad de vida, demostrando la importancia que tiene el programa para el desarrollo humano, así: "esta carrera es lo máximo, es una forma de mejor vida"; "la formación que estamos recibiendo nos sirve para colaborarle a aportarle a la población que está afectada por el conflicto armado"; "al finalizar el programa podremos prestar un gran servicio a la comunidad"; "el programa es súper importante ya que en Colombia hay muchas personas en estado de discapacidad por efecto de la guerra"; "este programa brinda mejor calidad de vida a personas en condición de discapacidad haciendo más fácil su estilo de vida"; "ésta es una oportunidad para mí como ser humano, así 
como para toda la población así como para toda la población colombiana"; "hay formación intelectual y desarrollo de diferentes destrezas"; "es una oportunidad para que las personas de bajos recursos adquieran su órtesis o su prótesis, puesto que el ensamble se va a realizar directamente en Colombia”.

Según los aprendices encuestados, los beneficiados del programa de formación son ellos mismos, y también las personas afectadas por el conflicto armado, las familias de bajos recursos, la población discapacitada, las fuerzas militares, y la comunidad en general. Estas personas deciden estudiar el programa de órtesis y prótesis, no sólo por la discapacidad adquirida en las actividades de combate, sino también por sus ansias de ayuda a la comunidad en general, especialmente individuos que por una $\mathrm{u}$ otra circunstancia sufren de discapacidades similares; así mismo, la iniciativa está siendo apoyada por una alianza suscrita entre el SENA y las fuerzas militares, quienes se comprometen a ubicar laboralmente a los aprendices en los Centros de Sanidad Militar situados en los lugares de origen de los aprendices. Sobresale el hecho que las alianzas con entes como las fuerzas militares, ayudan al fortalecimiento del proyecto encaminándolo a su área social, CEPAL (2014).

Entre las notas finales escritas en los cuestionarios por los aprendices encuestados en el campo de comentarios finales, se manifiesta el agradecimiento por la oportunidad de estar en la formación, solicitan se siga apoyando el programa con mantenimiento preventivo y correctivo de 
los ambientes de aprendizaje, piden la adquisición de materiales de formación y gestión de nuevas alianzas, entre otros, y también destacan que este programa es una herramienta para la inclusión de las personas discapacitadas en la sociedad, ya que da la oportunidad de superarse profesionalmente abriendo caminos en el campo laboral para la generación de ingresos que ayudarán al apoyo de la familia y ubicación en un sitio de la sociedad, conceptos acordes con lo expresado por Nussbaum (2007) y por Sen (2000) quienes coinciden en el hecho que el desarrollo humano comprende la creación de un entorno adecuado para que las personas desarrollen su máximo potencial incluyendo la mayor cantidad de oportunidades.

\subsubsection{Personal administrativo}

La entrevista semiestructurada individual se aplicó al Subdirector del Centro de Formación de "Diseño y Metrología", en el mes de octubre del año 2014; el lugar de realización fue la ciudad de Bogotá, complejo de Paloquemao, en las instalaciones del SENA.

Los resultados emanados se plasman a continuación:

El Centro de Diseño y Metrología del SENA, Regional Distrito Capital, consciente de las necesidades del sector productivo colombiano y datos entregados por el Departamento Administrativo Nacional de Estadística -DANE-, diseñó el programa denominado "desarrollo y 
adaptación de prótesis y órtesis", que se originó teniendo en cuenta que, según el censo de población realizado en Colombia en el año 2005, de cada 100 colombianos, 6.4 tienen una limitación; así mismo, de esos 6.4 con limitaciones, 51.3\% tienen limitaciones para caminar, correr o saltar así mismo el 9.7\% tiene limitación para alimentarse o asearse por sí mismos y el $18 \%$ no puede utilizar objetos con las manos.

Así mismo, el crecimiento de población en situación de discapacidad en el país, como lo determina el "estudio de la discapacidad en el horizonte de los derechos humanos" presentado por la Universidad del Rosario de Bogotá en el año 2007, se ve enfrentado a escasas posibilidades de atención, debido al reducido número de entidades dedicadas a brindar soluciones en rehabilitación, se agrega la falta de capacitación idónea de las personas que ofrecen soluciones en órtesis (dispositivos mecánicos que ejercen fuerza sobre una parte del cuerpo para ayudarle a estabilizarla, protegerla o corregirla, como son las férulas y los zapatos ortopédicos) y prótesis (son extensiones artificiales que reemplazan las partes perdidas de las extremidades inferiores o superiores del cuerpo); tal como lo señala el entrevistado.

Es así que, como lo comunica el subdirector del Centro de Formación, "las soluciones que se brindan actualmente no son personalizadas y deben modificarse para que se adapten a la morfología y tallas de los usuarios", puesto que en buena medida se producen para estándares y morfologías de la población de otros países, razones estas para 
que las soluciones ortopédicas que se ofrecen requieran ajustes por talla y diseño elevando de esta manera los costos de las mismas, originando baja accesibilidad a estos elementos, para la mayoría de la población afectada. En términos cuantitativos, la población en situación de discapacidad en Colombia es del orden de los 2.7 millones de colombianos, de los cuales 1.2 millones están afectados por discapacidad de marcha, limitaciones para moverse o caminar y limitación para usar brazos y manos. En este mismo contexto, la Organización Mundial de la Salud -OMS- informa que más de mil millones de personas en el mundo viven con algún tipo de discapacidad, así mismo otras entidades de cooperación nacional como lo es la Fundación Saldarriaga Concha (2012), especifica que el 61\% de las personas con discapacidad no reciben ningún tipo de ingreso económico para su subsistencia, subrayando que el educarse y tener un empleo digno representa para la comunidad discapacitada el poder de acercarse a la sociedad.

Continuando, de acuerdo con un estudio realizado por la Universidad Nacional de Colombia en el año 2007, las empresas involucradas en el proceso de fabricación de órtesis y prótesis en Colombia, buscan la contratación de personal con experiencia aunque no siempre esté certificado como tecnólogo protesista ortesista; sin embargo, aclara textualmente el entrevistado "la situación planteada es consecuencia de la escasez de escuelas de formación en el país, conllevando a que la mayoría de la población que labora en este campo adquiera su conocimiento y experticia 
desde el abordaje empírico o bajo la asesoría de una persona formada en escuelas en el exterior".

A nivel nacional, como lo manifiesta el subdirector "algunas instituciones desarrollan actividades de capacitación a través de seminarios y cursos de actualización pero sin experticias de pregrados y/o postgrados", por consiguiente, actualmente el país cuenta con un número muy pequeño de técnicos orto-protesistas formados en la Universidad de Don Bosco del Salvador, con categoría y de reconocimiento por la ISPO. En lo que respecta a la parte regulatoria, el Ministerio de Salud y Protección Social publicó en el año 2010 la Resolución 1349 que busca normar las actividades de los establecimientos donde se fabrican y/o adaptan los dispositivos médicos sobre medida de órtesis y prótesis, lo que exigirá contar con personal certificado y competente, así mismo se encuentra adelantando otras reglamentaciones que corresponda a la regulación de actividades relacionadas con órtesis y prótesis.

Con base en la realidad planteada, el SENA debe impulsar programas de formación profesional integral en el área de prótesis y órtesis, acordes a las actuales necesidades del sector; también, el subdirector entrevistado expresa "nuestro Centro de Formación, en el año 2010 incursionó en la especialidad de tecnología ortopédica con el ánimo de suplir la necesidad del sector productivo", mostrando así importancia en el cubrimiento de necesidades de la comunidad. El Centro de Diseño y Metrología, a través de este programa, ha dado un valor especial a los 
aspectos sociales, teniendo en cuenta el carácter transversal mediante el desarrollo de conocimiento con propuestas estratégicas que se encaminan a alcanzar niveles de progreso y competitividad con equidad y solidaridad; para la ANSPE (2014), la innovación es pieza clave del progreso social y gestión del desarrollo sostenible, abarcando el desarrollo del conocimiento, para aportar a la solución de problemas importantes de la comunidad.

Por otra parte, entre los obstáculos que ha tenido el desarrollo del programa están la dificultad para encontrar instructores capacitados en el área, dificultad para conseguir diversos materiales de formación y la necesidad de pacientes para la realización del proyecto formativo; entre las alternativas de solución están la generación de nuevas alianzas y dar mayor visibilidad al programa de formación a nivel nacional e internacional.

El perfil del egresado, en cuanto a funciones, "incluidas las de tecnólogos a cargos de sus propias empresas" como lo expresa el entrevistado, son las siguientes: manufacturar dispositivos ortopédicos sobre medidas, de acuerdo a la fórmula interdisciplinaria, participar en equipos interdisciplinarios con el fin de evaluar el estado integral del usuario y prescribir el dispositivo ortopédico sobre medida; asegurar la calidad de los dispositivos ortopédicos sobre medida en el laboratorio de acuerdo con procedimientos definidos por la empresa; administrar el proceso de la manufactura de dispositivos ortopédicos según normatividad vigente. Los comentarios aquí presentados, son el resultado de la entrevista realizada al Subdirector del centro de Diseño y Metrología. 
En el mismo contexto, el Centro de Diseño y Metrología del SENA busca posicionarse a nivel nacional y suramericano como la mejor entidad de formación de tecnólogos de Prótesis y Órtesis cumpliendo con los requisitos establecidos por ISPO.

Hasta este momento, desde SENA con liderazgo del Centro de Formación, se han efectuado convenios y alianzas con las siguientes entidades:

- Deutsche Gesellschaft für Internationale Zusammenarbeit GIZ - Agencia Alemana de Cooperación Técnica: con un experto técnico categoría I enviado por Alemania como asesor e instructor del programa.

- Universidad Don Bosco del Salvador: con tres instructores expertos categoría I según ISPO, actualmente están formando a 30 aprendices en modalidad a distancia con prácticas presenciales en el Centro de Formación.

El entrevistado expresa que "el trabajar con organizaciones pioneras contribuye al mejoramiento continuo del programa" fortaleciendo así la consolidación de capacidades. Además, entre otras alianzas y convenios suscritos, según la persona entrevistada, también están: Mercy Corps que apoyó con becas a tres colombianos para formarse como profesionales con 
categoría determinada por ISPO, en la Universidad Don Bosco, pago de matrículas y gastos de viaje de instructores y aprendices en curso a distancia con la Universidad Don Bosco para realización de prácticas en talleres de Bogotá; el Comité Internacional de la Cruz Roja donación de equipos para SENA avaluados aproximadamente en US\$800.000; ISPO, organismo que gestiona la acreditación internacional del programa y OTTO BOCK que es una multinacional alemana con sedes en varios países la cual suscribió con el SENA un convenio para transferencia tecnológica y capacitación de instructores. Según las Memorias del Seminario Taller "Los retos de la innovación social en Colombia" (2013), la conformación de alianzas y redes con otras instituciones o sectores, permiten el desarrollo, la implementación de mecanismos de financiación, difusión a menor escala y la gobernabilidad.

Respecto al desarrollo de la formación, hay vinculados cinco instructores capacitados en diferentes ramas, como lo es ingeniería mecánica e ingeniería ortopédica, entre otros. Igualmente, para contribuir al desarrollo de la formación se cuenta con seis ambientes de aprendizaje los cuales son: taller de laminación, taller de termo-formado, taller con bancos de trabajo, taller con máquinas de coser y máquinas de acabado y la recepción.

Como resultado a lo expuesto, entre otras razones, el programa de formación contribuye directamente con la elaboración de prótesis y órtesis de alta calidad, proporcionando satisfacción y calidad de vida para los 
usuarios, así como el mejoramiento de los índices nacionales de inclusión socio-laboral de las personas en situación de discapacidad, implicando como base el crecimiento educativo hacia un desarrollo incluyente comprendiendo así la discapacidad desde el punto de vista de los derechos humanos según Weigt(2014).

Con lo expresado por el Subdirector del Centro de Formación se refleja la necesidad de impulsar el programa con la realización de nuevas alianzas, adquisición de presupuesto para la compra de materiales de formación, construcción de nuevos ambientes de aprendizaje, así como el fortalecimiento y aumento de visibilidad a nivel de los entes privados y los entes gubernamentales, en búsqueda del posicionamiento de los egresados y el apoyo para la consecución de recursos y captación de nuevos pacientes para el desarrollo del proyecto formativo, direccionado a la apuesta en la formación por la inclusión desde un enfoque de desarrollo humano; con el impulso de los elementos nombrados, en el SENA, como entidad del gobierno, se contribuirá a la solicitud del DNP (2014) que consiste en el aumento de la eficiencia y la pertinencia en la prestación de servicios que mejoren la calidad de vida de la población en situación de vulnerabilidad, caso de las personas con discapacidad.

\subsubsection{Actores beneficiados con el proyecto (testimonio de aprendiz)}

El aprendiz que entrega el testimonio es un Policía en ejercicio (Policía Nacional), con 24 años de edad, de origen bogotano, con discapacidad 
física, amputado transfemoral (amputación arriba de la rodilla), herido en el Cauca, mientras prestaba sus servicios como persona vinculada de la Policía. Es importante aclarar que la persona que sufre una amputación transfemoral enfrenta entre otros desafíos, la necesidad de aumentar su energía, búsqueda de equilibrio y estabilidad de su cuerpo ya que cuanto más alto es el nivel de la amputación, se gasta más energía en menos tiempo, de acuerdo al relato dado por el aprendiz.

El joven informa que se enteró del programa de formación que imparte el SENA a través de divulgación por parte de la Policía Nacional; esta entidad ya había participado en alianzas para otros programas de formación, en otras sedes SENA del país. El aprendiz percibe el programa de formación como una oportunidad para reintegrarse a la sociedad económica y familiarmente; no sólo porque recibirá un título de tecnólogo con el que podrá entrar nuevamente al mundo laboral sino porque además, y de manera simultánea, apoyará a sus compañeros, también heridos en combate, con la elaboración del dispositivo médico que los ayude a reintegrarse igualmente a la vida social.

De igual manera, con la reintegración se consigue volver a efectuar actividades de vida diaria, tal vez no con la misma facilidad de antes pero sí consiguiendo un amplio beneficio al usarlas, mayor comodidad, mejores beneficios y mejores ingresos que se traducen en mejoramiento de vida familiar, y ubicación en una sociedad. Se considera que esta opción de vida, que comprende el desarrollo de competencias para insertarse 
nuevamente en el mundo laboral es una oportunidad que debería estar abierta a todas las personas que sufren algún tipo de discapacidad, más conociendo que el Ministerio de Salud y Protección Social (2012) registra que el $81 \%$ de las personas que sufren algún tipo de discapacidad afirman que su condición ha sido el motivo para no ser aceptados en ningún empleo, así mismo el $61 \%$ reitera en que no recibe ningún recurso económico para su subsistencia.

Por otro lado, según lo informado por el aprendiz que da su testimonio y de acuerdo con la observación hecha en campo, entre los beneficios que ofrece el programa de formación titulada, modalidad presencial, están las siguientes: el SENA brinda formación gratuita, sin distinción de sexo, ni edad, ni clase social, a personas con fragilidad o vulnerabilidad, abarcando nuevas condiciones para mejorar el nivel de vida; desde el programa de órtesis y prótesis se implementan proyectos de formación para la población en situaciones especiales (heridos en combate), acordes con las necesidades del mercado laboral para mejorar el grado de empleabilidad, permitiendo el restablecimiento socio-económico a través del desarrollo e implementación de planes específicos. Según el Plan Nacional de Desarrollo 2010 - 2014 (DNP, 2010) y posteriormente en el Plan Nacional de Desarrollo 2014 -2018 (DNP, 2014) se establece la innovación como plataforma principal para dar soluciones a la población en condiciones de vulnerabilidad o fragilidad, encaminando el país hacia espacio de oportunidades sociales para lograr mejores estándares de calidad promoviendo la formación del capital humano. 


\subsubsection{Observaciones efectuadas en campo}

Se realizó la observación de campo con el papel activo de reflexión permanente, dando mayor atención a detalles, intervenciones y acciones, entre otros. También se identificaron componentes como el entorno de relaciones entre actores externos con los que se busca el fortalecimiento de alianzas con el sector público y privado, un ejemplo de ello son las alianzas que se tienen con las fuerzas militares; respecto al entorno social y humano, se evidenciaron falencias en la comunicación entre personal administrativo e instructores aunque el compañerismo entre instructores es notable; según la OCDE (2005), el mejoramiento de la comunicación y la interacción entre distintas actividades de la entidad, es un factor necesario para posicionar la innovación.

Por otra parte, en relación al entorno físico constituido por los ambientes de aprendizaje en los cuales se desarrollan las competencias del programa de formación con inmersión en espacios de práctica y de bienestar, se cuenta con tecnologías de punta al servicio de la comunidad académica; en el Manual de Oslo (OCDE, 2005), se expresa que los cambios innovadores se realizan mediante la aplicación de nuevos conocimientos y tecnología que pueden ser desarrollados internamente, en colaboración externa o adquiridos mediante servicios de asesoramiento o por compra de alta tecnología. 
Continuando, entre los ambientes de aprendizaje físicos identificados para el desarrollo de la formación se constataron los siguientes: (para mayor detalle puede referirse al Anexo No. 15).

- Ambiente de aprendizaje 1: recepción

- Ambiente de aprendizaje 2: taller para coser

- Ambiente de aprendizaje 3: taller de bancos de trabajo

- Ambiente de aprendizaje 4: taller de laminación

- Ambiente de aprendizaje 5: taller de termoformado

Hay que mencionar en cuanto a la entidad como tal, que a través de la observación de campo también se evidenció que existe el Sistema de Investigación, Desarrollo Tecnológico e Innovación del SENA denominado -SENNOVA-, el cual integra componentes encaminados a la Gestión del Conocimiento, y son: investigación; desarrollo tecnológico y competitividad; innovación, desarrollo tecnológico y competitividad; cualificaciones del SENA; redes de conocimiento y observatorios laborales.

\subsubsection{Estrategia SENNOVA.}

Resultado dado a partir de la observación hecha en campo, con inclusión de documentos, acciones por parte del área de innovación, videoconferencias e intervenciones con la comunidad académica en general, concluyendo que SENNOVA surge en el año 2013 como una estrategia concluyente de 
articulación de los proyectos y procesos enfocados a la ciencia, la tecnología y la innovación, liderado desde el SENA. También se validan los objetivos principales de SENNOVA los cuales son consolidar la competitividad institucional, cualificar al alumno, dar pertinencia y calidad en programas de formación y aumentar la competitividad del sector productivo.

Figura 20. El SENA, motor de la innovación en Colombia.

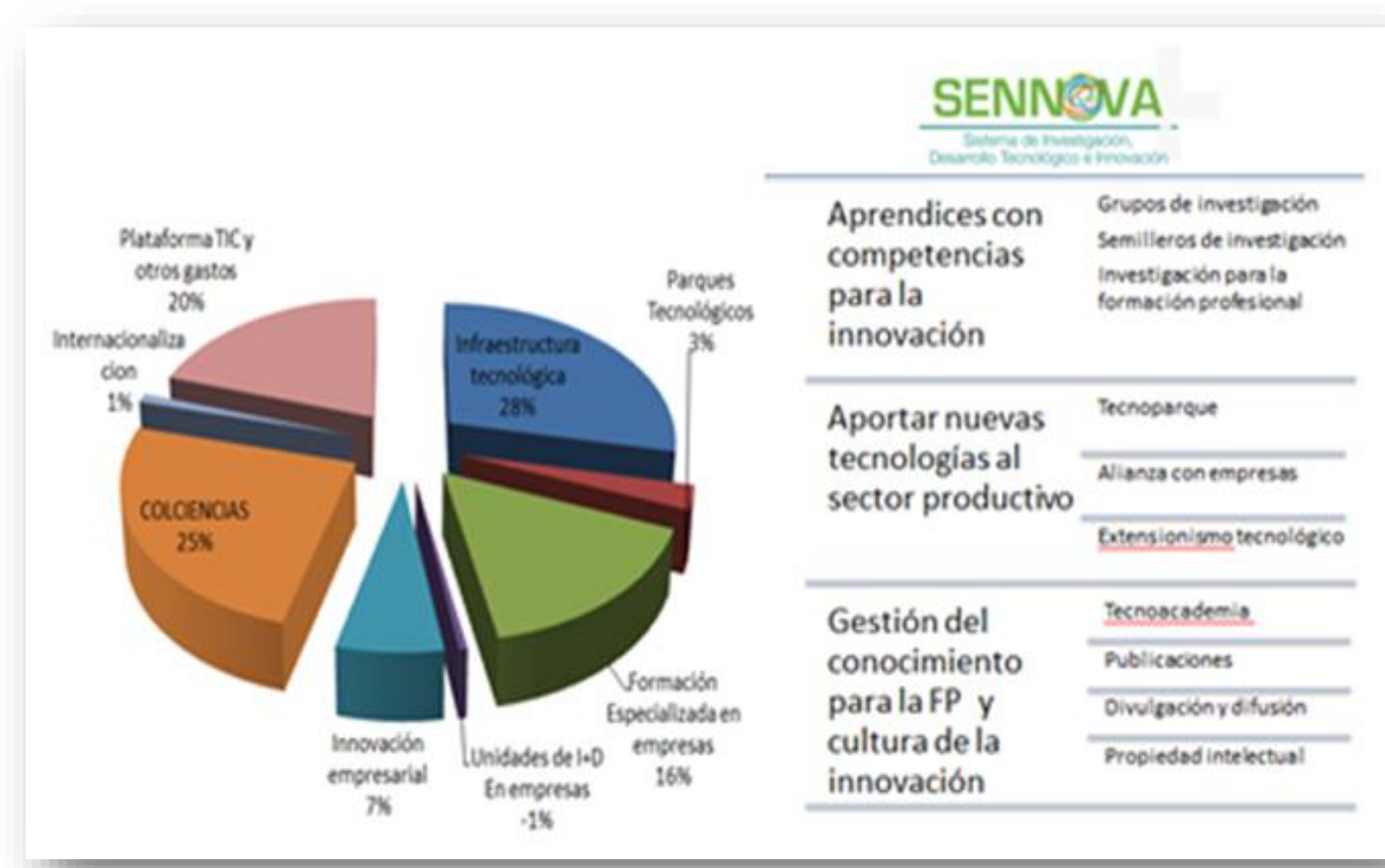




\section{Atendiendo a la asignación presupuestal ordenada para ejecución en} innovación según la ley 344, la figura inmediatamente anterior detalla los porcentajes de inversión efectuada en el año 2013, para impulsar la innovación en Colombia.

Figura 21. Actividades y procesos que estructuran el sistema SENNOVA.

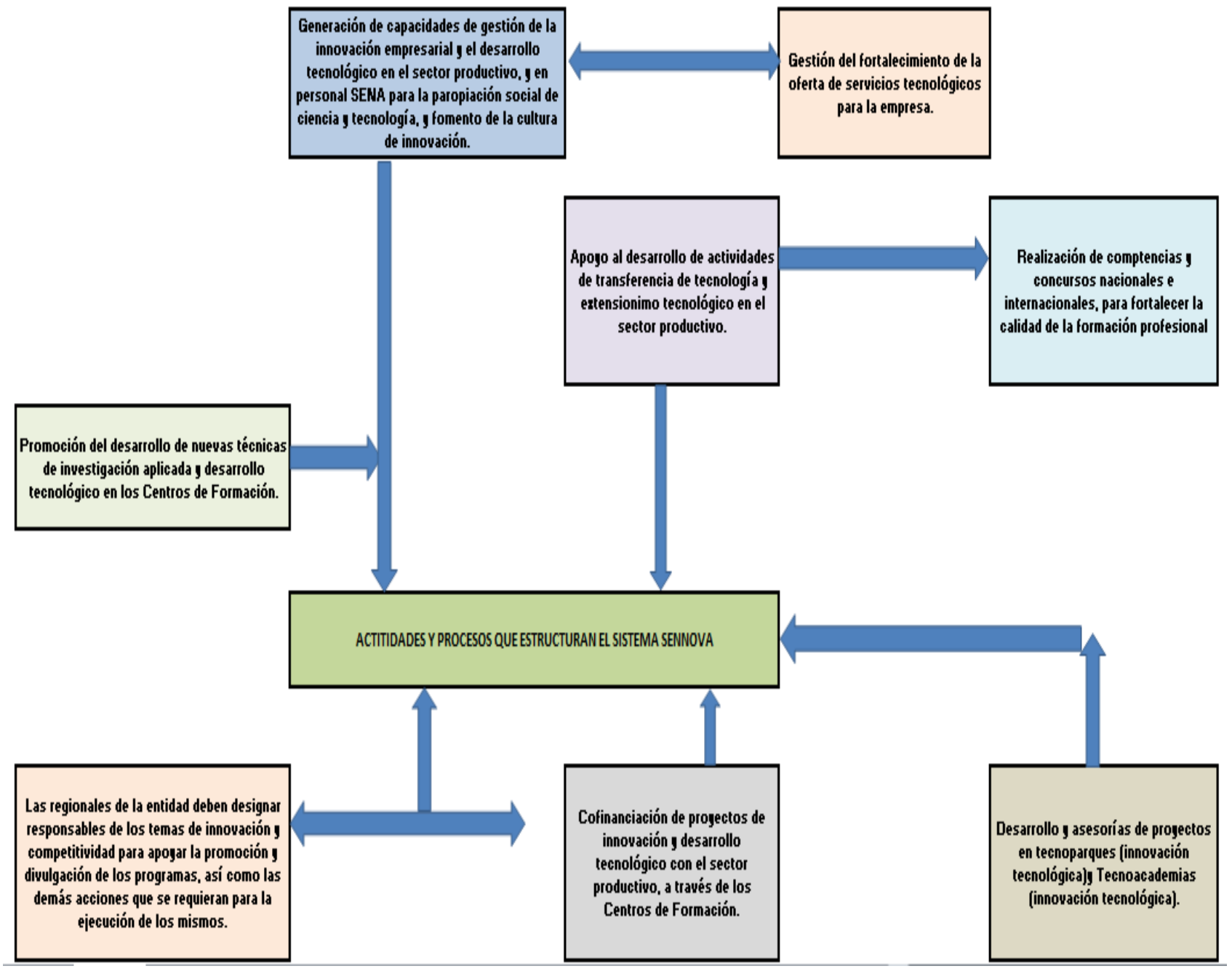

Fuente: Elaboración propia, con base en el documento "Dirección de Formación Profesional SENA (2.014)". 
En la figura se observa como existe un conjunto de ocho actividades las cuales se estructuran para consolidar el sistema SENNOVA.

En relación con la innovación social: aunque la innovación y el aspecto social forman parte de los ejes estratégicos de la institución, no se definen de manera concreta los factores de innovación social necesarios para el fortalecimiento de los programas de formación que se imparten en el SENA.

6.2 Contextualización y análisis, a partir de la triangulación de la información

La información fue contextualizada en términos de las categorías de articulación especificadas para la investigación y las variables previamente identificadas con enfoque en la cadena de valor como modelo teórico sugerido por Michael Porter (1985) integrando un conjunto de actividades y procesos articulados estratégicamente para añadir valor a los servicios de la institución, basándose en los resultados arrojados por los instrumentos aplicados, los cuales se analizaron por medio de la técnica de triangulación de métodos (INNOBASQUE, 2011).

6.2.1 Análisis dado bajo las tres etapas determinadas por los objetivos específicos planteados 


\subsubsection{Etapa A. Análisis del estado real del programa de formación}

Se establece determinando, entre otras, nociones de innovación social en la comunidad académica y la manera en que estas nociones afectan la intervención en la población beneficiaria.

6.2.1.2 Etapa B. Niveles de participación en la ejecución de la formación

Dado a partir de variables de innovación social de los actores del programa, y su impacto institucional.

\subsubsection{Etapa C. Elementos de innovación social del programa de formación,}

Con determinación de factores para fortalecimiento, y especificación de causas que obstaculizan visibilización de factores. Incluye la identificación de las características de innovación social que generan desarrollo humano.

De acuerdo a lo anterior, a continuación se muestra la estructura de la triangulación utilizada según los datos emanados de los instrumentos aplicados en la investigación, a partir de las categorías instituidas. 
Figura 22. Estructura de la triangulación de datos, a partir de las categorías establecidas.

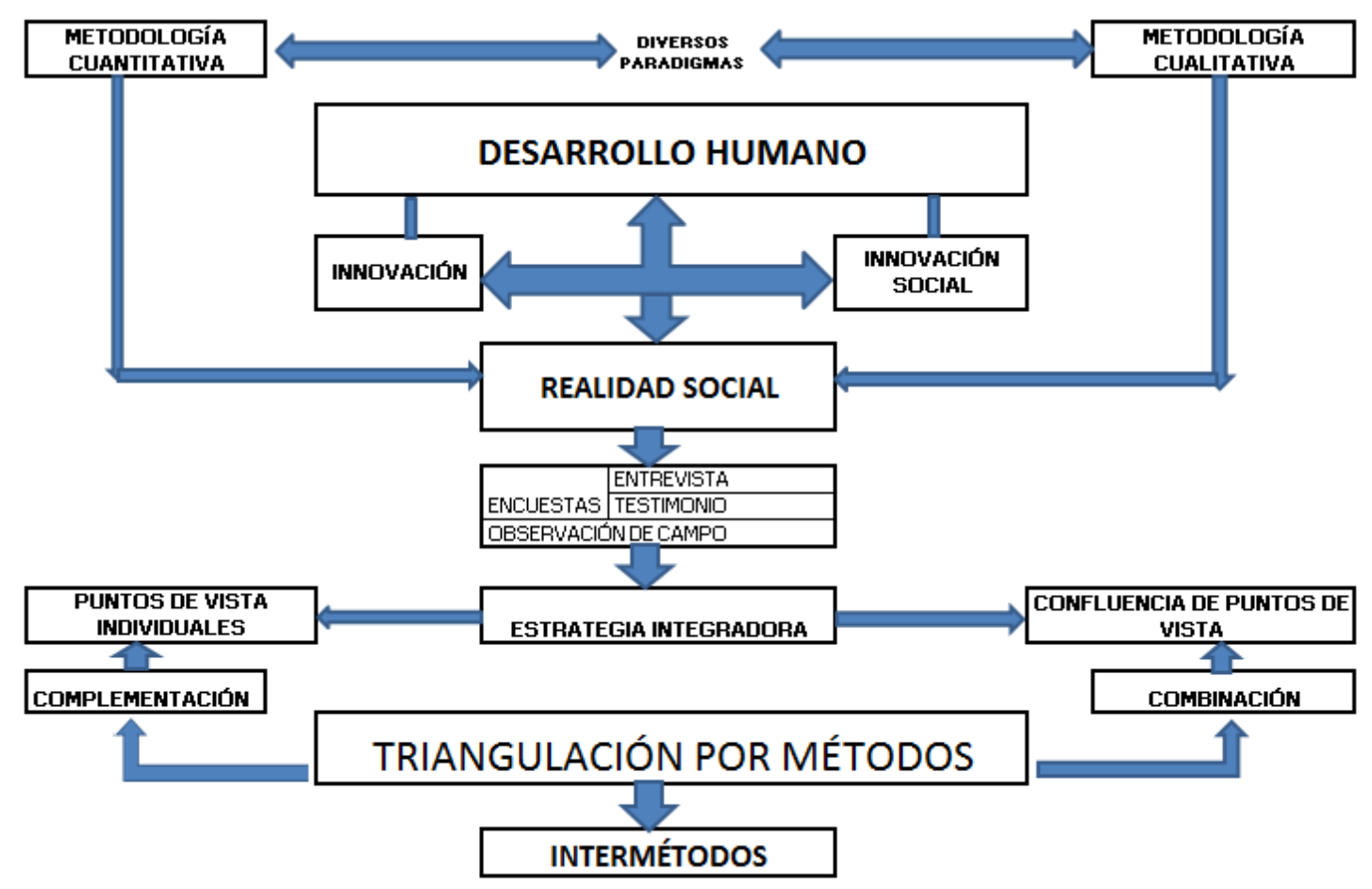

Fuente: Elaboración propia a partir del método de triangulación, categorías establecidas y los instrumentos utilizados.

En la figura anterior se especifica el proceso realizado con los datos obtenidos utilizando la técnica de triangulación (Hernández y Fernández, 2008, p. 439), a partir de los instrumentos aplicados en la investigación, permitiendo así comprender el proceso de una forma integral.

Continuando, se identifican cada una de las categorías dadas en la investigación (desarrollo humano, innovación, innovación social) y su relación con los otros componentes de la estructura, dados a partir de la integración del método cuantitativo y el método cualitativo, a fin de analizar una realidad social que incluyó la aplicación de diversos instrumentos 
(entrevista, encuesta, observación de campo y testimonio), los cuales confluyen en una estrategia integradora en la que se combinan y complementan todos sus aspectos.

6.2.2 Análisis etapa A: nociones de innovación en la comunidad académica

Determinar las nociones de innovación social en la comunidad académica del programa de formación titulada "desarrollo y adaptación de prótesis y órtesis", y la manera en que estas nociones afectan la intervención en la población beneficiaria; este análisis fue dado bajo elementos de innovación e innovación social, identificando componentes a través de la información procedente de los instrumentos y técnicas utilizadas para la recolección de datos en la investigación.

Respecto a los resultados de aprendizaje a darse en la práctica, desde el diseño del programa de formación presentado por SENA están: aplicar en la resolución de problemas reales del sector productivo, los conocimientos, habilidades y destrezas pertinentes a las competencias del programa de formación, atribuyendo estrategias y metodologías de autogestión; así pues, a pesar que se estimulan aspectos adicionales como el manejo de tecnología informática, el trabajo colaborativo, la autocrítica y la reflexión, elementos identificados por Moreira (DNP, 2013), no se evidenciaron resultados de aprendizaje conectados concretamente con la innovación, y menos con la innovación social. 
En ese orden de ideas, en cuanto a los ambientes de aprendizaje, se disponen de herramientas y equipos adecuados para el desarrollo de los productos dando amplitud a la creatividad y apalancando comportamientos innovadores, con tecnología de última generación que incluye el desarrollo de prototipos, las zonas de pulido, de yesos, de laminación y termoformado, almacén, pruebas dinámicas, toma de molde y análisis de marcha; el PNUD (2014), y autores como Sen (2000) y Nussbaum (2007), coinciden en el hecho que debe existir un ambiente adecuado donde los individuos puedan desarrollar sus capacidades y así ampliar sus opciones para llevar una vida cálida y productiva. Para mayor detalle, puede ver el Anexo No. 15, correspondiente a los ambientes de aprendizaje en donde se imparte la formación del programa de órtesis y prótesis.

Por otro lado, se evoca nuevamente, debido a su importancia, que el $100 \%$ de los aprendices cuestionados son de sexo masculino, discapacitados por heridas en combate, pertenecientes en su gran mayoría (86\%) de la Policía Nacional y al Ejército; además, provienen de 12 departamentos del país, lugares a los que retornarán a ejercer su profesión en el momento que reciban su título en el SENA.

De acuerdo a lo anterior, se refleja que la implementación de programas de formación dirigidos a personas con discapacidad, como estrategia que incluye diversos actores privados y gubernamentales, interactuando con la disposición de recursos para inversión, entre otros, de tecnología, infraestructura y materiales, necesarios para la ejecución y 
escalabilidad del proyecto transformando el conocimiento en un producto y servicio que busca suplir necesidades sociales.

\section{Variable: innovación}

Atendiendo a los resultados obtenidos se determinó que la innovación es abierta, más no tradicional, ya que conjuga actores internos (aprendices, instructores, personal administrativo) y actores externos como son las entidades privadas como la GIZ, Universidad Don Bosco del Salvador, Otto Bock, Mercy Corps, y Cruz Roja, entre otros, para el desarrollo del proceso (Chesbrough, 2011, p. 2), además aprovecha la inteligencia colectiva implicando el potencial de la comunidad académica, quienes son conocedores de sus capacidades y conocimientos para efectuar procesos encaminados al desarrollo humano, mejorando así la calidad de vida de la población, confirmado por Moreira (DNP, 2013); se destaca la colaboración y la multidisciplinariedad de los actores presentes en la comunidad académica.

Igualmente, a partir de los ejes de las actividades que se consideran innovadoras, el tipo de innovación definido es "organizativa" (Rodríguez y Alvarado, 2008, p. 23), donde se implementan prácticas direccionadas a la inclusión de nuevos clientes como es la población discapacitada para la ejecución del servicio educativo, es decir, el desarrollo de la formación.

Así la situación y partir de la triangulación de datos realizada, se identifica una innovación inmersa en el cambio significativo del servicio 
educativo prestado por la entidad, diseñando e impartiendo un programa de formación nivel tecnólogo, con alta demanda por parte del sector productivo debido a la baja oferta a nivel nacional y escaso personal calificado para el desarrollo de las actividades especializadas en prótesis y órtesis.

Continuando, el programa tiene dentro de sus características especiales, el que articula de forma simultánea actores como son aprendices en formación, que no sólo son población vulnerable, para el caso las personas heridas en combate, sino que también serán beneficiarios de la órtesis y prótesis que ellos mismos fabrican como producto del programa de formación como resultado de la formación por proyectos; además, los aprendices que finalicen con éxito el programa de formación, tendrán derecho a recibir un título para salir a sus respectivas regiones de origen a laborar en el oficio aprendido, optimizando su calidad de vida y ayudando así a mejorar condiciones de otras poblaciones también discapacitadas.

Así, desde las condiciones para la formación, se determinó que el programa incluye la tecnología adecuada y espacios físicos requeridos para el desarrollo de la formación; también se confirmó que el acceso a las herramientas, recursos y elementos necesarios para lograr los resultados de aprendizaje se da en un alto porcentaje, ampliando así los espacios para la innovación, ya que el $67 \%$ de los instructores encuestados, muestra 
considerada como representativa según Hernández (2008), estuvieron "totalmente de acuerdo", y el 33\% estuvo "de acuerdo".

En esta misma dirección, respecto a los resultados de los aprendices enfocados a las condiciones para la formación, se encontró que el 50\% de los aprendices encuestados coinciden en el hecho que existen las condiciones para la formación del programa incluida la motivación, se tiene acceso a los ambientes de aprendizaje asociados al programa, se cumplen con las expectativas generadas, se afianzan las estrategias pedagógicas concertadas, hay oportunidad de interactuar con los instructores, claridad en los servicios de apoyo, bienestar y emprendimiento, así mismo, a través del programa se identifican oportunidades para solucionar dificultades del entorno social; también existen en el programa elementos de innovación, el programa es una solución al problema social, y hay elementos que ayudan al mejoramiento de la calidad de vida de la población en camino al desarrollo humano. La CEPAL (2008) enuncia que los gobiernos tienen la obligación de apoyar las diferentes soluciones que nacen en la innovación social, puesto que son retos para replicar acciones relacionadas con experiencias subjetivas y procesos de aprendizaje colectivo.

En lo que refiere a los aspectos de investigación y fortalecimiento, el $33 \%$ de los instructores encuestados consideran que no se les asigna el suficiente tiempo para el desarrollo de la investigación, que no han recibido acciones de capacitación para el fortalecimiento de su perfil como profesional en el área y que no han tenido la oportunidad de socializar el 
proyecto formativo con entes externos al SENA; la OCDE (2005) enfatiza en la importancia de asignación de tiempo para investigación en los procesos de innovación. Adicionalmente, en el aspecto de transferencia a nivel interno del programa, el $100 \%$ de los instructores estima que existe transferencia interna de tecnología y conocimientos. Se evidencia la necesidad de fortalecer espacios para la investigación.

* Variable: generación de valor social

A partir de los principios que se atribuyen a la innovación social y la triangulación de los resultados obtenidos de los instrumentos, se determinó que la innovación hallada contribuye al desarrollo social reduciendo la pobreza como aspecto del desarrollo humano, ya que se fortalecen las comunidades a través de la oportunidad de estudiar gratuitamente desarrollando competencias que servirán para ampliar las posibilidades en el mundo laboral (CEPAL, 2013), en un sector poco explorado en Colombia y con necesidad de demanda en el sector empresarial.

Continuando, se constató el enlace entre innovación social, reducción de la pobreza, transparencia de la gestión pública y afianzamiento de la democracia (CEPAL, 2008); a su vez, el proceso de innovación social dado consolida el ente gubernamental empoderando la comunidad académica, especialmente los aprendices con el desarrollo de competencias que contribuyen al fortalecimiento en los resultados de aprendizaje, incidiendo 
de manera positiva en la intervención de la población beneficiaria como es la comunidad con discapacidad.

Figura 23. Características del programa de prótesis y órtesis.

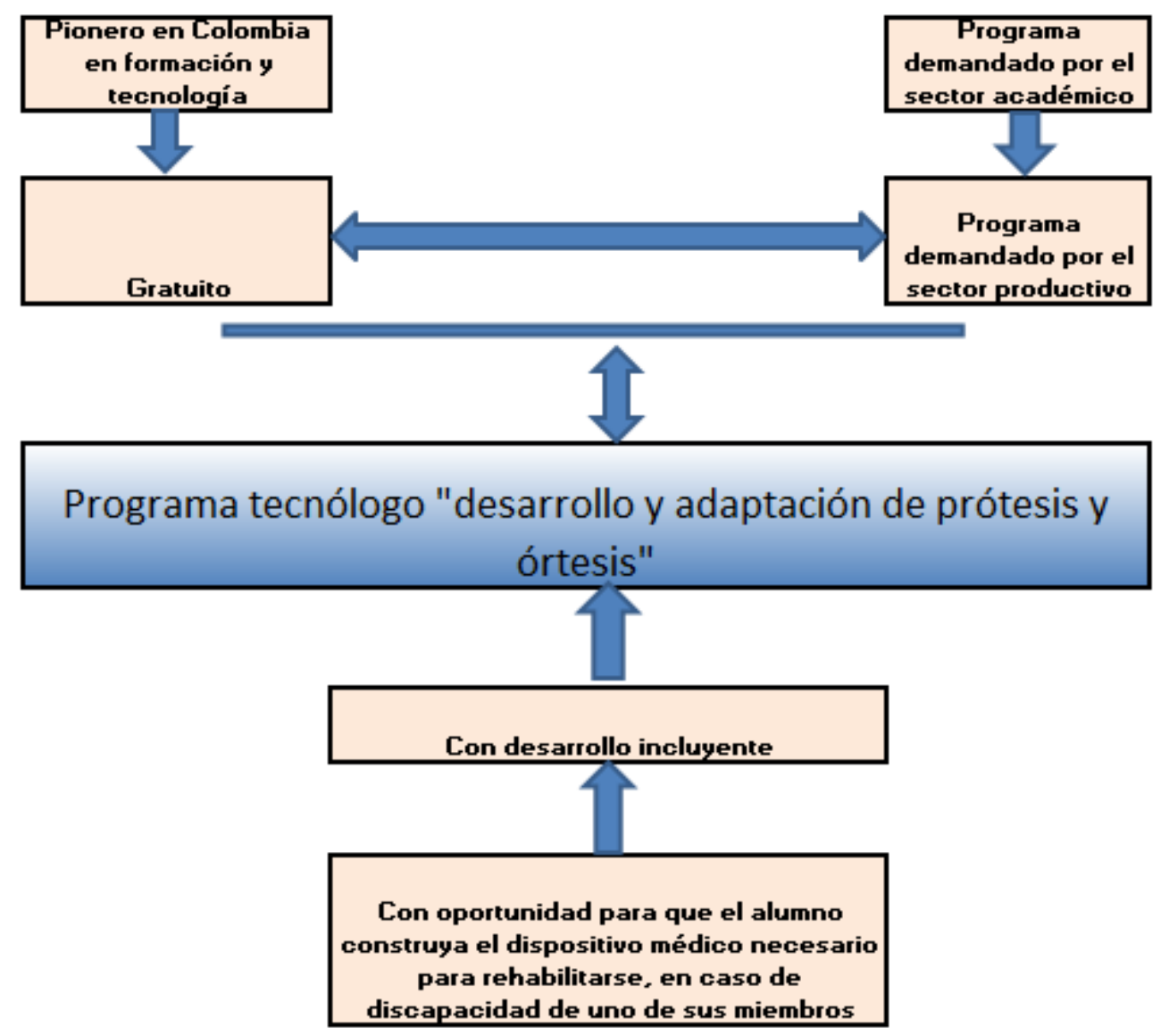

Fuente: elaboración propia a partir de resultados obtenidos con los instrumentos aplicados.

En el mismo contexto, y a partir de la figura presentada según características identificadas, se estableció que además hay potencial para política pública nacional, con la debida articulación entre entidades del Estado, ya que se evidencian públicamente posibles soluciones estructurales a necesidades que no se pueden dejar de lado por parte del gobierno, como 
es el caso de la erradicación de la pobreza, formando gratuitamente a la población para el ingreso al mundo laboral (ANSPE, 2014), superación de la inequidad dando oportunidad de formarse a cualquier clase social de población que cumpla con ciertos requisitos académicos, inclusión social abriendo el ingreso a la formación de la población con discapacidad (DNP, 2014), generación de ingresos con la obtención de una titulación que servirá para ubicación en el mundo laboral.

Simultáneamente, entre los factores que impulsaron a la comunidad académica, para el caso los directivos del Centro de Formación de Diseño y Metrología, hacia el área de la innovación introduciendo nuevas prácticas en el programa de formación fueron: la búsqueda de reducción del plazo de respuesta a las necesidades tanto del sector productivo en cuanto a demanda de personal calificado, como de las personas con discapacidad respecto a la demanda de formación pertinente y de bajo costo para tener mayores oportunidades de ingreso en el mundo social y laboral, enfocado en el desarrollo incluyente dado que se comprende la discapacidad desde el punto de vista de los derechos humanos, según lo expresado por Weigt (2014).

Otro factor importante que motivó el impulso de esta innovación fue el desarrollo humano a partir de la búsqueda del mejoramiento de la calidad de vida de una comunidad (CEPAL, 2014), razón por la cual se decidió entregar un elemento que mejora las funciones de un cuerpo con discapacidad como producto de un programa de formación profesional a 
desarrollarse a partir de competencias, propiciando el aumento de la adaptabilidad a las necesidades de los clientes, estableciendo relaciones más estrechas con los usuarios y mejorando condiciones laborales; adicionalmente este programa se diseña con otro fin, como es la educación gratuita que abre oportunidades para la obtención de un empleo digno.

Así la situación, según resultados arrojados por los instrumentos aplicados, se estableció que el 100\% de los instructores encuestados consideran que las personas beneficiadas de los dispositivos médicos que se desarrollan en el Centro de Formación, dentro del programa en el proyecto formativo, mejoran la calidad de vida de las familias favoreciendo el desarrollo humano (PNUD, 2015), se dan nuevas posibilidades laborales, aportan solución al problema social e incluyen componentes de innovación social. Además, como aportes al mejoramiento de la calidad de vida, identificados por los aprendices, están: son nuevos programas de formación para la población colombiana, hay colaboración y apoyo para la población por el conflicto armado, se fortalece la formación intelectual y el desarrollo de nuevas competencias (DNP, 2010), mejora la calidad de vida de las personas amputadas de cualquier extremidad, ayuda a la recuperación de personas afectadas por cualquier accidente, es una oportunidad para la población colombiana, habrán mayor número de profesionales en el área.

De igual modo, la optimización de la flexibilidad y prestación del servicio educativo del programa ha evolucionado por medio de la modernización de los ambientes de aprendizaje con última tecnología e 
infraestructura física, el aumento de la capacidad de prestación del servicio, la reducción de costos de diseño de los productos, la reducción de tiempos en la producción de los dispositivos, la mejora de la capacidad tecnológica, la búsqueda del cumplimiento de normas técnicas en el sector de la actividad internacional, es decir de ISPO, para llegar en un momento dado a la acreditación internacional. La visita de la ISPO para la acreditación internacional de los ambientes de aprendizaje y del programa de formación está confirmada para el mes de septiembre de 2015.

No obstante, y aunque se desee impulsar la innovación como tal, la comunidad académica, constituida por aprendices, instructores, y funcionarios administrativos, deben solucionar las barreras que obstaculizan la efectiva intervención en la población beneficiaria, como son:

-Mejorar la comunicación. La falencia en cuanto a comunicación entre actores de la comunidad académica impide el intercambio de conocimientos, a fin de fortalecer los aspectos detectados como innovaciones sociales.

-El desconocimiento de los factores que potencian la innovación social por parte de algunos funcionarios administrativos, conllevando al desajuste financiero respecto a los recursos asignados para la compra de materiales de formación del programa vs los costos reales del material para la fabricación de los dispositivos, los cuales son muy elevados (costo vs conocimiento). 
-La poca divulgación en los medios de la labor que realiza el programa de formación a nivel social, obstaculiza la visibilización del mismo por parte de la comunidad necesitada conllevando a la débil búsqueda del servicio por parte de los pacientes que lo requieren.

-Debilidad para encontrar socios de cooperación. Las alianzas entre el sector público y privado son insuficientes para soportar los compromisos visualizados desde el programa de formación, producto del desconocimiento de las nociones de innovación social.

-El tiempo destinado para actividades de investigación debe ser suficiente para el desarrollo de conocimiento direccionado a la innovación, a mayor investigación hay mayores posibilidades de innovación.

\subsubsection{Análisis etapa B: niveles de participación de actores}

En esta fase se especifican los niveles de participación en la ejecución de la formación, de los actores del programa, además del impacto institucional, establecido a partir del análisis de los resultados emanados. Para determinar los niveles de participación de los actores del programa de formación, se debe anotar que la innovación se presenta en un entorno del sector público, abordando el servicio de formación para el trabajo de 
manera gratuita, específicamente para la comunidad discapacitada; impulsando así procesos y toma de decisiones con el ánimo de arrojar productos de innovación a partir de procesos formativos.

De acuerdo con lo anterior, la innovación identificada en el programa de órtesis y prótesis no se desarrolla de forma aislada ya que incluye diversos actores identificados en el proceso, y son: instructores, aprendices, funcionarios administrativos, comunidad en general, entes gubernamentales y entes privados. Así, según los resultados de los instrumentos aplicados y el análisis de la información por medio de la triangulación, se constataron niveles de participación de los actores, especificados a continuación desde la variable de participación de la comunidad, y colaboración intersectorial.

Variable: participación de la comunidad

Con los resultados obtenidos se estableció una participación activa de la comunidad beneficiaria, es este caso, los aprendices, quienes además de recibir formación, fueron partícipes del producto de dicho proceso.

De otro lado, partiendo del hecho que la innovación social del programa es impulsada por un ente gubernamental, el SENA, particularmente por el Subdirector del Centro de Formación de Diseño y Metrología (innovador social) en conjunto con su equipo administrativo(actores de soporte), sin un constante apoyo de algunos funcionarios, se procedió a analizar los instructores (actores de soporte) y 
aprendices (actores de soporte) involucrados determinando su amplio compromiso con la causa de tal forma que buscan un máximo de aprovechamiento intelectual, convirtiéndose en actores principales de su propio bienestar y no sólo receptores pasivos de los beneficios. Para INNOBASQUE (2011), la innovación social incluye un proceso participativo de colaboración de personas con el objetivo de transformar situaciones sociales.

Conjuntamente, se destacó el trabajo colaborativo entre docentes, quienes, aunque no cuentan con espacios de tiempo concretos para la generación de procesos y actividades articuladas con la investigación, identifican y aprovechan momentos para resolver conjuntamente las adversidades, generando así capacidad de trabajo direccionado a la óptima ejecución del programa de formación.

A su vez, la comunidad es otro de los actores de gran importancia en el proceso innovador por su responsabilidad como gestor de su propio desarrollo, seguimiento al proceso y su capacidad para proponer ajustes a la innovación dada, desde sus propios problemas. La participación de la comunidad es una característica relevante para que se dé la innovación (DNP, 2013).

* Variable: colaboración intersectorial 
La participación activa de actores públicos y privados en el proceso da lugar a espacios académicos de gran interés donde las instituciones gubernamentales y privadas juegan un rol decisivo para el desarrollo y escalamiento del programa de formación, vinculándose al mismo de forma progresiva, a través de alianzas y/o convenios, entre otros (CEPAL, 2013), según los resultados del programa, hasta el punto que pueden llegar a convertirse en sus promotores, fortaleciendo así el impacto institucional.

Así pues, entre las instituciones que actualmente se encuentran vinculadas están la GIZ, Universidad Don Bosco del Salvador, Otto Bock, Mercy Corps, y Cruz Roja

Simultáneamente, a través del estudio del proceso dado desde la cadena de valor basada en el concepto de Weigt (2014), identificado plenamente con las acciones originadas en el programa, implicados aspectos como análisis de la realidad social, generación de conocimiento, proceso de transformación social, sensibilización, difusión, y, dinamización y colaboración (CEPAL, 2013), se encuentra que las decisiones importantes necesitan más tiempo ya que incluyen varias personas, cada actor individual tiene un control parcial, cada actor parcial tiene un control individual sobre las actividades que se comparten, cada actor individual pierde algo de flexibilidad e independencia.

Cabe señalar que el enfoque de la innovación social también influye para los niveles de participación de los actores en cuanto a la ejecución del 
programa, razón por la cual se presentan a continuación las orientaciones identificadas en el programa de formación: se establece que una de las orientaciones del programa de formación es sociológica, ya que hay un cambio en la sociedad, donde la comunidad académica tiene un rol como actor importante frente a otras organizaciones; simultáneamente existe del mismo modo, un enfoque económico en el cual la innovación social actúa como servicio de formación para el trabajo satisfaciendo así una demanda social, con un papel protagónico para la organización; otro enfoque evidenciado es el de ciencia política, dado como un proceso que consolida cambios en las relaciones sociales tomado como elemento de justicia social; también está el enfoque participativo ya que el proceso genera confianza entre comunidades responsables de sus capacidades y sus propios desarrollos. Se busca crear un cambio social, impulsado por la motivación de función social y creación de valor compartido.

6.2.4 Análisis etapa C: descripción bajo elementos de innovación social definidos

Descripción del programa de formación referenciado bajo los elementos de innovación social definidos, teniendo en cuenta las variables establecidas, para finalmente determinar los factores de innovación social necesarios en el fortalecimiento del mismo; encontrar las causas que obstaculizan la visibilización de dichos factores. Identificación de las características de innovación social que generan desarrollo humano. 
La generación del conocimiento y su aplicación posterior a las necesidades reales de la población, se establecen en el estudio del programa de órtesis y prótesis, añadiendo un valor adicional al servicio de la formación el cual es devolver a las personas su corporalidad, motivo por el cual es importante fomentar la sensibilización expresada como resultante de la transformación social del pueblo (CEPAL, 2013), así como la difusión del programa de formación.

Este programa es una respuesta clara para la coyuntura que vive el país, atendiendo de forma contundente tanto a nivel laboral como educativo y físico, las necesidades de la población discapacitada (DNP, 2010).

Ahora, se presenta un análisis del programa de formación originado por las fases establecidas para la innovación social, así: creación, desarrollo, sostenimiento, escalabilidad (CEPAL, 2013).

-Creación: teniendo en cuenta que esta fase surge de la percepción de necesidades sociales no resueltas, donde se establece el problema y el reto, se puede afirmar que la necesidad nace de la población discapacitada quien solicita ayuda para vincularse laboral y socialmente a una sociedad, por el sector académico consecuencia de la reducida oferta a nivel nacional y por la demanda del sector productivo respecto a la necesidad de personal capacitado en órtesis y prótesis para vinculación. Reto: diseñar un programa de formación que cumpla con expectativas académicas, productivas y de la población con discapacidad. 
-Desarrollo (experimentación): la puesta en marcha de la propuesta inició en el año 2009, incluyendo un ejercicio piloto con dos grupos, en total cincuenta (50) aprendices, que entran a formación en el año 2010, incidiendo así en la celeridad para modernizar los ambientes de aprendizaje incluyendo la capacidad tecnológica. Posteriormente se abre la oferta para nuevos grupos, y se contratan instructores capacitados en la Universidad del Salvador; el total de aprendices formados desde el año 2010 son doscientos once (211) aprendices. La debilidad encontrada fue entre otras, la baja infraestructura física ya que está quedándose pequeña para atender los nuevos aprendices, comparando con la demanda del sector productivo.

\section{* Variable: sosteniblidad}

Partiendo del hecho que la variable incluye ejecución de estrategias para sostenimiento del programa de formación, se puede establecer que éste trata de consolidar sus aspectos financieros por medio de la cooperación con entidades del sector privado y con la conformación de alianzas con otras instituciones que permitan la sostenibilidad del programa, en DNP (2013), incluye la sostenibilidad como herramienta fundamental de la innovación social y del crecimiento y desarrollo de los procesos sociales que impulsarán la competitividad y el progreso de Colombia; habría que agregar que el SENA como ente del gobierno y siendo su misión principal la formación, destina parte de sus recursos para acciones de oferta y 
ejecución de todos los programas de formación en camino a la sostenibilidad.

En cuanto a los aspectos de difusión del programa, fuera de los que efectúa la página principal del SENA con la oferta regular, se hacen también otras difusiones del programa a mínima escala, motivo que hace necesario fortalecer la comunicación masiva del mismo en otras instancias.

Con respecto a mecanismos y procesos consolidados del programa, se puede afirmar que éste cuenta con un diseño que incluye las competencias laborales necesarias para generar un aprendiz con el perfil de egreso requerido por el sector productivo, pero es necesario incluir en cualquier parte del proceso aspectos de innovación social, generando resultados que inciten a la innovación dentro de la ejecución del programa. Actualmente se está gestionando el fortalecimiento y actualización del diseño en cuanto a competencias técnicas del programa se refiere, con acompañamiento del Ministerio de Salud y Protección Social.

De igual modo, se puede afirmar que el programa cubre un nicho de mercado en donde no hay muchas alternativas, dando un valor agregado como es el desarrollo incluyente. 
* Variable: escalabilidad

Atendiendo a que esta variable mide el crecimiento del servicio continuo sin la pérdida de la eficiencia del mismo (CEPAL, 2013), se encontró que el programa de formación ha logrado sus objetivos de sostenibilidad, ampliando el servicio a otras comunidades, con 50 aprendices que inician formación en el año 2010 y un total de 211 aprendices (titulados y en formación) para el año 2015, con optimización de espacios y ambientes de aprendizaje.

Así, la infraestructura física de los ambientes fue modernizada con dotación de tecnología de punta en pro de la acreditación internacional a darse desde el organismo con sede en Alemania, denominado ISPO. De otro lado, de los instructores se puede decir que se amplió la planta con la contratación de instructores egresados de la Universidad del Salvador, líder en formación de orto-protesistas con categorización internacional; es de agregar que actualmente el programa cuenta con instructores alemanes fortaleciendo así los procesos formativos.

* Variable: replicabilidad

El resultado también arrojó que existe potencial de éxito, con elevada probabilidad de aceptación, socialización y escalabilidad en su aplicación (CEPAL, 2013), resolviendo dificultades de personas discapacitadas como son las carencias sociales, físicas y emocionales a través del servicio de 
educación para el trabajo (DNP, 2014); paso a seguir es la réplica de las acciones, para así compartir su aplicación en otros lugares con otros actores.

Después de establecer resultados y la forma efectiva de resolver un problema social, es necesario ampliar la escalabilidad del proyecto, para lo cual se propone diseñar y adquirir un aula móvil que incluya autonomía para su movilidad y un ambiente de aprendizaje interno, generada por cooperación con otras instituciones, además, de forma simultánea otra es necesario realizar la ampliación de la infraestructura física y tecnológica del Centro de Formación; otra opción que se propone es la réplica del modelo para que sea impartida la formación en otros Centros SENA del país.

Se debe agregar que, en el SENA se desarrolla la investigación aplicada, ya sea en alianza con el sector productivo o directamente en el Centro de Formación, fundamentada en tres pilares que consolidan los servicios para el desarrollo de la formación: innovación del capital humano; la innovación empresarial y emprendimiento innovador; ciencia y tecnología. Como se pudo identificar, aunque uno de los ejes de la entidad es enfático en la innovación, no se da oportunidad a referirse directamente a la innovación social, abriendo más puertas para el sector tecnológico y productivo. 


\section{CONCLUSIONES}

El concepto de innovación entendido en su componente social implica un proceso de creación, difusión y puesta en marcha de respuesta a las necesidades de la población, en búsqueda del mejoramiento de prácticas orientadas al cambio transformador en la optimización de la calidad de vida de una comunidad que mira hacia la construcción de una sociedad incluyente, a través de la formación profesional por medio del desarrollo de capacidades, abriendo espacio al desarrollo humano. A su vez, la CEPAL (2013), ha confirmado que es indispensable la incorporación de soluciones sociales innovadoras que se encaminen, particularmente y en forma detallada en cada país, para identificar factores a escala zonal que lleguen a influir en el desarrollo humano vinculado a la capacidad de innovación.

Es así como Colombia, registra en el documento Pre-CONPES de innovación social 2014, la necesidad de robustecer dentro de sus componentes claves, los servicios de soporte a la innovación social como herramienta fundamental de la sostenibilidad, del crecimiento y desarrollo de los procesos sociales, basados, entre otros, en los procesos de gestión del conocimiento potenciando el capital humano a través de la formación para el trabajo, como condición de vida que alivie a las personas más necesitadas (BID, 2015, p. 9).

Por ende, nace la importancia de visibilizar características que permitan identificar los factores de innovación social que apuntalen la 
ejecución de los programas de formación a impartirse a través del desarrollo de competencias, como es el caso del programa de formación denominado "desarrollo y adaptación de prótesis y órtesis", curso de formación titulada único en Colombia, diseñado en el 2009 e impartido en el SENA, donde los aspectos para determinar los factores de innovación social generados en el programa de formación, aún no son claramente identificados para poder efectuar el respectivo fortalecimiento $\mathrm{y}$ visibilización; por consiguiente, para identificar los aspectos referidos, esta investigación fue realizada tomando como base las categorías de: desarrollo humano, innovación, innovación social y cadena de valor.

De otra parte, la investigación recoge el enfoque cualitativo y cuantitativo, y se centra en un estudio de caso que se vale de herramientas de la investigación mixta integrando sistemáticamente un proceso de recolección, análisis y vinculación simultánea de datos cuantitativos y cualitativos a fin de obtener una fotografía más completa del asunto en análisis, y así lograr hallazgos complementarios que permiten desarrollar el conocimiento relativo alrededor del tema en referencia (Hernández y Fernández, 2008, p. 26).

De ahí que, las tres etapas para esta investigación se establecieron de la siguiente forma: la primera comprendió el análisis del estado real del programa de formación profesional en órtesis y prótesis, según elementos de innovación e innovación social, determinando nociones de innovación social en la comunidad académica por medio de la identificación de los 
principales componentes de la innovación y cómo estas afectan su intervención en la población beneficiaria, dada a través de información procedente de las técnicas e instrumentos para la recolección de datos utilizados en la investigación; la segunda etapa consistió en la especificación de los niveles de participación de los actores del programa a partir del análisis de los resultados emanados; la tercera apuntó a la descripción de los elementos de innovación social del programa de formación profesional referenciado teniendo en cuenta las variables establecidas, para finalmente determinar los factores de innovación social necesarios en el fortalecimiento del mismo.

De esta forma, la población de estudio abarcó la comunidad académica plasmada en los actores del programa de formación titulada modalidad presencial "diseño, desarrollo y adaptación de prótesis y órtesis", impartido en el Centro de Formación de Diseño y Metrología - Regional Distrito Capital, del SENA.

También, para el logro de los objetivos y debida recolección de datos, se utilizaron los siguientes instrumentos: la entrevista semiestructurada, encuesta aplicada a instructores a través de la herramienta del cuestionario, encuesta aplicada a aprendices a través de la herramienta del cuestionario, testimonio de aprendiz con discapacidad física y actualmente en formación, y la observación de campo. Así mismo, las variables definidas en esta investigación se basaron tanto en los criterios dados por la CEPAL para evaluar los proyectos de innovación social, como en las fases establecidas 
en el seminario taller "Los retos de la innovación social en Colombia" efectuado en la ciudad de Bogotá, en el año 2013; estas variables fueron: innovación, generación de valor social, participación de la comunidad, potencial de sostenibilidad, potencial de escalabilidad, potencial de replicabilidad y colaboración intersectorial.

Continuando, a fin de aumentar la validación de los resultados obtenidos y disminuir los problemas de sesgo se utilizó la técnica denominada triangulación, la cual consiste básicamente en la combinación de diferentes fuentes de datos emanadas de los instrumentos utilizados, integrando resultados cuantitativos y cualitativos en el mismo estudio de investigación. Entre las ventajas de la técnica están la productividad en el análisis y recolección de datos para dar mayor validez de los resultados (Hernández y Fernández, 2008, p. 439), más proximidad del investigador al objeto de estudio, integración de métodos e instrumentos, aumentando la garantía de la investigación disciplinaria y aproximación al entendimiento de la realidad en los procesos dinámicos (Denzin y otros, 2005, p. 2).

De igual manera, el tipo de triangulación utilizada para esta investigación fue de métodos, basada en los instrumentos aplicados, el procedimiento y el tratamiento de la información, sumando productos cualitativos y cuantitativos de forma simultánea (intermétodos: método cualitativo y método cuantitativo), ya que mejoran el diagnóstico sintetizado en los resultados derivados del cruce de la información, en una interpretación válida y coherente. (Bericat, 1998, p. 372) 
Por consiguiente, para realizar la caracterización del programa de formación denominado "desarrollo y adaptación de prótesis y órtesis" nivel tecnólogo, implementado en el SENA y con el ánimo de identificar los factores de innovación social necesarios en pro de su fortalecimiento, se clasificaron las características y los hallazgos, emanados de la determinación de las nociones de innovación social en la comunidad académica del programa de formación y la manera en que estas nociones afectaron la intervención en la población beneficiaria, también se especificaron los niveles de participación de los actores del programa en la ejecución de la formación a partir de variables de innovación social, y su impacto institucional; y por último se describió el programa bajo elementos de innovación social definidos.

\subsection{La caracterización del programa de formación}

-El SENA se encarga de formar el capital humano con un enfoque de aporte al desarrollo regional, con competencias de análisis y comprensión de los contextos globales, e integrando este proceso de formación con las necesidades de desarrollo regional, a través de mecanismos de generación de ingresos.

-El programa de formación en órtesis y prótesis fue diseñado para atender necesidades del sector productivo en el área de la salud (biomédica), en búsqueda de la contribución al desarrollo social, económico 
y tecnológico de la nación; es una formación relativamente nueva en Colombia.

-La innovación dada en el programa de formación es abierta más no tradicional, integrando tanto actores internos SENA (comunidad académica), como entes externos articulados con el sector productivo.

-El desarrollo del proceso formativo aprovecha la inteligencia colectiva implicando el potencial de la comunidad académica, quienes inciden en la evolución de nociones de innovación (instructores y aprendices).

-El análisis de las nociones de innovación social en la comunidad académica desprende un enlace entre gestión pública e inclusión social, direccionada al desarrollo de las personas con discapacidad de miembro superior o inferior.

-El SENA y la comunidad académica del programa, buscan favorecer la población en general a través de la oportunidad de estudiar gratuitamente, a fin de desarrollar competencias que sirvan para ampliar las posibilidades en el mundo laboral, contribuyendo así al desarrollo social para el mejoramiento de la calidad de vida de la población (comunidad discapacitada). 
-A través del programa en referencia se identifican oportunidades para solucionar dificultades del entorno social; la comunidad académica es consciente de la existencia de entornos de innovación a partir de novedades que aportarán a la solución de un problema social (elemento de replicabilidad en innovación social), mejorando la calidad de vida de la población. Por tanto, el desarrollo humano empieza a ser un pilar para el programa de formación.

-Para la comunidad académica, el desarrollo humano es tomado como impulso al camino de la innovación en pro de solución a necesidades de población posteriormente intervenida, aumentando la adaptabilidad a las necesidades de los beneficiarios para abrir oportunidad a un empleo digno.

-El 37\% de los instructores como parte de la comunidad académica manifestaron que no se les asigna el suficiente tiempo para el desarrollo de la investigación, influyendo así en el debilitamiento de opciones para la generación de ideas y creación de procesos que intervengan a la población beneficiaria, solucionando problemas de índole social; el fin es el desarrollo de la innovación.

-En cuanto a las condiciones de la formación, es necesario abrir camino hacia procesos innovadores. De esta forma y a fin de brindar mayor calidad en el desarrollo del programa tanto a comunidad académica como a población en general, el SENA está gestionando la certificación internacional de los ambientes de aprendizaje y del programa de formación 
en referencia, proceso que incluye visita técnica de ISPO para Septiembre del año 2015.

-Según la comunidad académica, las estrategias pedagógicas desarrolladas influyen en la calidad de los procesos formativos, mediando positiva o negativamente en el proceso de innovación.

-Los académicos coinciden en el hecho que las acciones de capacitación para el fortalecimiento del perfil profesional, son aspectos claves para la consolidación de acciones innovadoras.

-Se evidencian facilidades en innovación, debido al conocimiento desde el área administrativa y subdirección del Centro de Formación.

-El desarrollo de capacidades y oportunidades se basa en el entendido que los individuos son y deben ser los protagonistas de su propio desarrollo abriéndose el camino en espacios sociales, premisa validada por la comunidad académica.

-Los académicos están convencidos que la innovación requiere de compromiso de diversos sectores del país, obligando a revisar lineamientos del gobierno hacia la sociedad en general, a través del análisis para formulación, ejecución y evaluación de políticas públicas para contribuir al desarrollo humano. 
-Hay conciencia de la búsqueda de mejoramiento en la calidad de vida de la población colombiana, siendo necesario optimizar la comprensión de la innovación a nivel social.

-La comunidad académica, interesada por el sostenibilidad, escalamiento y replicabilidad de las innovaciones, subraya la importancia de la relación entre innovación e investigación incluido el intercalamiento de relaciones multidireccionales.

-Hay conciencia en que el desarrollo de competencias hacia la formación para el trabajo satisface una necesidad humana y se transforma en un logro del desarrollo humano.

7.2 Frente a los hallazgos evidenciados en la investigación

-La innovación identificada en el programa de órtesis y prótesis no se desarrolla de forma aislada ya que involucra diversos actores en el proceso como son los instructores, aprendices, funcionarios administrativos, comunidad en general, entes gubernamentales y entes privados.

-Con los resultados obtenidos se establece una participación activa de la comunidad beneficiaria, en este caso los aprendices, quienes además de recibir formación fueron partícipes del producto de dicho proceso. 
-La conjugación de actores internos como son aprendices, instructores, personal administrativo, y de actores externos para el desarrollo del proceso, en este caso las agencias internacionales, universidades internacionales y sector productivo, están presentes en las etapas lectiva y productiva dadas en la ejecución del programa de formación.

-Con la innovación social que se asocia al desarrollo humano hallado en el programa de formación, se fortalece la formación intelectual y el desarrollo de nuevas competencias, mejorando la calidad de vida de personas amputadas de cualquier extremidad, ayudando a la recuperación de personas afectadas por cualquier accidente.

-Los actores que asisten el proceso, como conocedores de sus capacidades y conocimientos, se encaminan al desarrollo humano, mejorando así la calidad de vida de la población. Cada actor individual tiene un control parcial, y cada actor parcial tiene un control individual.

-Se destaca la colaboración y multidisciplinariedad de actores presentes en la comunidad académica, y la transparencia de los mismos en cuanto a la ejecución de la formación.

-EL $100 \%$ de los aprendices cuestionados, son personas discapacitadas por heridas en combate, pertenecientes en su gran mayoría a la policía nacional y al ejército; así mismo, ellos retornarán a sus lugares de 
origen para trabajar en pro de la comunidad en general, en el área de prótesis y órtesis.

-Los actores externos se convierten en facilitadores del proceso, involucrando recursos y abriendo la posibilidad de expandir beneficios a las poblaciones.

-Se confirma el protagonismo de los actores en la transformación social incidiendo en el impacto a la comunidad. No obstante falta liderazgo de la entidad en general para incentivar la innovación y la divulgación de los beneficios.

-Los actores afirman que la innovación ocurre en la intersección de diversos individuos $y / 0$ instituciones ampliando las iniciativas que afirmarán el rol en el proceso.

-La innovación se presenta en un entorno del sector público, abordando el servicio de formación para el trabajo de manera gratuita, específicamente para comunidad discapacitada, impulsando así procesos y toma de decisiones con el ánimo de arrojar productos de innovación a partir de procesos formativos.

-El SENA se encarga de formar el capital humano, con un enfoque de aporte al desarrollo regional, a través de competencias de análisis y comprensión de los textos globales, integrando este proceso de formación 
con las necesidades de desarrollo regional, a través de mecanismos de generación de ingresos; esto buscando el bienestar de la población.

-Este programa es pionero en Colombia respecto a los aspectos de formación en nuevos conocimientos y en tecnología adquirida (de punta), así mismo es pertinente ya que se demanda desde el sector académico y desde el sector productivo, incluyendo la optimización del bienestar de la población discapacitada; además en éste, se da la oportunidad al alumno para que durante el desarrollo del proceso, él mismo construya el dispositivo médico necesario para rehabilitarse.

-En el programa se intuye la innovación social desde la perspectiva de desarrollo de conocimiento en procura de suplir necesidades sociales para el desarrollo humano; entre las variables que fomentan la innovación social en el programa están: la modernización de los ambientes de aprendizaje (infraestructura física, tecnología de punta), el capital humano (su nivel educativo), el seguro y fácil acceso a la formación, la capacidad de la institución para usar nuevas tecnologías y adoptar nuevos procesos, el empoderamiento de la comunidad beneficiaria, la generación de espacios de investigación y la pertinencia del programa de formación en la región.

-A partir de los ejes de las actividades que se consideran innovadoras, el programa se orienta en un tipo de innovación organizativa, en el cual se introducen prácticas direccionadas a la inclusión de nuevos clientes como es la población discapacitada para la ejecución del servicio educativo. 
-De mecanismos y procesos del programa, se puede afirmar que éste cuenta con un diseño que incluye competencias laborales necesarias para generar un perfil de egreso requerido por el sector productivo, pero se hace necesario incluir en cualquier parte del proceso los aspectos de innovación social, generando resultados que inciten a la innovación dentro de la ejecución del programa.

-Con los resultados obtenidos se valida que el programa de formación cubre un nicho de mercado en donde no hay muchas alternativas, dando un valor agregado como es el desarrollo incluyente.

-El programa de formación cubre sus objetivos de sostenibilidad ampliando el servicio a nuevas comunidades, optimizando espacios y ambientes de aprendizaje.

-Las causas vinculadas al desconocimiento de los factores, incorporada la insuficiencia de disponibilidad de servicios y falta de personal calificado dentro de una entidad, bajan el potencial de innovación social.

-Entre las barreras identificadas como obstáculos de visibilización de factores de innovación social están: la falta de capacitación gerencial, la complejidad en la estructura de la entidad, la diversidad de procesos a ejecutar, la cultura organizacional, la dificultad en la obtención del capital 
financiero para la ejecución del programa de formación, la necesidad de ampliación de la infraestructura física.

-La falencia en cuanto a comunicación entre actores de la comunidad académica, impiden el intercambio de conocimientos, a fin de fortalecer los aspectos detectados como innovaciones sociales.

-El desconocimiento de los factores que potencian la innovación social por parte de empleados administrativos, conllevan a desajustes en los recursos asignados para la adquisición de materiales de formación, los cuales son muy elevados (costo vs conocimiento).

-La poca divulgación en los medios de la labor que realiza el programa de formación a nivel social, obstaculiza la visibilización del mismo por parte de la comunidad necesitada, conllevando a la débil búsqueda del servicio por parte de los pacientes de lo requieren.

-Hay debilidad para encontrar socios de cooperación; las alianzas entre el sector público y el privado son insuficientes para soportar los compromisos visualizados desde el programa de formación, producto del desconocimiento de las nociones de innovación social.

-El desarrollo incluyente sólo es posible si se otorga a las personas discapacitadas la oportunidad de ganarse la vida en condiciones de equidad e igualdad, y esto se logra con opciones como la cualificación del recurso 
humano, para el caso a través del desarrollo de competencias direccionadas a la innovación, que impulsen la posibilidad de superación en sectores como el laboral.

-Se destaca el trabajo colaborativo entre docentes, quienes, aunque no cuentan con espacios de tiempo concretos para la generación de procesos y actividades articuladas con la investigación, identifican y aprovechan momentos para resolver conjuntamente las adversidades, generando así capacidad de trabajo direccionado a la óptima ejecución del programa de formación.

-Según características identificadas, se estableció que hay potencial para política pública nacional, con la debida articulación entre entidades del Estado, ya que se evidencian públicamente posibles soluciones estructurales a necesidades que no se pueden dejar de lado por parte del gobierno, como es el caso de la erradicación de la pobreza, formando gratuitamente a la población para el ingreso al mundo laboral (ANSPE, 2014), superación de la inequidad dando oportunidad de formarse a cualquier clase social de población que cumpla con ciertos requisitos académicos, inclusión social abriendo el ingreso a la formación de la población con discapacidad (DNP, 2014), generación de ingresos con la obtención de una titulación que servirá para ubicación en el mundo laboral. 


\subsection{Presentación de propuestas}

-Aunque se desee impulsar la innovación como tal, la colectividad académica del programa de órtesis y prótesis, constituida por aprendices, instructores y funcionarios administrativos, debe eliminar barreras que obstaculizan la efectiva intervención en la población beneficiaria, como son: deficiente comunicación entre instructores y directivos, insensibilización en aspectos de innovación social en algunos funcionarios administrativos encargados de asignar recursos conllevando a la asignación de insuficiente presupuesto para la compra de materiales, poca divulgación en medios de la labor que realiza en programa a nivel social puesto que se obstaculiza la visibilización por parte de la comunidad, debilidad para encontrar socios de cooperación

-Para continuar avanzando en materia de innovación social, y sabiendo que dicha innovación merece más atención de la que actualmente se concede, es importante pensar en una nueva dimensión de políticas de ciencia, desarrollo e investigación que se direccione a factores sociales, dejando de lado aspectos económicos y de tipo tecnológico (hoy en día de alta importancia), e involucrando capital instalado.

-Con el ánimo de impulsar la innovación, se encontró que hay dentro

de la comunidad académica las condiciones necesarias para que la institución apuntale el aspecto social, a saber: las actuaciones contundentes de quienes proponen el cambio creando un estado de oportunidad para la 
población en discapacidad, la movilización de la comunidad académica, la especificidades de las propuestas de innovación direccionadas a la verdadera necesidad del cliente, la toma de decisiones con un control del riesgo, la puesta en práctica con alta probabilidad de alcanzar los objetivos previstos.

-Según la comunidad académica, no todas la innovaciones sociales se desarrollan de la misma manera, además existen diversas formas de escalarlas interviniendo factores que se adhieren al proceso de replicabilidad y sostenibilidad. Por tanto, se propone la sensibilización en una cultura innovadora capacitando todos los niveles de la organización (la gestión humana es un facilitador de la innovación).

-La concepción que dimensiona la innovación social como instrumento que crea enlaces entre colaboración y conocimiento, a través del aprendizaje interactivo entre actores de la comunidad académica puede generar procedimientos consolidados de innovación, incrementando el impacto en la población intervenida.

-Se refleja que la implementación de un programa de formación dirigido a personas con discapacidad, es una estrategia que incluye diversos actores, interactuando con la disposición de recursos, para la inversión de tecnología, infraestructura y materiales, adjuntos en la ejecución y escalabilidad del proyecto. 
-La participación activa de actores públicos y privados en el proceso, dan lugar a espacios académicos de gran interés, jugando un rol decisivo para el desarrollo y escalamiento del programa de formación a través de la vinculación progresiva por medio de alianzas y convenios; así pues, pueden llegar a convertirse en promotores fortaleciendo el impacto institucional.

-Se evidencia la necesidad de implementar un modelo de capacitación para generación de instructores líderes (como actores del programa) en el área de innovación social, construyendo una ruta que promueva la respuesta inmediata a las necesidades de las comunidades, contenida en formas de asociatividad, propagación y desarrollo de buenas prácticas direccionadas a la generación de conocimiento y una producción científica que marque la diferencia. Si se difunde una cultura socialmente innovadora, gran parte de las necesidades y de las problemáticas sociales quedarán resueltas.

-La innovación social debe ser un pilar clave tal como lo evidenciaron los distintos actores de la investigación, que es necesario adherir a la estrategia denominada por SENA como SENNOVA, para que proyecte en todos los Centros de Formación, además de los tecno-parques y las tecno-academias, elementos de innovación social sobre la comunidad académica y en general sobre todos los actores que pueden llegar a tener un rol, visibilizando y consolidando así factores de innovación social. 
-El proceso del programa en órtesis y prótesis, establece un potencial para política pública nacional con la debida articulación entre entidades del Estado, ya que se evidencian públicamente posibles soluciones estructurales a necesidades que no pueden ser dejadas de lado por el gobierno (erradicación de la pobreza, superación de la inequidad, inclusión social).

-La entidad debe conformar equipos de innovación multidisciplinarios a fin de establecer la gestión de proyectos en el área de innovación social, midiendo avances y resultados de una cultura innovadora.

-La dificultad de asociatividad entre entes públicos y privados debilita los procesos de generación de innovación social del programa, razón por la cual se propone incentivar las asociaciones, alianzas y convenios.

-Es importante que se estimulen todos los eslabones de la cadena de valor en el proceso de innovación social que subyacen del programa de formación, incorporada la comunicación entre todos los actores, para crear de esta forma un patrón de desarrollo de la innovación (aspectos inmersos: análisis de la realidad social, generación de conocimiento, proceso de transformación social, sensibilización, difusión, dinamización y colaboración). 
-Como estrategia de visualización, potenciación y fortalecimiento de los factores de innovación social en los programas de formación que se desarrollan en el SENA, como es el caso del programa de órtesis y prótesis, se propone reestructurarlos con la inclusión de criterios de evaluación en los resultados de aprendizaje que se articulen desde las competencias inmersas en cada programa. Así mismo se sugiere como segunda opción de reestructuración, para establecer en los diseños, la creación de una norma de competencia laboral originada desde la mesa sectorial correspondiente. Es así como, de forma automática se enfocarán los programas directamente desde la fase de planeación en el camino de la innovación, ya sea través de los diseños o directamente desde los instructores, a un proceso de formación inmerso en la innovación, para el caso, social.

Esta investigación puede replicarse en otras regiones del territorio nacional, contribuyendo así a otros proyectos que busquen también una cultura innovadora, en tanto que permite réplica identificando diferencias territoriales y culturales. 


\section{REFERENCIAS BIBLIOGRÁFICAS}

Acevedo, M. (2011). Centro de Innovación Social - Gobierno Colombiano. http://www.dinero.com/administracion/articulo/centro-innovacionsocial-gobierno-colombiano/135690, consulta en octubre 27 de 2014.

Agencia Nacional para la Superación de la Pobreza Extrema "ANSPE", (2014).

Proyectos

de

Innovación

Social, http://www.anspe.gov.co/es/programa/que-es-el-centro-innovacionsocial/proyectos-de-innovacion-social, consulta en octubre 27 de 2014.

Agencia Vasca de la Innovación "INNOBASQUE" (2010). Análisis Benchmarking de Centros de Innovación Social. Definición de la estrategia de investigación en innovación social del País Vasco. Deloitte - País Vasco. http://www.innobasque.com/home.aspx?tabid=1, consulta en noviembre 18 de 2014.

Alvarez, J. et al (2003). Cómo hacer investigación cualitativa. Fundamentos yetodología. PAIDÓS. https://mayestra.files.wordpress.com/2013/03/bibliografc3ada-de$\underline{\text { referencia-investigacic } 3 b 3 n-c u a l i t a t i v a-j u a n-l u i s-a l v a r e z-g a y o u-~}$ jurgenson.pdf, consulta en febrero de 2015.

Bases Plan Nacional de Desarrollo 2014 - 2018 (2014). Todos por un nuevo país: paz, equidad y educación. Versión Preliminar. Departamento Nacional de Planeación Colombia. 
Bericat (1998). La integración de los métodos cuantitativo y cualitativo en la investigación social. Revista española de investigaciones sociológicas- Centro de Investigaciones. Barcelona, Ariel.

Buckland, H. \& Murillo, D. (2014). La innovación social en América Latina. Marco Conceptual y Agentes. ISBN: 978-84-697-17301.Century y Franklin Gothic.

Carrero, W \& Petit, E. (2011). Aspectos del desarrollo social para la innovación desde la perspectiva de la corriente del pensamiento creativo y transformador latinoamericano. Omnia Año 17, No.1. ISSN: 1315-8856. Universidad del Zulia. Depósito legal pp $199502 Z U 2628$.

Centro de Innovación Social (2012). Catálogo de iniciativas de innovación social.

Centro Latinoamericano para el Desarrollo del Conocimiento en la Formación Profesional. OIT/CINTERFOR. http://www.oitcinterfor.org/, consulta en enero 15 de 2015.

Chesbrough, H. (2011). Innovación Abierta. Harvard Deusto Business Review. Europa. Sim.ucm.es, consulta en mayo 10 de 2015.

Colciencias, ciencia, tecnología e innovación (2015). http://www.colciencias.gov.co/, consulta en abril 23 de 2015.

Comisión Económica para América Latina y el Caribe "CEPAL" (2014). Claves para la Innovación Social en América Latina y el Caribe. http://.cepal.org,http://www.cepal.org/publicaciones/xml/2/34682/cla ves_de_innovacion_social.pdf, consulta en agosto 14 de 2014. 
Comisión Económica para América Latina y el Caribe "CEPAL" (2014). Experiencias de Innovación Social en América Latina y el Caribe. http://www.cepal.org/dds/innovacionsocial/, consulta en septiembre 10 de 2014.

Comisión Económica para América Latina y el Caribe "CEPAL" (2006). Manual de prospectiva y decisión estratégica: bases teóricas e instrumentos para América Latina y el Caribe. http://www.cepal.org/ilpes/publicaciones/xm1/3/27693/manual51.pdf, consulta en 27 agosto 2015.

Comisión Económica para América Latina y el Caribe "CEPAL" (2011). Anuario estadístico de América Latina y el Caribe. Santiago. http://.cepal.org, consulta en agosto 15 de 2014.

Comisión Económica para América Latina y el Caribe "CEPAL" (2014). Experiencias en Innovación Social. América Latina y el Caribe. http://www.cepal.org/dds/innovacionsocial/e/proyectos/co/cadenaspr oductivas/, consulta en octubre 30 de 2014.

Comisión Europea (2014). Investigación e Innovación. Comprender las políticas de la Unión Europea. Bruselas. Comisión Europea. Investigación en Innovación http://europa.eu/pol/index_es.htm, consulta en enero 13 de 2015.

Confederación Empresarial de Madrid (2000). La innovación: un factor clave para la competitividad de las empresas. Dirección general de investigación. Consejería de Educación. Comunidad de Madrid. http://www.oei.es/salactsi/libro9.pdf, consulta en mayo 04 de 2015. 
Consejo Nacional de Política Económica y Social "CONPES" 3527 de 2008. Política Nacional de Competitividad y productividad. http://wsp.presidencia.gov.co/sncei/politica/Documents/Conpes-

3527-23jun2008.pdf, consulta en octubre 11 de 2014.

Consejo Nacional de Política Económica y Social "CONPES" 3668 de 2010. Informe de seguimiento a la política nacional de productividad $y$ competitividad.

http://wsp.presidencia.gov.co/sncei/politica/Documents/Conpes-

3668-28jun2010.pdf, consulta en agosto 10 de 2014.

Deldago, M. et al. (2008). La innovación tecnológica desde el marco del capital intelectual. Cuaderno de Trabajo No. 4 de 2008. Escuela Universitaria de Estadística. Universidad Complutense de Madrid. http://estudiosestadisticos.ucm.es/data/cont/docs/12-2013-02-06-

CT04_2008.pdf, consulta en septiembre 18 de 2014.

Denzin, N. \& Yvonna, S. (2005). The Sage Handbook of Qualitative Research. Thousand Oaks: Sage Publications, Inc. Introduction. The Discipline and Practice of Qualitative Research.

Departamento Administrativo Nacional de Estadística. "DANE" (2012). Declaración Comité de Expertos de Pobreza, pobreza extrema y desigualdad. Bogotá D.C.

Departamento Administrativo Nacional de Estadística. "DANE" (2015). Censos de población. http://www.dane.gov.co/, consulta en enero 15 de 2015.

Departamento Nacional de Planeación DNP (2011). Plan Nacional de Desarrollo 2010-2014: "Prosperidad para todos". 
Departamento Nacional de Planeación. (2011). Recomendaciones sobre competitividad e innovación para la elaboración de planes de desarrollo regional. http://www.dnp.gov.co/, consulta en octubre 12 de 2014.

Departamento Nacional de Planeación. https://www.dnp.gov.co/programas/desarrollo-empresarial/cienciatecnologia-e-innovacion/Paginas/ciencia,-tecnologia-einnovacion.aspx , consulta en octubre 27 de 2014.

Departamento Nacional de Planeación (2014). El papel de los consejos territoriales. Bogotá D.C. DNP. http://www.dnp.gov.co/, consulta en octubre 12 de 2014.

Diario Oficial No. 39702 (1991). Decreto Ley 585 de 1991.

Diario Oficial No. 47186 (2008). Ley 1253 de 2008.

Dirección de Formación Profesional SENA (2013). Proyecto Educativo Institucional. Bogotá 2014.

Dirección para la Acción Integral contra Minas Antipersonal. http://www.accioncontraminas.gov.co/Paginas/victimas.aspx, consulta en noviembre 03 de 2014.

Domanski, j. \& Howaldt, P (2013). Social Innovation. Sozialforschungsstelle Dortmund. Central Scientific Unit of TU Dortmund University.

Dubois, A (2002). Un concepto de Desarrollo para el Siglo XXI. Universidad de Deusto. País Vasco. España. 
Foro Económico Mundial Sobre América Latina (2012). Puerto Vallarta. http://www3.weforum.org/docs/LA12/WEF_LA12_Report_SP.pdf, consulta en junio 10 de 2015.

Echeverría, J. (2008). El Manual de Oslo y La Innovación Social. Arbor Ciencia, Pensamiento y Cultura.

Edwards, M (2008). Nuevos paradigmas en innovación. http://www.tendencias21.net/innovacion/Nuevos-paradigmas-eninnovacion-a8-html, consulta en mayo 22 de 2015.

Elola, I. (2010). Collaborative writing: fostering language and writing conventions development. Volume 14 Number 3. Language learning \& technology. Texas tech University. http://llt.msu.edu/issues/october2010/elolaoskoz.pdf, consulta en marzo 20 de 2015.

Estudio de la discapacidad en el horizonte de los derechos humanos.(2007). Universidad del Rosario. Bogotá, D.C.,

Estatuto de Formación Profesional (2014). Pe-04. Servicio Nacional de Aprendizaje SENA.

Euskadi (2015). Plan Euskadi en la Sociedad de la Información 2015. $\begin{array}{lll}\text { Agenda Digital } & 2015 .\end{array}$ http://www.innova.euskadi.eus/contenidos/informacion/innovacion_e uskadi/es_innova/AGENDA_DIGITAL_DE_EUSKADI_2015.pdf, consulta en junio 14 de 2015.

Euskadinnova (2014). $\quad$ http://www.euskadinnova.net/es/innovacionsocial/noticias/elhuyar-aholkularitza-presenta-herramienta-paramedir-innovacion-social/12160.aspx, consulta en octubre 22 de 2014. 
Finquelievich, S. (2007). Innovación, tecnología y prácticas sociales en las ciudades: hacia los laboratorios vivientes. Revista iberoamericana de ciencia tecnología y sociedad. ISSN 1850-003. V.3N.9. Ciudad Autónoma. Buenos Aires.

Frías, A., \& Aparicio. L. (2013). Barreras e Incentivos para Innovación Social en Colombia.

Fundación CODESPA(2011). Metología de análisis de cadenas productivas bajo el enfoque de cadena de valor.

Fundación Saldarriaga Concha (2012). En Colombia, el $61 \%$ de las personas con discapacidad no recibe ningún tipo de ingreso económico para su subsistencia. http://www.saldarriagaconcha.org, consulta en junio 25 de 2015.

García, F. (2012). Contribución al análisis PEST (política, economía, sociedad, tecnología. Plan estratégico 2013-2020. Asociación Colombiana de Facultades de Ingeniería.

Gerhuny, J. (1983). Social Innovation and the Division of Labour, Oxford University Press, OUP, Massachusset.

Gough, I (2007). El enfoque de las capacidades de M. Nussbaum: un análisis comparado con nuestra teoría de las necesidades humanas. Centro de Investigación para la Paz. Papeles de Relaciones Ecosociales y Cambio Social No. 100, CIP-Ecosocial/Ivaria, invierno 2007/08http://www.otrodesarrollo.com/desarrollohumano/GoughEnf oqueCapacidadesNussbaum.pdf, consulta en junio 03 de 2015.

Guerra, P. (2010). Estudio sobre la percepción en innovación y desarrollo entre administradores de las pequeñas y mediana empresas: caso de 
estudio Monterrey, Nuevo León. ISSN 1870-557X. Daena: International Journal of Good Conscience. 5(2) 246-276.

Guía clínica órtesis Ministerio de Salud.

http://web.minsal.cl/portal/url/item/7222754637d38646e04001011f0

14e64.pdf, consulta en mayo 22 de 2015.

Guía de Innovación Social (2013). Comisión Europea.

http://www.chap.gva.es/documents/599445/599488/Traducci\%C3\%B

$\underline{3 n+d e+l a+G u \% C 3 \% A D a+d e+I n n o v a c i \% C 3 \% B 3 n+\text { Social.pdf } / 86278}$

f94-5f81-4df7-b949-61e69c583588, consulta en octubre 22 de 2014.

$\begin{array}{llll}\text { Guía de } & \text { sistematización } & \text { ASOCAM. }\end{array}$

http://www.asocam.org/biblioteca/files/original/982bf39614afd657e0

21917b9b869f7d.pdf, consulta en enero 13 de 2015.

Gurrutxaga, A. (2009) Recorridos por la Innovación Social. México D.F. Innobasque.

Hernández, R. \& Fernández, C. (2008). Metodología de la Investigación. México D.F: McGraw-Hill.

Herrera, R. \& Gutiérrez, J. (2011). Conocimiento, Innovación y Desarrollo. Cátedra de innovación y desarrollo empresarial. Universidad de Costa Rica. ISBN: 978-9968-900-10. Primera edición. San José de Costa Rica.

Hobbs, et al. Value Chains inthe AGRI-Food sector. (2003). En: Lundy Mi., Gottret V., Cifuentes W., Ostertag F. y Best, R. Diseño de estrategias para aumentar la competitividad de cadenas productivas con productores de pequeña escala. CIAT. Cali. 
Horizonte

http://ec.europa.eu/programmes/horizon2020/sites/horizon2020/files/ H2020_ES_KI0213413ESN.pdf, consulta en enero 13 de 2015.

Informe Regional de Desarrollo Humano 2.013 - 2.014. (2013). Comunidad con rostro humano: diagnóstico y propuestas para América Latina. Programa de las Naciones Unidas para el Desarrollo "PNUD".

Informe sobre desarrollo humano (2013). El ascenso del sur, progreso humano en un mundo diverso. Programa de las Naciones Unidas para el Desarrollo "PNUD”.

Informe sobre desarrollo humano (2014). Sostener el progreso humano: reducir vulnerabilidades y construir resiliencia. "PNUD".

Innobasque (2011). Estrategia de innovación social. Una ventana de oportunidad para Euskadi.

Innovación tecnológica ¿Cómo cambian las conductas? http://www.nuevarevista.net/articulos/la-innovacion-tecnologicacomo-cambian-las-conductas, consulta en enero 17 de 2015.

International Society for prosthetics and orthotics "ISPO" (2015) http://www.ispoint.org/, consulta en marzo 05 de 2015.

ISEA S.Coop. (2008). Análisis prospectivo sobre modelos de innovación en el sector servicios. Innovación e-services. Programa de Centros del Conocimiento y Contenidos Digitales, marco del plan AVANZA.

Manual de Bogotá (2001). Normalización de Indicadores de innovación tecnológica en América Latina y el Caribe. 
Manual de Oslo (2005). Directrices para la recogida e interpretación de información relativa a innovación. Plan regional de ciencia y tecnología de la comunidad de Madrid.

Martínez, J. (2001). Generación y protección del conocimiento: propiedad intelectual, innovación y desarrollo económico. CEPAL. México 2008.

Marulanda, N. \& Tancredi, F. (2010). De la innovación a la política pública. Historias de éxito en América Latina y el Caribe. Naciones Unidas. CEPAL. Santiago de Chile.

Memorias del Seminario Taller - Observatorio Colombiano de Ciencia y Tecnología. (2013). DNP, COLCIENCIAS, ANSPE.

Memorias del Seminario Taller - Los retos de la innovación social en

Colombia (2013). Observatorio Colombiano de Ciencia y Tecnología, DNP, COLCIENCIAS, ANSPE.

Ministerio de Educación Nacional.

(2015),

http://www.mineducacion.gov.co;http://www.mineducacion.gov.co/c vn/1665/articles-317375_recurso_1.pdf, consulta en febrero 14 de 2015.

Ministerio de Salud y Protección Social (2014), https://www.minsalud.gov.co/, consulta en octubre 10 de 2014.

Moreira, R. (2.013). Bases conceptuales de una política de innovación social. Departamento Nacional de Planeación DNP.

Mulgan, G., Tucker, S., Ali, R., \& Sanders, B. (2007).Social Innovation. What it is why it matters and how it can be accelerated. Oxford Said Bussiness School. 
Nodo

de

innovación

social

(2015).

http://www.politicadeinnovacionsocial.co/37, consulta en enero 15 de 2015.

Norma UNE 11-909-90/1 (2015). Acogida de la ISO 8549/1.

Nussbaum, M. (2012). El enfoque de las capacidades.

http://www.otrodesarrollo.com/desarrollohumano/GoughEnfoqueCap

acidadesNussbaum.pdf, consulta en junio 03 de 2015.

Organización Internacional del Trabajo "OIT". (2014). Centro

Interamericano para el Desarrollo del Conocimiento en la Formación Profesional "CINTERFOR",

http://www.oitcinterfor.org/, consulta en enero 15 de 2015.

Organización Mundial de la Salud (2013),

http://www.who.int/countries/col/es/, consultado en agosto 13 de 2014.

Organización para la Cooperación y el Desarrollo Económicos "OCDE" (2014). http://www.oecd.org/, consulta en agosto 25 de 2014.

Organización para la Cooperación y el Desarrollo Económico OCDE. (2005). Manual de Oslo: Guía para la recogida e interpretación de datos sobre innovación. Tercera Edición. Eurostat.

Órtesis y Prótesis /CEREFHI, http://cerefhi.com/servicios/ortesisprotesis/, consulta en octubre 27 de 2014.

Ortopedia (2015). http//ortopedia1.com/órtesis, consulta en febrero 08 de 2015. 
Otto

Bock

(2014)

http://www.ottobock.com/cps/rde/xchg/ob_com_es/hs.xsl/23289.html consulta en noviembre 23 de 2014.

Paez, D. (2012). Modelo Pedagógico de formación profesional. V-1. SENA

Pascale, R. (2015). Innovación: de cerrada a abierta. El País. Zelmar Michelini 1287, CP. 11100, Montevideo, Uruguay. 2015.

Plan Nacional de Desarrollo 2010 - 2014 (2010). DNP. https://sinergia.dnp.gov.co/SISMEG/Archivos/PND2010-

2014\%20Tomo\%20I\%20CD.pdf, consulta en octubre 27 de 2014.

Plan Nacional de Desarrollo 2014-2018. (2014) DNP. http://www.fedesarrollo.org.co/wp-content/uploads/Luis-FernandoMej\%C3\%ADa-DNP.pdf, consulta en junio 02 de 2015.

Política Nacional de Ciencia, Tecnología e Innovación (2015). CONPES 3582. http://www.ceo.org.co/conozcanos/centro-dedocumentacion/ciencia-tecnologia-e-innovacion/319-documentoconpes-3582-politica-nacional-de-ciencia-tecnologia-e-innovacion, consulta en enero 14 de 2015.

Porter, M. (1985). Webyempresas - Cadena de Valor (2015). http://www.webyempresas.com/la-cadena-de-valor-de-michaelporter/, consulta en enero 17 de 2015.

Pre CONPES Innovación Social (2014). http://www.politicadeinnovacionsocial.co/, consulta en junio de 2015.

Programa de las Naciones Unidas para el Desarrollo en Colombia "PNUD". http://www.ispoint.org/, consulta en mayo 06 de 2015. 
Pulido, A. (2005). La innovación en el siglo XXI. Centro de predicción económica CEPREDE. Universidad Autónoma de Madrid.

Ramírez, A. (2012). Los nuevos desafíos de la dirección pública profesional: innovación abierta, gobernanza colaborativa, cocreación y pensamiento de diseño en la gestión pública. Grupo de investigación en gobierno, administración y políticas públicas. Paper 15327 presentación XXII Congreso mundial de ciencia política IPSA AISP.

Madrid

2012.

http://paperroom.ipsa.org/papers/paper_15327.pdf , consulta en junio 13 de 2015.

Rey, N \& Tancredi, F (2010). De la innovación social a la política. Historias de éxito en América Latina y el Caribe. Comisión Económica para América Latina y el Caribe "CEPAL". Naciones Unidas. Santiago de Chile.

Rodríguez, A. \& Alvarado, H. (2008). Claves de la Innovación Social en América Latina y el Caribe. Chile: CEPAL. http://repositorio.cepal.org/bitstream/handle/11362/2536/S0800540_e s.pdf?sequence $=1$, consulta en junio 25 de 2014 .

Rodríguez, P., \& Alvarado, M. (2008). Innovación Social, conceptos y etapas.

Roitman Rosenmann, M. (2008). El desarrollo de la sociología Latinoamericana, Pensar América Latina. CLACSO. ISBN 978-9871183-86-9. Buenos

Aires. http://bibliotecavirtual.clacso.org.ar/ar/libros/campus/roitman/02Roit. pdf, consulta en junio 14 de 2015 . 
Servicio Nacional de Aprendizaje "SENA" (2014). SENNOVA. Vol1, No.1. ISS 2389-9573. 2014.

Servicio Nacional de Aprendizaje "SENA" (2014).

http://www.sena.edu.co/, consulta en febrero 13 de 2014.

Servicio Nacional de Aprendizaje "SENA" (2014). Plan de Acción 2014 2014. Dirección de Planeación y Direccionamiento Corporativo.

Sen, A. (2000). Desarrollo y Libertad. Editorial Planeta, 9 Edición. Barcelona 2002.

Tres experiencias vascas, referencia europea en innovación social. http://www.innobasque.com/home.aspx?tabid=20\&idNoticia=1050\& $\underline{\text { mostrar}=\mathrm{P}}$, consulta en octubre 22 de 2014.

The global innovation index. (2014). The human factor in innovation. Jonhson Cornell University. https://www.globalinnovationindex.org/userfiles/file/reportpdf/GII2014-v5.pdf, consulta en abril de 2014.

Villa, L. \& Melo, J. (2015). Panorama actual de la innovación social en Colombia. BID -Banco Interamericano de Desarrollo. Instituciones para el Desarrollo. División de Competitividad e Innovación. Documento para discusión No. IDB-DP-381.

Weigt, G (2014). Desarrollo Incluyente. http://www.iiz-

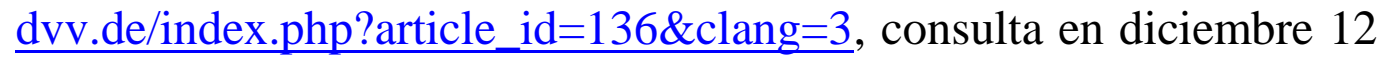
de 2014. 